\title{
Psychopathology and ageing : towards a better understanding of psychosis and depression in later life
}

Citation for published version (APA):

Köhler, S. (2009). Psychopathology and ageing : towards a better understanding of psychosis and depression in later life. [Doctoral Thesis, Maastricht University]. NeuroPsych Publishers. https://doi.org/10.26481/dis.20091002sk

Document status and date:

Published: 01/01/2009

DOI:

10.26481/dis.20091002sk

Document Version:

Publisher's PDF, also known as Version of record

Please check the document version of this publication:

- A submitted manuscript is the version of the article upon submission and before peer-review. There can be important differences between the submitted version and the official published version of record.

People interested in the research are advised to contact the author for the final version of the publication, or visit the DOI to the publisher's website.

- The final author version and the galley proof are versions of the publication after peer review.

- The final published version features the final layout of the paper including the volume, issue and page numbers.

Link to publication

\footnotetext{
General rights rights.

- You may freely distribute the URL identifying the publication in the public portal. please follow below link for the End User Agreement:

www.umlib.nl/taverne-license

Take down policy

If you believe that this document breaches copyright please contact us at:

repository@maastrichtuniversity.nl

providing details and we will investigate your claim.
}

Copyright and moral rights for the publications made accessible in the public portal are retained by the authors and/or other copyright owners and it is a condition of accessing publications that users recognise and abide by the legal requirements associated with these

- Users may download and print one copy of any publication from the public portal for the purpose of private study or research.

- You may not further distribute the material or use it for any profit-making activity or commercial gain

If the publication is distributed under the terms of Article $25 \mathrm{fa}$ of the Dutch Copyright Act, indicated by the "Taverne" license above, 


\section{Psychopathology and ageing}

\section{Towards a better understanding of}

psychosis and depression in later life

Neuropsych Publishers Maastricht, the Netherlands 
(C) S. Köhler, Maastricht, 2009

All rights reserved. No part of this thesis may be reproduced, stored or transmitted in any way or by any means without the prior permission of the author or, when appropriate, from the publishers of the publications.

Cover design: Kirsten Köhler Production: Datawyse BV, Maastricht

Publisher: Neuropsych Publishers

ISBN: 978-90-75579-42-0

Neuropsych Publishers is a non-profit organisation, which aims at promoting the science of 'Brain and Behaviour' and improving the application of the products of this science in health care and education. Neuropsyc Publishers accomplishes these aims by publishing books, dissertations and other products of scientific activity, by disseminating educational materials and publication of tests, assessment scales and other psychometric instruments in the field of Neuropsychology, Neuropsychiatry and other areas within the domain of Brain and Behaviour.

Postal address:

Neuropsych Publishers, Department of Psychiatry and Neuropsychology, Maastricht University, P.O. Box 616, 6200 MD Maastricht, The Netherlands 


\title{
Psychopathology and ageing
}

\author{
Towards a better understanding of
}

\author{
psychosis and depression in later life
}

\section{PROEFSCHRIFT}

ter verkrijging van de graad van doctor aan de Universiteit Maastricht, op gezag van de Rector Magnificus, Prof. mr. G.P.M.F. Mols, volgens het besluit van het College van Decanen, in het openbaar te verdedigen op vrijdag

2 oktober 2009 om 10:00 uur

door

\section{Sebastian Köhler}

Geboren op 6 november 1978 te Schleswig 
PROMOTOREN

Prof. dr. F. R. J. Verhey

Prof. dr. J.J. van Os

COPROMOTOR

Dr. J.G.S. Allardyce

BEOORDELINGSCOMMISSIE

Prof. dr. E. Griez (voorzitter)

Prof. dr. J. Jolles

Dr. A. Leentjens

Dr. M. Stek, VU Medisch Centrum

Prof. dr. M. Vandenbulcke, Universitair Centrum Leuven

\section{Wetenschapskring}

South Limburg Mental Health and Teaching Network, PhD Series

The research described in this thesis was performed at the Department of Psychiatry and Neuropsychology, School for Mental Health and Neuroscience, Maastricht University, Maastricht, the Netherlands, and at the Wolfson Research Centre, Institute for Ageing and Health, Newcastle University, Newcastle upon Tyne, United Kingdom.

Lundbeck, AstraZeneca and IPC Neurobrain kindly provided additional financial support for the publication of this thesis. 
"How much have you seen, eh, Thieflet? Africa, have you seen it? No? Then is it truly there? And submarines? Huh? Also hailstones, baseballs, pagodas? Goldmines? Kangaroos, Mount Fujiyama, the North Pole? And the past, did it happen? And the future, will it come? Believe in your own eyes and you'll get into a lot of trouble, hot water, a mess."

Salman Rushdie in Haroun and the Sea of Stories 



\section{CONTENTS}

CHAPTER 1 General introduction

PART I

Late life psychosis

17

CHAPTER 2 Incidence of and risk factors for psychotic symptoms in middle-age

CHAPTER 3 Age of onset, gender and the 5-year outcome of firstepisode psychosis

PART II

CHAPTER 4 Late life depression as a risk factor for cognitive decline in the general population

CHAPTER 5 Pattern and course of cognitive impairment in late life depression

CHAPTER 6 Late life depression, continuing cognitive impairment and vascular brain lesions

CHAPTER 7 General discussion 
"I have no special talent. I am only passionately curious." - Albert Einstein 
CHAPTER 1

General introduction 



\section{PART ONE}

\section{Late onset psychosis}





\section{CHAPTER 2}

\section{Incidence and risk factors for psychotic symptoms in middle-age}

Köhler S, van Os J, de Graaf R, Vollebergh W, Verhey F, Krabbendam L. Psychosis risk as a function of age at onset: A comparison between early- and late-onset psychosis in a general population sample. Social Psychiatry and Psychiatric Epidemiology. 2007;42:288-294. 


\section{Abstract}

Background: Little is known about late-onset psychosis (onset after the age 45 years) and how it relates to early-onset psychosis (before age 45 years). The aims of this study were to calculate the incidence of non-affective, non-organic psychotic symptoms across the life span and to explore the contribution of different sets of risk factors in relation to age at onset.

Methods: Data were obtained from the three measurements of the Netherlands Mental Health Survey and Incidence Study. Symptoms of psychosis were assessed in individuals aged 18-64 years using the Composite International Diagnostic Interview. All individuals reporting first-onset of psychotic symptoms within a three-year interval were included. The degree to which sets of risk factors affected the psychosis outcome similarly across age groups was assessed.

Results: The number of subjects displaying incident psychotic symptoms was similar across age groups. Cumulative incidence rates ranged from $0.3 \%$ to $0.4 \%$. Age differences were found for life-time depressive symptoms (risk difference = $5 \%, 95 \% \mathrm{Cl}=1 \%, 9 \%$ ) and baseline neuroticism (risk difference $=3 \%, 95 \% \mathrm{Cl}=$ $0 \%, 6 \%)$, indicating that late-onset psychosis was less often preceded by these. In contrast, no effect modification by age was observed for female sex, hearing impairment, being single, or lifetime cannabis use.

Conclusions: Onset of psychotic symptoms in late life is no rare event. Compared to early onset psychosis, the late-onset counterpart less often arises in a context of emotional dysfunction and negative affectivity, suggesting qualitative differences in aetiology and more effective premorbid coping styles. 


\section{Introduction}

Schizophrenia and related non-affective, non-organic psychotic disorders have predominantly been studied in adolescence and young adulthood (early-onset psychosis, EOP). Some individuals, however, experience psychotic symptoms for the first time after the age of 40 years (late-onset psychosis, LOP) $(7,77)$. In LOP, the clinical picture is dominated by hallucinations in all modalities and systematic delusions that concern the patient's personal space and security like paranoid delusions or partition delusions (78-80), while disorganized and negative symptoms are uncommon $(81,82)$. In $45 \%$ of subjects, the onset of LOP is preceded by a history of paranoid or schizotypic personality styles (83-85) which raises the question whether these cases constitute a group of schizophrenia with delayed expression of a latent disorder rather than truly late onset of a disorder de novo.

\subsection{Incidence rates}

Studies of first admission rates over the last four decades have consistently found low incidence rates for LOP. Copeland (1998) estimated an annual incidence of 3.0 per 100,000 for DSM-III-R schizophrenia and 16.6 per 100,000 for delusional disorder in those aged 65 years and over (86). Castle and Murray (1993), applying the same criteria, calculated a rate of 12.6 per 100,000 person-years (87). Using the broader concept of late paraphrenia, Kay (1972) estimated the annual rate for those aged 55 years and older to be 10-15 per 100,000 for males and 20-25 per 100,000 for females (88). In the general population aged 60 years or older, Van Os (1995) showed an $11 \%$ increase in first admission rates for ICD-9 schizophrenia, paraphrenia, paranoid states and other non-affective, non-organic psychosis for each 5 year increase in age (89). Incidence rates rose from 10 per 100,000 personyears in those aged 65 years to 19 per 100,000 in those aged 75 with further progression to 25 per 100,000 in the $90+$ age group. Häfner (1998) found an annual incidence rate of 13 per 100,000 for broadly defined schizophrenia-spectrum disorders within the age range of 50-59 years (18).

These figures match well with those reported for schizophrenia $(90,91)$. Servicebased studies, however, are likely to underestimate the frequency of the disorder, and community surveys independent of service use generally find higher rates (92), but researchers have been reluctant to carry out such studies with LOP (93). Methodological obstacles in conjunction with the supposed infrequency of the disorder may explain this. For example, a diagnosis of LOP is difficult to make using lay interviews. Hence, an alternative approach is to collect data on the basis of presence of single functional psychotic symptoms without focussing on diagnostic categories. Using this strategy, Christenson and Blazer (1984) identified prevalent paranoid ideation in $4 \%$ of a sample of community living elderly (94). Similar figures have been found among the non-institutionalised cognitively intact elderly (95), with prevalence rates as high as $10 \%$ among the non-demented very old (older than 84 years) (9). Prevalence rates, however, cannot distinguish between 
persistence of psychosis with an early onset and psychosis with a true onset in old age.

\subsection{Risk factors}

If LOP constitutes a separate phenotype within the schizophrenia spectrum, it is attractive to hypothesize that there will be quantitative or qualitative differences between LOP and EOP with respect to risk factors associated with psychosis such as cannabis use (96-98), childhood trauma $(99,100)$, urbanisation (101-103), schizoid and paranoid premorbid personality $(104)$, neuroticism $(95,105)$, depressive and other affective symptoms $(106,107)$ or social isolation $(108)$. Among the list of putative risk factors for LOP, female sex presents itself as the most prominent one, with women running a two to six times greater risk than men $(18,87,109)$, especially if only paranoid states are considered $(110,111)$. It seems that men consume their lifetime risk more rapidly than women and are thus hardly found in late-onset pools (Häfner, 1998). A protective role for female sexual hormones in LOP has hence been suggested, as estrogens may decrease the risk in premenopausal women by virtue of their antidopaminergic effects $(17,18,112,113)$. Another hypothesized age-related risk factor may be hearing impairment, particularly in patients aged 60 years and older $(108,114-116)$, although recent work suggests the effect of hearing impairment is not age specific (117).

\subsection{Research questions and hypotheses}

The present study calculates incidence rates for psychosis as a function of age in the general population of the Netherlands. It was hypothesized that onset of functional psychosis occurs less often in old age than in young and middle age. Secondly, possible effect modification by age of sets of known risk factors for psychosis was assessed, such as depression, neuroticism, urbanisation, cannabis use, sex, sensory impairment and family history of psychosis.

\section{Method}

\subsection{Sample}

This study made use of the data from the Netherlands Mental Health Survey and Incidence Study (NEMESIS), a longitudinal study of the prevalence, incidence, course and consequences of psychiatric disorders in the Dutch general population (118-120). The study consists of three measurement points with a total duration of three years: at baseline (hereafter: T0), 1 year thereafter (hereafter: T1) and again 2 years after T1 (hereafter: T2). Participants were identified by means of a multistage, stratified, random sampling procedure in which 90 municipalities were sampled randomly. In a second step, random selections of addresses from private households were made. Thirdly, the person with the most recent birthday at the moment of selection and aged between 18-64 years received an introductory letter form the Minister of Health. Not included were institutionalized individuals. At 
baseline, 7076 subjects participated, which is a response rate of $69.7 \%$. According to the General Health Questionnaire, 12 items (GHQ-12) (121) responders and nonresponders did not differ with respect to psychiatric morbidity $(118,119)$. At T1, 5618 subjects (79\%) participated, at T2, 4848 subjects (69\%) participated. The local ethics committee approved the study proposal.

\subsection{Instruments}

At T0 to T2, the Composite International Diagnostic Interview (CIDI) version 1.1 (122) was administered at home. The CIDI is a structured interview and is designed for the use by trained interviewers who are not clinicians. It has satisfactory interrater reliability (123) and test-retest reliability (124). Ninety interviewers experienced in systematic data collection administered the interview after having received intensive training. In order to assess psychotic symptoms, ratings from the $\mathrm{CIDI}$ core psychosis section on delusions (13 items) and hallucinations (4 items) were used (items G1-G13, G15, G16, G20, G21). These concern classic psychotic symptoms involving, for example, thought interference and passivity phenomena, persecution and auditory hallucinations. All these items can be rated in six ways: ' 1 ', no symptom; '2', symptom present but not clinically relevant (not bothered by it and not seeking help for it); ' 3 ', symptom result of ingestion of drugs/medication; ' 4 ', symptom result of a somatic disease; ' 5 ', true psychiatric symptom causing distress or help-seeking behaviour; ' 6 ', symptom may not really be a symptom because there appears to be some plausible explanation for it. In order to verify symptom presence and their clinical relevance, clinical re-interviews were conducted over the telephone by a senior registrar in psychiatry for all individuals who had at least one rating of 5 or 6 , using single questions from the Structural Clinical Interview for DSM-III-R (SCID), an instrument with proven reliability and validity in diagnosing schizophrenia (125). CIDI ratings of ' 5 ' and ' 6 ' were corrected on the basis of these clinical interviews. Lifetime depression was assessed using the 28 items of the CIDI core depression section (E) with exclusion of four items related to dysthymia. Lifetime mania was assessed using the 11 items of the CIDI core mania section (F). All these items can be rated as either 'yes' (1) or 'no' (0). Symptoms of depression (e.g. anhedonia) had to be present for at least two weeks, manic symptoms (e.g. persistently elevated, expansive or irritable mood) had to be present for at least two days. In order to make a DSM-III-R diagnoses, the CIDI assesses whether the mood symptoms and other symptoms were present within the same time period (126). Neuroticism was assessed at baseline with the 14-item Groningen Neuroticism Scale (127). Family history of depression and psychosis was examined at T1, by asking the subject whether any of his first-degree biological relatives had ever experienced depressive symptoms and/or delusions or hallucinations, providing descriptions of these. Family history of treated depression and psychosis was examined at $\mathrm{T} 1$, by asking the subject whether the affected firstdegree biological relatives had ever received medical or psychological help for these symptoms. Urbanicity was coded as rural if a municipality had fewer than 500 addresses per square kilometre and urban otherwise. Single living status was assessed by asking the subject whether or not he permanently shares a household 
with someone else, irrespective of ownership. Visual or auditory impairment was scored as present if respondents self-reported such a condition being treated or monitored by a physician in the 12 months before T0.

\subsection{Statistical analysis}

For the current investigation, two outcome measures were created. First, all subjects with broadly defined psychosis-like experiences (CIDI ratings of ' 2 ', ' 3 ', ' 4 ', ' 5 ' and ' 6 ') at T1 or T2 were included in the analyses if they had not displayed such symptoms at T0 (hereafter: broad psychosis outcome). This outcome was rated as either present $\left(={ }^{\prime} 1\right.$ ') or absent $\left(={ }^{\prime} 0\right.$ '). For the second outcome, only subjects who reported narrowly defined clinically relevant psychotic symptoms (CIDI ratings of ' 5 ') were included if they had had no evidence of psychosis at T0 (hereafter: narrow psychosis outcome). This outcome was similarly scored as either present (= ' 1 ') or absent $\left({ }^{\prime} 0^{\prime}\right)$. Subjects were then divided into three age groups of young (18-34 years), middle (35-49 years) and old age (50-64 years). Contrasts were expected to show up most powerfully in the comparisons between the youngest and oldest age groups, thus the analysis has this contrast as its focus. In order to test for contributions of different sets of risk factors to the psychosis outcome, a general linear modelling (GLM) strategy was applied. Interaction effects were analysed using the BINREG procedure in STATA (128), a GLM extension for the binomial family. Interaction effects between age group and categorical or dummy coded exposure variables were estimated under an additive model (129) yielding risk difference effect sizes. Cumulative incidences of psychosis outcome at T1 and/or T2 were calculated in subjects with absence of the narrow psychosis outcome at baseline (risk set: $n=4637$ ) and in subjects with absence of the broad psychosis outcome (risk set: $n=4041$ ). Cumulative incidence rates across age groups were compared by means of Pearson $\chi^{2}$ tests. A post-hoc analysis was performed for first contact rates. All data were analysed using the STATA program, version 9.1 (128).

\begin{tabular}{|c|c|c|c|c|}
\hline & \multicolumn{3}{|c|}{ Age groups (96) } & \multirow[b]{2}{*}{ Total sample } \\
\hline & Young & Middle & Old & \\
\hline Mean age & 27.7 & 41.6 & 56.7 & 41.2 \\
\hline Female sex & 55.6 & 50.8 & 54.7 & 53.5 \\
\hline \multicolumn{5}{|l|}{ Education (in years) } \\
\hline $0-11$ & 17.1 & 25.2 & 37.0 & 25.7 \\
\hline 12 & 40.4 & 35.8 & 33.1 & 36.6 \\
\hline $13-15$ & 9.2 & 7.3 & 5.9 & 7.6 \\
\hline $16+$ & 323 & 30.7 & 22.3 & 28.9 \\
\hline Single & 56.4 & 14.9 & 6.2 & 26.5 \\
\hline Urban & 83.4 & 81.4 & 83.4 & 82.6 \\
\hline \multicolumn{5}{|l|}{ Sensory deficits } \\
\hline Hearing impairment & 1.4 & 2.2 & 3.9 & 2.4 \\
\hline Visual impairment & 0.7 & 1.2 & 2.5 & 1.4 \\
\hline Total number & 1,891 & 2,198 & 1,527 & 5,616 \\
\hline
\end{tabular}




\section{Results}

Table 1 lists the demographic characteristics of the sample participating in the follow-up at T1 and/or T2. No differences existed for urbanicity $\left(\chi^{2}=3.78, d f=2, p\right.$ $=.151)$ across groups. Differences emerged for level of education $\left(\chi^{2}=44.14, \mathrm{df}=2\right.$, $p<.001)$, single living status $\left(\chi^{2}=1300, d f=2, p<.001\right)$, and visual and auditory impairment $\left(\chi^{2}=19.47, \mathrm{df}=2, \mathrm{p}<.001\right.$ and $\chi^{2}=24.34, \mathrm{df}=2, \mathrm{p}<.001$, respectively) with older subjects having had less higher education than the young and the middle group, living alone more often and reporting sensory impairment more often. The male:female ratio also differed across groups with women being somewhat overrepresented in the young and old group $\left(\chi^{2}=10.92, d f=2, p=.004\right)$.

\subsection{Cumulative incidence}

At T1 or T2, 56 out of 4637 individuals with no psychosis at baseline had the narrow psychosis outcome. Of all these incident psychosis, 19 were in the young group (34\%), 25 in the middle group (44\%) and 12 in the old group (21\%). The cumulative incidence of LOP was $0.3 \%$. This rate was comparable to the cumulative incidence rate of $\operatorname{EOP}(0.4 \%)$ and $\operatorname{MOP}(0.4 \%)\left(\chi^{2}=1.19, d f=2, p=.55\right)$. Out of 4401 subjects without any self-reported psychotic experiences in the past, 132 had developed the broad psychosis outcome at T1 or T2. Fifty-one of these were in the young group (38\%), 54 were in the middle group (42\%) and 27 (20\%) were in the old group. The cumulative incidence for the broad psychosis outcome was $0.8 \%$ in the old group, $1.3 \%$ in the young group and $1.1 \%$ in the middle group $\left(\chi^{2}=4.66, d f=2, p=.097\right)$.

$$
\begin{aligned}
& \text { Table } 2 \text { Risk increasing effect of the } \\
& \text { nisk factors life-time depression and } \\
& \text { high neuroticism on the broad } \\
& \text { psychosis outcome for those with } \\
& \text { onset of first psychotic symptoms in } \\
& \text { young age (18-34 years), middle age } \\
& \text { (35-49 years) and old age (50- } \\
& 64 \text { years) }
\end{aligned}
$$

\begin{tabular}{|c|c|c|c|c|c|}
\hline & \multirow[b]{2}{*}{ Age at onset } & \multicolumn{2}{|c|}{ Risk factor } & \multirow[b]{2}{*}{ Risk differences } & \multirow[b]{2}{*}{$95 \% \mathrm{Cl}$} \\
\hline & & Yes & No & & \\
\hline \multirow[t]{3}{*}{ Depression } & Young & $8.8 \%$ & $23 \%$ & $65 \%$ & $3.3 \%, 9.7 \%$ \\
\hline & Middle & $5.1 \%$ & $2.5 \%$ & $25 \%$ & $0.4 \%, 4.7 \%$ \\
\hline & Old & $3.7 \%$ & $2.0 \%$ & $1.7 \%$ & $-0.7 \%, 4.1 \%$ \\
\hline \multirow[t]{3}{*}{ Neuroticism } & Young & $7.4 \%$ & $2.1 \%$ & $53 \%$ & $2.9 \%, 10 \%$ \\
\hline & Middle & $5.2 \%$ & $2.4 \%$ & $28 \%$ & $0.8 \%, 5 \%$ \\
\hline & Old & $3.8 \%$ & $15 \%$ & $2.2 \%$ & $0.2 \%, 4.2 \%$ \\
\hline
\end{tabular}

Effect sizes are expressed as risk differences between those who had the risk factor and later on developed the psychosis outcome (yes) and those who did not have the risk factor but still developed the psychosis outcome (no).

\subsection{Risk factors}

\subsubsection{Age effect modification}

Main effects of risk factors on the broad psychosis outcome in NEMESIS have been described in other reports $(98,99,105,106,116,130,131)$. Significant interactions with age at onset were found for depression (Risk Difference $=-2.2 \%, 95 \% \mathrm{Cl}=-$ $4.1 \%,-0.3 \%$ ) and family history $(\mathrm{FH})$ of treated delusions/ hallucinations ( $\mathrm{RD}=3.3 \%$, 
$95 \% \mathrm{Cl}=0.3 \%, 6.2 \%)$, suggesting that the effects of both varied across age groups. The negligible prevalence, however, of $\mathrm{FH}$ treated delusions/ hallucinations in those having the broad psychosis outcome made further analysis impracticable $(n=$ 3 , all in the middle group). Statistical trends for interaction were observed for sex $(\mathrm{RD}=-1.3 \%, 95 \% \mathrm{Cl}=-0.8 \%, 2.7 \%)$, neuroticism $(\mathrm{RD}=-1.5 \%, 95 \% \mathrm{Cl}=-3.1 \%, 0.1 \%)$ and hearing impairment $(\mathrm{RD}=-5.9 \%, 95 \% \mathrm{Cl}=-12.1 \%, 0.2 \%)$. For the latter, the prevalence was too small to carry out stratified analyses, leaving depression, neuroticism and sex as targets for further analyses (Table 2 and Table 3).

\subsubsection{Age at onset and depression}

Stratified comparisons demonstrated that baseline depressive symptoms significantly increased the risk for developing the broad psychosis outcome within a three-year interval in the young $(\mathrm{RD}=6.5 \%, 95 \% \mathrm{Cl}=3.3 \%, 9.7 \%)$ and middle group $(\mathrm{RD}=2.5 \%, 95 \% \mathrm{Cl}=0.4 \%, 4.7 \%)$, but not in the old group $(\mathrm{RD}=1.7 \%, 95 \% \mathrm{Cl}=-$ $0.7 \%, 4.1 \%)$. In the youngest group, $8.8 \%$ of those reporting lifetime depressive symptoms at baseline had the broad psychosis outcome three years later as opposed to $2.3 \%$ of those reporting no depressive symptoms. In the old group, $3.7 \%$ of those reporting lifetime depressive symptoms developed the broad psychosis outcome as opposed to $2.0 \%$ of those reporting no depressive symptoms. The absolute RD between the young and the old group was significant ( $R D=4.8 \%$, $95 \% \mathrm{Cl}=0.8 \%, 8.8 \%)$. Thus, the risk-increasing effect of depression declined by a factor of $3.8(6.5 \% / 1.7 \%)$ with age at onset.

\subsubsection{Age at onset and neuroticism}

A significant risk-increasing effect of neuroticism was observed for the young (RD = $5.3 \%, 95 \% \mathrm{Cl}=2.7 \%, 7.9 \%)$, middle $(\mathrm{RD}=2.8 \%, 95 \% \mathrm{Cl}=0.8 \%, 4.9 \%)$ and old group $(\mathrm{RD}=2.2 \%, 95 \% \mathrm{Cl}=0.2 \%, 4.2 \%)$. In the young group, $7.4 \%$ of those with high neuroticism scores at baseline developed the broad psychosis outcome, versus $2.1 \%$ of those with low neuroticism scores. These figures dropped to $5.2 \%$ versus $2.4 \%$ in middle age with further progression to $3.8 \%$ versus $1.5 \%$ in old age. The absolute RD between the young and the old group, however, did not reach significance $(\mathrm{RD}=3.1 \%, 95 \% \mathrm{Cl}=-0.2 \%, 6.4 \%)$. Thus, the risk increasing effect of neuroticism declined by a factor of $2.4(5.3 \%$ / $2.2 \%)$ with age at onset.

\subsubsection{Age at onset and sex}

The overall interaction between sex and age showed a trend towards significance, but no clear effect was apparent after stratification for age at onset. No greater risk for female sex was found in the young $(\mathrm{RD}=1.7 \%, 95 \% \mathrm{Cl}=-0.4 \%, 3.7 \%)$, the middle $(\mathrm{RD}=0.4 \%, 95 \% \mathrm{Cl}=-1.4 \%, 2.1 \%)$ or the old group $(\mathrm{RD}=-0.9 \%, 95 \% \mathrm{Cl}=-2.7 \%, 0.9 \%)$. 


\section{Discussion}

\subsection{Incidence}

With an annual incidence of $0.3 \%$, the community rate for (clinically relevant, but mostly untreated) non-affective, non-organic psychotic symptoms with late-onset was twenty times higher than the rate of treated clinical disorders reported previously $(18,86-89)$. Of all new "cases", $21 \%$ were over 44 years of age at illness onset, which is in line with previous findings $(79,85)$. Similar disparities between clinical and community levels have been published with regard to prevalence rates of psychotic symptoms among the cognitively intact old $(94,95)$ and very old $(9)$. Psychosis in old age seems much more common than previously thought (132) and so does psychosis with late onset. The high incidence rate of psychotic symptoms as opposed to clinical disorder may not only be due to the fact that most of the sample with isolated psychotic symptoms would not have clinical needs, but may also be related to the argument that paranoid elderly often do not seek help (94, 133), and LOP, therefore, tends to be associated with longer community stays (134). This lack of help-seeking behaviour may, in turn, be a direct reflection of persecutory ideation, illness behaviour or of social isolation in old age $(93,134)$. In a post-hoc analysis for those with the broad psychosis outcome, however, we were unable to find any differences in first-contact rates as a function of age at onset (young vs. middle: $\chi^{2}=.61$, $d f=1, p=.435$; young vs. old: $\chi^{2}=.08, d f=1, p=.777$; middle vs. old: $\chi^{2}=.14, \mathrm{df}=1, \mathrm{p}=.708$ ).

It has to be noted that cell sizes for new psychosis were rather small and decreased even further by stratification for age groups. Hence, only 12 subjects out of 1282 aged 50 to 64 years developed a recent-onset psychosis in the present study. This number may be considered too small to calculate reliable incidence rates. This finding, therefore, calls for replication, but echoes similar findings in the younger age groups (135).

\subsection{Risk factors}

Symptoms of depression and neurotic personality styles were found to have some association with age at onset. In young age, subjects reporting life-time depressive symptoms at baseline run a higher risk of developing psychotic experiences later on than those who do not report depressive symptoms. The risk-enhancing effect in young age decreased to a much lower level in middle and old age. Although effect sizes did not reach significance in those aged 45 to 64 , a history of depressive symptoms went together with a twofold increase in psychosis risk, which suggests that significance may have been reached with bigger cell sizes. Depression is known to be a common antecedent of psychosis in general $(106,107)$ and in late life $(95)$, but it now seems that the strength of this relationship diminishes as the illness onset shifts towards later ages, pointing towards aetiological differences between LOP en EOP. This observation very nicely fits the repeated finding of less emotional co-morbidity in $\operatorname{LOP}(85,134,136,137)$. 
In a similar fashion, the risk-enhancing effect of neuroticism has been studied previously (105), but its association with psychosis appears to be less strong with onset in old age (138). Häfner et al. (1998) found that, although the severity of psychopathology decreased with age at first episode, this was not caused by a decrease in the severity of psychotic symptoms but by a decrease in neurotic syndrome levels (18). Neuroticism is a personality trait related to stress reactivity, anxiety proneness and emotional instability in the context of daily stressors (127, 139). In schizophrenic patients, high neuroticism levels are associated with avoidant coping styles and emotional discomfort (140), which might indicate that the diminishing effect of neuroticism in LOP reflects more adaptive coping skills in later adulthood. This lends further support to the notion of possible aetiological differences with psychosis in young age.

Men and women run an equal risk for LOP in the present study, which is at odds with earlier findings, but in line with the community-based study by Henderson and colleagues (1998). The authors explain their result by the higher refusal of women to take part in the study (95). This does not apply to NEMESIS. Alternatively, it may be that older men are less likely to come to professional attention and are for this reason missed in clinical studies. Although being highly speculative, it is compatible with the notion of profoundly lower symptom levels in males with LOP (18). Unfortunately, we were unable to explore this issue in depth.

Sensory impairment was not found to increase the risk for psychosis in later life. The outcome measures of deafness and visual impairment appeared to be too stringent. In addition, the sample may have been too young for these variables to exert significant effects. Only two out of 132 subjects with recent-onset psychotic symptoms suffered from severe visual deficits and 4 reported severe auditory deficits. All were younger than 50 years.

No notable differences in risk profiles between groups were found for level of urbanisation, lifetime cannabis use, life-time manic symptoms, family history of psychiatric treatment, family history of psychosis or single living status

\subsection{Limitations}

Regrettably, NEMESIS does not provide information for those older than 64 years. One may expect (qualitative) differences in risk profiles with EOP to show up more profoundly in those aged 65 years and older including cognitive ageing, sensory loss, death of a spouse or retirement $(7,114,141)$. The reported differences between LOP and EOP might be considered an underestimation of true risk differences, because analyses of risk factors was based on the broad psychosis outcome. It has been shown previously that this outcome results in smaller effect sizes than narrowly defined psychosis $(135,142)$. Further limitations include the use of lay interviewers and difficulties in excluding psychosis due to prodromal dementia. Although the CIDI is designed for the use by non-clinicians and 
interviewers underwent intensive training, these well-known problems cannot be completely solved in studies of this kind (93). They were nevertheless minimized by conducting re-interviews by an experienced psychiatrist to ascertain clinical relevance of psychotic symptoms using questions from the SCID.

\subsection{Conclusions}

This study fuels the finding that non-affective, non-organic psychotic symptoms arise more often in the second half of life than studies on a syndromal level have implied. LOP is less likely to be preceded by neuroticism and emotional disturbances, which suggests that those affected have learned to use more effective coping styles in daily life. Yet, the similarities in risk profiles across different ages at onset outweigh the differences. 


\section{CHAPTER 3}

\section{Age of onset, gender and the 5-year outcome of first episode psychosis}

Köhler S, van der Werf M, Hart B, Morrison G, McCreadie R, Kirkpatrick B, Verkaaik $M$, Krabbendam L, Verhey F, van Os J, Allardyce J. Evidence that better outcome of psychosis in women is reversed with increasing age of onset: A population-based 5year follow-up study. Schizophrenia Research. 2009;113(2-3):226-32. 


\section{Abstract}

Background: Female gender and later onset of psychosis are both associated with better outcome. However whether their effects are independent, is not known.

Method: In 379 incident cases of psychoses, from an epidemiologically defined catchment area, admixture analysis was employed to generate age of onset classes. Five-year course and outcome measured across clinical and social domains were used as dependent variables in regression analyses, to estimate associations of outcomes with gender, age of onset and gender by age of onset interaction.

Results: Three age of onset classes were identified: early (14-41 years), late (42-64 years) and very late onset psychosis (65-94 years). Overall, women had better outcomes, including milder delusions, fewer negative symptoms, less deterioration from baseline functioning, fewer hospital readmissions and shorter psychotic episodes. Later age of onset was also associated with better outcome, although in the very late onset class the results were mixed. There was a statistically significant gender by age of onset interaction (in the ratio scale) within this sample with men displaying poorer outcome in the early/late onset class, whereas women tended to have a worse outcome in the very late onset class.

Conclusions: The favourable outcome in women becomes reversed in old age, suggesting gender-age-related differences in the distribution of aetiological factors for psychosis. 


\section{Introduction}

Psychotic disorders show significant variation in their clinical presentation, course and outcome, probably reflecting aetiological and pathophysiological heterogeneity (143). Studying outcome can help elucidate the causes of such heterogeneity $(144,145)$. Several published studies suggest women have a better prognosis, including better global and psychosocial functioning, a less chronic course, fewer re-hospitalizations, shorter inpatients stays, reduced negative symptoms and significantly less disability $(14,146)$. Furthermore, other putative differences have been reported such as fewer obstetric complications, less structural brain changes, less severe negative symptoms, more affective symptoms and better premorbid functioning in women (14). These differences suggest the distribution of aetiological factors may vary between the genders (147).

Yet the most consistent finding regarding gender differences in psychosis is the later age of onset in women and female overrepresentation in later onset samples $(7,148)$. As later age of onset is also associated with better outcome in schizophrenia and other psychoses $(15,16,149)$, it can be hypothesised that gender and age of onset are not independent predictors of outcome.

The present study therefore reports the 5-year outcome, in a population of patients with first-episode psychoses, across the full adult age-range, and examines the effects of gender and age of onset (and their statistical interaction) on multiple clinical and social domains of outcome, while adjusting for factors known to potentially influence outcome, namely a positive family history for schizophrenia, a diagnosis of schizophrenia (as opposed to other psychoses), baseline symptoms and marital status (150).

\section{Method}

\section{1 Participants}

Case ascertainment has been described elsewhere (151). Briefly, all first contacts with an ICD-9 or ICD-10 diagnosis of schizophrenia, schizoaffective disorder, delusional disorder, mania, drug-induced psychotic disorder and acute, transient or unspecified psychotic disorder presenting to the psychiatric service (inpatients, day patients, outpatients, domiciliary assessments and informal out-of-hour contacts) of Dumfries and Galloway (D\&G) between the years 1979 and 1998 were identified. Exclusions criteria were: no resident of D\&G, psychotic symptoms prior to the study period, organic psychosis. This left a cohort of 464 patients for inclusion.

\section{2 Baseline assessment}

Demographic characteristics and the absence or presence of symptoms were extracted from the case records and ancillary documentation. Two experienced 
psychiatrists (JA, GM) completed The Operational Checklist for Psychotic Disorders (OPCRIT) (152). Good inter-rater agreement for both 1) individual symptom measures (kappa $=.69-.92)$ and 2) DSM-IV diagnoses generated using OPCRIT 3.4 algorithm (kappa $=.79$ ) have been demonstrated (151). Age of onset was defined as age of first contact with psychiatric service. As described previously (153), an exploratory factor analysis of first year OPCRIT ratings identified five latent symptom dimensions, explaining 58\% of the variance: mania, depression, disorganization, hallucinations, delusions. Factor scores were calculated for each individual for the five dimensions.

\section{3 Outcome measures}

The Local Regional Ethics Committee and the Privacy Committee of Information and Statistical Division in Scotland approved the follow-up study. Patients were traced between the years 2004 and 2005 using medical, regional and nationwide registers. Four-hundred-and-twenty-two (91\%) patients were traced (median time from presentation to follow-up $=11.82$ years, inter-quartile-range $=6.67-18.41$ ) . Where possible, multiple sources of information were used (systematic review of case notes, patient interviews, information from health professionals involved in day-to-day patient care and family members). All staff were formally trained and participated in regular review meetings and exercises from recorded interviews. Five-year outcome measures were created using items from the OPCRIT, WHO Life Chart Schedule (LCS) (154) and Life Time Dimensions of Psychosis Scale (LTDS) (155). The LCS was rated by research workers demonstrating good reliability (pairwise agreement $>0.8$ for all items used in the analyses) and the LTDS was completed by a single rater (JA). Outcomes included severity of delusions and hallucinations (both: $0=\mathrm{mild} /$ moderate, 1 = severe), presence of formal thought disorder, negative symptoms, first rank symptoms of Schneider and functional deterioration from levels at baseline/first admission (all: 0 = absent, 1 = present), course type ( 1 = one episode, 2 = multiple episodes, 3 = continuous symptoms), type of remission ( 1 = none, 2 = residual, 3 = complete), number of readmissions ( 1 - 5 or more), time of longest psychotic episode (in months), and time spent in supported residences (in months). The variables longest psychotic episode and time spent in supported residency suggested a skewed distribution. Therefore categories based on tertile cut-offs were generated and used in the analyses.

\section{4 Statistical analysis}

\subsubsection{Admixture analysis of age of onset}

Rather than using arbitrary age cut-offs to construct age of onset subgroups, we used admixture analysis in Mplus 4.0 (156). This method examines whether the observed continuous age of onset distribution could be better modelled as a mixture of two or more Gaussian distributions (157). It starts with the most parsimonious single-Gaussian distribution model and fits successive models with increasing numbers of distributions. Whether the model with $n+1$ distributions fits the observed distribution better than the model with only $n$ distributions was compared using several model fit indices: 1) adjusted Lo-Mendell-Rubin likelihood 
ratio test (LRT) (158), 2) Akaike's information criterion (AIC) (159) and 3) Bayesian information criterion (BIC) (160). Subjects can then be classified into age of onset subgroups identified by the different underlying distributions. How well this classification fits the data is measured using standardised entropy scores (161).

\subsubsection{Missing outcome data}

Missing values are almost inevitable in epidemiological studies but most follow up studies ignore possible bias introduced by analyzing cases with complete information only. To deal with the missing data we used multiple imputation methods which assume data is missing at random (MAR) (162). The method imputes several alternative versions of the complete dataset using the data that was not missing. These are then analyzed separately and the effect sizes and standard errors, which may vary, are combined using simple arithmetical procedures to obtain overall estimates. For follow-up measures with missing values, other than death, we imputed 20 datasets in STATA 9.2 (163) using the ICE routine (164) without restriction to observed variable ranges.

\subsubsection{Prediction of outcome}

Using gender as the predictor variable, logistic regressions (presence of formal thought disorder, negative symptoms, first rank symptoms, deterioration) or ordinal logistic regressions (severity of delusions and hallucinations, course type, remission type, number of readmissions, longest episode, supported residency) were run adjusted for continuous age of onset. Next regression analyses were repeated using the age of onset subgroups from the admixture analysis as outcome predictors, adjusted for gender. However, as age of onset group membership is not deterministic but based on posterior probabilities, we weighted the analyses for probability of belonging to a particular age of onset group. We further included the following covariates in all analyses: diagnosis of schizophrenia $(0=$ other nonorganic psychosis, 1 = DSM-IV schizophrenia), family history of schizophrenia (0 = absent, 1 = present), family history of other psychiatric disorders $(0=$ absent, $1=$ present), marital status ( $0=$ ever married, $1=$ single) and the factor scores of the five symptom dimensions. The interaction between gender and indicator-coded age of onset classes was tested using the LINCOM procedure in STATA.

\section{Results}

\subsection{Admixture analysis}

The observed age of onset distribution (Figure 1) suggests a major peak in young adulthood for both genders. A second and third peak appears to be primarily - but not exclusively - caused by a higher incidence in middle and old aged women. Admixture analysis was run in order to decompose the continuous age of onset distribution into age of onset classes. Model fit statistics and classification performance are shown in Table 1. A model with three Gaussian distributions 
showed superior model fit than the models with either two or four distributions. After class allocation based on posterior probability, these classes were called 'early onset psychosis' (EOP), 'late onset psychosis' (LOP) and 'very late onset psychosis' (VLOP).

Figure 1. The observed age of onset distributions for the total population, men and women.

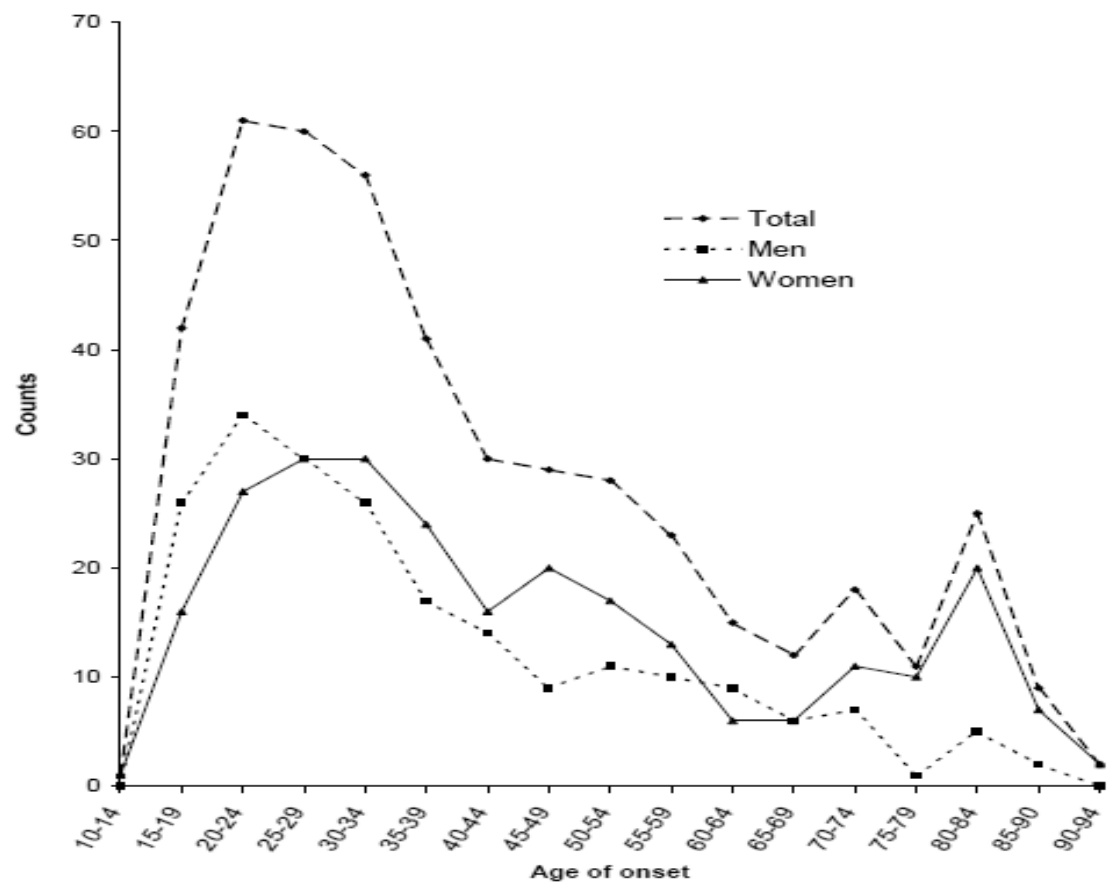

Table 1. Goodness of model fit indices for the one to six class solution of the admixture analysis using age of onset as indicator.

\begin{tabular}{cllllll}
\hline Classes & Log-likelihood & AIC $^{\mathbf{a}}$ & BIC $^{\mathbf{a}}$ & Entropy & LMR LRT $^{\mathbf{a}}$ & $\mathbf{P}$ \\
\hline 1 & -2046.5 & 4097.0 & 4105.3 & & & \\
2 & -1983.3 & 3974.7 & 3991.2 & 0.844 & 116.8 & $<.0001$ \\
$\mathbf{3}$ & $-\mathbf{1 9 5 8 . 1}$ & $\mathbf{3 9 2 8 . 1}$ & $\mathbf{3 9 5 3 . 0}$ & $\mathbf{0 . 8 4 8}$ & $\mathbf{4 6 . 7}$ & $<.0001$ \\
4 & -1953.3 & 3922.7 & 3955.8 & 0.786 & 8.7 & .1505 \\
5 & -1947.9 & 3915.8 & 3957.2 & 0.810 & 10.1 & .0615 \\
6 & -1947.9 & 3919.8 & 3969.4 & 0.822 & 0.0 & .8313 \\
\hline
\end{tabular}

a AIC = Akaike's information criterion, BIC = Bayesian information criterion, LMR LRT = adjusted LoMendell-Rubin Likelihood Ratio Test 


\subsection{Gender differences at baseline}

As shown in Table 2, women had a later mean age of onset and were married more often. No differences were found for family history of schizophrenia or other psychiatric disorders and diagnosis of schizophrenia between the gender, although there was a trend for men to be diagnosed with schizophrenia more often. The male-to-female ratio approached unity for EOP, but gradually shifted towards female preponderance in LOP and VLOP.

Table 2. Differences between men and women in baseline characteristics and outcome of psychosis at 5-year follow-up.

\begin{tabular}{|c|c|c|c|c|c|c|c|c|}
\hline & & \multirow{2}{*}{$\begin{array}{l}\text { Men } \\
N=207\end{array}$} & \multirow{2}{*}{$\begin{array}{l}\text { Women } \\
N=256\end{array}$} & \multicolumn{4}{|l|}{ Total } & \multirow[b]{2}{*}{$P^{a}$} \\
\hline & & & & $N=463$ & & $T / \chi^{2}$ & $D F$ & \\
\hline \multicolumn{9}{|l|}{ Baseline } \\
\hline \multicolumn{2}{|c|}{ Age of onset, mean (s.d.) } & $37.6(17.9)$ & $45.3(21.2)$ & $41.8(20.1)$ & \multirow{2}{*}{\multicolumn{2}{|c|}{2.86}} & \multirow[t]{2}{*}{$2 / 461$} & \multirow[t]{2}{*}{$<.001$} \\
\hline \multicolumn{2}{|c|}{ EOP (age of onset: $14-41$ ), $n(\%)$} & $139(67)$ & $131(51)$ & $270(58)$ & & & & \\
\hline \multicolumn{2}{|c|}{ LOP (age of onset: $42-64$ ) } & $47(23)$ & $69(27)$ & $116(25)$ & \multirow{2}{*}{\multicolumn{2}{|c|}{15.3}} & \multirow[t]{2}{*}{$2 / 461$} & \multirow[t]{2}{*}{$<.001$} \\
\hline \multicolumn{2}{|c|}{ VLOP (age of onset: $65-94$ ) } & $21(10)$ & $56(22)$ & $77(17)$ & & & & \\
\hline \multicolumn{2}{|c|}{ Ever married, $\mathrm{n}(\%)$} & $97(47)$ & $175(68)$ & $272(59)$ & & 21.83 & $2 / 461$ & $<.001$ \\
\hline \multicolumn{2}{|c|}{ Positive $\mathrm{FH}-\mathrm{s}^{\mathrm{b}}, \mathrm{n}(\%)$} & $19(9)$ & $26(10)$ & $45(10)$ & & 0.12 & $2 / 461$ & .724 \\
\hline \multicolumn{2}{|c|}{ Positive FH-p ${ }^{b}, n(\%)$} & $41(20)$ & $56(22)$ & $97(21)$ & & 0.30 & $2 / 461$ & .587 \\
\hline \multirow{3}{*}{\multicolumn{2}{|c|}{ DSM-IV schizophrenia ${ }^{c}, \mathrm{n}(\%)$}} & $59(29)$ & $54(22)$ & $113(24)$ & & 2.86 & $2 / 461$ & .091 \\
\hline & & Men & Women & \multicolumn{4}{|l|}{ Total } & \multirow[b]{2}{*}{$P$} \\
\hline & & $N=183$ & $N=224$ & $N=407$ & & OR & $95 \% \mathrm{Cl}$ & \\
\hline \multicolumn{9}{|l|}{ Outcome $e^{d}$} \\
\hline \multicolumn{9}{|l|}{ Severity of, $n(\%)$} \\
\hline Delusions & $\begin{array}{l}\text { Mild/ moderate } \\
\text { Severe }\end{array}$ & $\begin{array}{l}63(37) \\
85(50)\end{array}$ & $\begin{array}{l}89(43) \\
76(37)\end{array}$ & $\begin{array}{l}152(40) \\
161(43)\end{array}$ & \multicolumn{2}{|r|}{0.57} & $\begin{array}{l}0.35 / 0 . \\
93\end{array}$ & .024 \\
\hline Hallucinations & $\begin{array}{l}\text { Mild/ moderate } \\
\text { Severe }\end{array}$ & $\begin{array}{l}69(41) \\
29(17)\end{array}$ & $\begin{array}{l}73(35) \\
35(17)\end{array}$ & $\begin{array}{l}142(38) \\
64(17)\end{array}$ & \multicolumn{2}{|r|}{1.04} & $\begin{array}{l}0.52 / 2 \\
07\end{array}$ & .911 \\
\hline Presence of, $n$ (\% & & & & & & & & \\
\hline Formal though & disorder & $48(28)$ & $42(20)$ & $90(24)$ & 0.66 & 0.33 & /1.31 & .239 \\
\hline Negative symp & oms & $53(31)$ & $33(16)$ & $86(23)$ & 0.50 & 0.27 & /0.94 & .031 \\
\hline First rank symp & oms & $75(44)$ & $83(40)$ & $158(42)$ & 0.85 & 0.52 & /1.40 & .530 \\
\hline Deterioration fro & m baseline, $\mathrm{n}(\%)$ & $84(50)$ & $69(33)$ & $153(40)$ & 0.56 & 0.35 & /0.90 & .017 \\
\hline Course type, n (9 & & & & & & & & \\
\hline One episode & & $48(29)$ & $70(34)$ & $118(31)$ & & & & \\
\hline Multiple episo & & $58(35)$ & $83(40)$ & $141(38)$ & 0.75 & 0.48 & /1.15 & .185 \\
\hline Continuous syr & ptoms & $62(37)$ & $53(26)$ & $115(31)$ & & & & \\
\hline
\end{tabular}


Table 2. Continued.

\begin{tabular}{|c|c|c|c|c|c|c|}
\hline \multicolumn{7}{|c|}{ Remission type, n (\%) } \\
\hline None & $61(36)$ & $55(26)$ & $116(31)$ & \multirow{3}{*}{1.34} & \multirow{3}{*}{$0.88 / 2.04$} & \multirow{3}{*}{.168} \\
\hline Residual & $38(23)$ & $66(31)$ & $104(28)$ & & & \\
\hline Complete & $69(41)$ & $89(42)$ & $158(42)$ & & & \\
\hline \multicolumn{7}{|c|}{ Number of readmissions } \\
\hline 0 & $19(10)$ & $52(23)$ & $71(17)$ & \multirow{4}{*}{0.59} & \multirow{4}{*}{$0.40 ; 0.87$} & \multirow{4}{*}{.009} \\
\hline $1-2$ & $96(52)$ & $117(52)$ & $213(52)$ & & & \\
\hline $3-4$ & $40(22)$ & $33(15)$ & $73(18)$ & & & \\
\hline 5 or more & $28(15)$ & $22(10)$ & $50(12)$ & & & \\
\hline \multicolumn{7}{|l|}{ Longest episode } \\
\hline First tertile & $56(31)$ & $80(36)$ & $136(33)$ & \multirow{3}{*}{0.77} & \multirow{3}{*}{$0.51 ; 1.18$} & \multirow{3}{*}{.231} \\
\hline Second tertile & $51(28)$ & $77(34)$ & $128(31)$ & & & \\
\hline Third tertile & $76(42)$ & $67(30)$ & $143(35)$ & & & \\
\hline \multicolumn{7}{|c|}{ Supported residency } \\
\hline First tertile & $52(28)$ & $83(37)$ & $135(33)$ & \multirow{3}{*}{0.87} & \multirow{3}{*}{$0.57 ; 1.31$} & \multirow{3}{*}{.503} \\
\hline Second tertile & $60(33)$ & $75(33)$ & $135(33)$ & & & \\
\hline Third tertile & $71(39)$ & $66(29)$ & $137(34)$ & & & \\
\hline
\end{tabular}

\footnotetext{
${ }^{a}$ EOP = early onset psychosis, LOP = late onset psychosis, VLOP = very late onset psychosis

${ }^{b} \mathrm{FH}-\mathrm{s}$ : family history of schizophrenia, $\mathrm{FH}-\mathrm{p}$ : family history of other psychiatric disorders

${ }^{c}$ Other non-organic psychosis: DSM-IV schizophreniform disorder, delusional disorder, and psychotic disorder NOS, major depression, bipolar disorder, and schizoaffective disorder

${ }^{d}$ corrected for age of onset, marital status, diagnosis of schizophrenia, FH-s, FH-p and baseline symptom factor scores
}

\subsection{Loss to follow-up}

At 5-year follow-up, information was obtained for 379 (82\%) of the total inception cohort. Of these, 351 (93\%) had continued contact with psychiatric services and 127 (34\%) had a face-to-face interview. Eighty-five (18\%) of the original cohort were lost to follow-up due to death in 56 and 29 were not traceable. Of those who had died, 32 were women and 24 were men $\left(\chi^{2}=0.09, \mathrm{df}=2 / 461, \mathrm{p}=.766\right)$. Causes of death were classified into circulatory system disease $(n=25,45 \%)$, cancer $(n=9$, $16 \%)$ respiratory system disease $(n=7,12 \%)$, suicide $(n=5,9 \%$, all in EOP) and other reasons ( $n=10,18 \%)$. In VLOP, $34(44 \%)$ of cases had died, $15(13 \%)$ in LOP and $7(3 \%)$ in EOP. The main cause of death in VLOP and LOP was circulatory system failure ( $50 \%$ and $53 \%$ respectively), whereas suicide accounted for most deaths in EOP (71\%). There were no significant differences between those traceable and untraceable in age of onset, diagnosis of schizophrenia, gender, marital status, pre-morbid social adjustment and family history of schizophrenia or other psychiatric disorders. Missing values for untraceable patients were multiply imputed. 
Table 3. Stratified comparisons of outcome across age of onset classes.

\begin{tabular}{|c|c|c|c|c|c|c|}
\hline \multirow[t]{2}{*}{ Outcome } & \multicolumn{3}{|c|}{ LOP versus EOP ${ }^{a}$} & \multicolumn{3}{|c|}{ VLOP versus EOP ${ }^{a}$} \\
\hline & $O R$ & $95 \% \mathrm{Cl}$ & $P$ & $O R$ & $95 \% \mathrm{Cl}$ & $P$ \\
\hline \multicolumn{7}{|l|}{ Severity of ${ }^{b}$} \\
\hline Delusions & 1.00 & $0.56 ; 1.79$ & .998 & 0.31 & $0.12 ; 0.82$ & .018 \\
\hline Hallucinations & 0.92 & $0.41 ; 2.10$ & .845 & 1.07 & $0.26 ; 4.38$ & .903 \\
\hline \multicolumn{7}{|l|}{ Presence of ${ }^{c}$} \\
\hline Formal thought disorder & 0.63 & $0.27 ; 1.45$ & .278 & 0.14 & $0.03 ; 0.75$ & .022 \\
\hline Negative symptoms & 0.46 & $0.20 ; 1.09$ & .078 & \multicolumn{3}{|c|}{ not observed in VLOP } \\
\hline First rank symptoms & 0.48 & $0.26 ; 0.88$ & .017 & 0.60 & $0.23 ; 1.58$ & .300 \\
\hline Deterioration $^{c}$ & 0.54 & $0.29 ; 1.00$ & .049 & 0.41 & $0.17 ; 0.96$ & .041 \\
\hline Course type $^{d}$ & 0.97 & $0.58 ; 1.61$ & .903 & 1.97 & $0.81 ; 4.79$ & .107 \\
\hline Remission type $^{\mathrm{e}}$ & 0.72 & $0.44 ; 1.17$ & .181 & 0.30 & $0.15 ; 0.60$ & .001 \\
\hline Longest episode $^{f}$ & 1.27 & $0.74 ; 2.19$ & .390 & 3.82 & $1.76 ; 8.30$ & .001 \\
\hline Supported residency ${ }^{\dagger}$ & 0.82 & $0.49 ; 1.38$ & .462 & 0.29 & $0.14 ; 0.61$ & .001 \\
\hline Number of readmissions & 0.65 & $0.40 ; 1.06$ & .082 & 0.15 & $0.08 ; 0.27$ & $<.001$ \\
\hline
\end{tabular}

${ }^{a}$ EOP: early onset psychosis, LOP: late onset psychosis, VLOP: very late onset psychosis

${ }^{b} 1$ : mild/ moderate, 2: severe

${ }^{\mathrm{c}} 0$ : absent, 1 : present

${ }^{\mathrm{d}} 0$ : one episode, $1:$ multiple episodes, 2 : continuous symptoms

${ }^{\mathrm{e}} 0$ : none, 1: residual, 2: complete

${ }^{\mathrm{f}}$ based on tertile cut-offs

\subsection{Gender, age of onset and 5-year outcome}

When age of onset and other confounders were controlled for (Table 2), being female was associated with milder delusions, less negative symptoms, lower risk of functional deterioration and less readmissions. When gender and other confounders were controlled for (Table 3), LOP was associated with a lower risk of first rank symptoms and risk of functional deterioration compared to EOP. VLOP was associated with milder delusions, a lower risk of having formal thought disorder, a lower risk of functional deterioration, less readmissions and less months spent in supported residences, but also with longer episodes and less likelihood of remission compared to EOP. Adjusted analyses further showed that worse outcome was seen in patients with a diagnosis of schizophrenia compared to other psychoses, including a higher likelihood of functional deterioration $(O R=2.37$, $95 \% \mathrm{Cl}=1.36 ; 4.07, \mathrm{p}=.002)$, negative symptoms $(\mathrm{OR}=2.22,95 \% \mathrm{Cl}=1.20 ; 4.13, \mathrm{p}=$ $.011)$, longer episodes $(\mathrm{OR}=4.87,95 \% \mathrm{Cl}=2.95 ; 8.05, \mathrm{p} \leq .001)$, more time spent in supported residency $(\mathrm{OR}=2.21,95 \% \mathrm{Cl}=1.37 ; 3.56, \mathrm{p} \leq .001)$, less chance of remission $(\mathrm{OR}=0.20,95 \% \mathrm{Cl}=0.11 ; 0.37, \mathrm{p} \leq .001)$ and higher risk of chronicity (OR $=4.12,95 \% \mathrm{Cl}=2.40 ; 7.08, \mathrm{p} \leq .001)$. Single living status was associated with longer episodes $(O R=2.13,95 \% \mathrm{Cl}=1.37 ; 3.32, \mathrm{p} \leq .001)$, higher risk of chronicity $(O R=$ $1.76,95 \% \mathrm{Cl}=1.13 ; 2.75, \mathrm{p}=.013)$ but less severe delusions $(\mathrm{OR}=0.54,95 \% \mathrm{Cl}=$ 
$0.33 ; 0.90, p=.018)$. A positive family history of schizophrenia related to the presence of formal thought disorders $(\mathrm{OR}=2.56,95 \% \mathrm{Cl}=1.22 ; 5.37, \mathrm{p}=.013$ ).

\subsection{Interaction between gender and age of onset class}

Significant gender by age of onset class interactions, in the ratio scale, were apparent for the outcomes of time of longest episode and course type, indicating the tendency for better outcome in EOP women to become inversed in VLOP, with psychosis becoming more persistent and chronic compared to men (Table 4). Thus, women in the EOP group were on average 0.63 times less likely to be in one of the higher tertiles of longest episode duration compared to men, which changing to 4.96 times more likely for women in the VLOP class. The same pattern was apparent for the outcome "course type", although the effect in the VLOP group was statistically inconclusive $(p=.075)$. A similar pattern was apparent for remission type, although the interaction was inconclusive $(p=.167)$. As formal thought disorders were virtually absent in VLOP men, this lead to a disproportional interaction effect.

Table 4. Comparison of the effect of gender ( $M=$ men, $W=$ women) within the three age of onset classes (conditional OR estimates), and the interaction between age of onset class and gender for 5-year outcome with the gender-effect in the youngest age of onset class as the reference value.

\begin{tabular}{|c|c|c|c|c|c|c|c|c|c|c|}
\hline \multirow[t]{2}{*}{ Outcome } & \multirow{2}{*}{$\begin{array}{l}\text { Age of } \\
\text { onset }^{a}\end{array}$} & \multicolumn{3}{|c|}{ Counts } & \multicolumn{2}{|c|}{ Effect of gender } & \multirow[b]{2}{*}{$P$} & \multicolumn{3}{|c|}{ Age of onset $X$ gender $^{b}$} \\
\hline & & $N$ & $M$ & $w$ & $O R$ & $95 \% \mathrm{Cl}$ & & $O R$ & $95 \% \mathrm{Cl}$ & $P$ \\
\hline \multirow{3}{*}{$\begin{array}{l}\text { Severity of } \\
\text { delusions }{ }^{c}\end{array}$} & EOP & 215 & 119 & 96 & 0.80 & $0.44 ; 1.46$ & .463 & - & & \\
\hline & LOP & 86 & 33 & 53 & 0.35 & $0.13 ; 0.93$ & .036 & 0.43 & $0.14 ; 1.37$ & .154 \\
\hline & VLOP & 32 & 9 & 23 & 0.27 & $0.04 ; 1.80$ & .176 & 0.34 & $0.05 ; 2.51$ & .288 \\
\hline \multirow{3}{*}{$\begin{array}{l}\text { Severity of } \\
\text { hallucinations }\end{array}$} & EOP & 147 & 79 & 68 & 1.24 & $0.56 ; 2.72$ & .592 & - & & \\
\hline & LOP & 47 & 18 & 29 & 0.92 & $0.23 ; 3.64$ & .903 & 0.74 & $0.15 ; 3.56$ & .707 \\
\hline & VLOP & 16 & 4 & 12 & 0.39 & $0.02 ; 6.31$ & .505 & 0.31 & $0.02 ; 5.59$ & .429 \\
\hline \multirow{3}{*}{$\begin{array}{l}\text { Formal thought } \\
\text { disorder }^{d}\end{array}$} & EOP & 263 & 133 & 130 & 0.58 & $0.27 ; 1.26$ & .171 & - & & \\
\hline & LOP & 101 & 39 & 62 & 0.96 & $0.22 ; 4.20$ & .960 & 1.65 & $0.32 ; 8.36$ & .547 \\
\hline & VLOP & 43 & 11 & 32 & e & e & $<.001$ & e & e & $<.001$ \\
\hline \multirow{3}{*}{$\begin{array}{l}\text { Negative } \\
\text { symptoms }\end{array}$} & EOP & 263 & 133 & 130 & 0.55 & $0.27 ; 1.09$ & .087 & - & & \\
\hline & LOP & 101 & 39 & 62 & 0.47 & $0.10 ; 2.15$ & .329 & 0.86 & $0.16 ; 4.52$ & .857 \\
\hline & VLOP & 43 & 11 & 32 & j & j & j & j & j & j \\
\hline \multirow{3}{*}{$\begin{array}{l}\text { First rank } \\
\text { symptoms }\end{array}$} & EOP & 263 & 133 & 130 & 0.92 & $0.51 ; 1.68$ & .796 & - & & \\
\hline & LOP & 101 & 39 & 62 & 0.71 & $0.26 ; 1.95$ & .501 & 0.76 & $0.24 ; 2.46$ & .652 \\
\hline & VLOP & 43 & 11 & 32 & 0.69 & $0.11 ; 4.49$ & .695 & 0.74 & $0.10 ; 5.50$ & .772 \\
\hline
\end{tabular}


Table 4. Continued.

\begin{tabular}{|c|c|c|c|c|c|c|c|c|c|c|}
\hline \multirow[t]{3}{*}{ Deterioration $\mathrm{d}$} & EOP & 263 & 133 & 130 & 0.55 & $0.31 ; 0.95$ & .035 & - & & \\
\hline & LOP & 101 & 39 & 62 & 0.63 & $0.23 ; 1.68$ & .351 & 1.14 & $0.37 ; 3.52$ & .816 \\
\hline & VLOP & 43 & 11 & 32 & 0.58 & $0.10 ; 3.39$ & .542 & 1.05 & $0.16 ; 6.80$ & .957 \\
\hline \multirow[t]{3}{*}{ Course type $f$} & EOP & 263 & 133 & 130 & 0.63 & $0.38 ; 1.04$ & .071 & - & & \\
\hline & LOP & 101 & 39 & 62 & 0.58 & $0.24 ; 1.40$ & .226 & 0.93 & $0.34 ; 2.49$ & .880 \\
\hline & VLOP & 43 & 11 & 32 & 5.80 & $0.84 ; 40.19$ & .075 & 9.23 & $1.21 ; 70.40$ & .032 \\
\hline \multirow[t]{3}{*}{$\begin{array}{l}\text { Remission } \\
\text { type } \mathrm{g}\end{array}$} & EOP & 263 & 133 & 130 & 1.55 & $0.90 ; 2.66$ & .111 & - & & \\
\hline & LOP & 101 & 39 & 62 & 1.40 & $0.63 ; 3.13$ & .413 & 0.90 & $0.34 ; 2.38$ & .837 \\
\hline & VLOP & 43 & 11 & 32 & 0.60 & $0.17 ; 2.06$ & .415 & 0.39 & $0.10 ; 1.49$ & .167 \\
\hline \multirow[t]{3}{*}{$\begin{array}{l}\text { Number of } \\
\text { readmissions } h\end{array}$} & EOP & 263 & 133 & 130 & 0.71 & $0.43 ; 1.16$ & .169 & - & & \\
\hline & LOP & 101 & 39 & 62 & 0.52 & $0.24 ; 1.15$ & .107 & 0.74 & $0.30 ; 1.83$ & .516 \\
\hline & VLOP & 43 & 11 & 32 & 0.31 & $0.12 ; 0.80$ & .015 & 0.43 & $0.15 ; 1.30$ & .136 \\
\hline \multirow{3}{*}{$\begin{array}{l}\text { Longest } \\
\text { episode }\end{array}$} & EOP & 263 & 133 & 130 & 0.63 & $0.38 ; 1.06$ & .082 & - & & \\
\hline & LOP & 101 & 39 & 62 & 0.67 & $0.29 ; 1.58$ & .362 & 1.06 & $0.39 ; 2.90$ & .902 \\
\hline & VLOP & 43 & 11 & 32 & 4.96 & $1.08 ; 22.82$ & .040 & 7.85 & $1.55 ; 39.66$ & .013 \\
\hline \multirow{3}{*}{$\begin{array}{l}\text { Supported } \\
\text { residency }\end{array}$} & EOP & 263 & 133 & 130 & 0.77 & $0.46 ; 1.27$ & .303 & - & & \\
\hline & LOP & 101 & 39 & 62 & 1.05 & $0.45 ; 2.48$ & .902 & 1.38 & $0.51 ; 3.75$ & .531 \\
\hline & VLOP & 43 & 11 & 32 & 1.12 & $0.26 ; 4.81$ & .881 & 1.46 & $0.31 ; 6.96$ & .635 \\
\hline \multicolumn{11}{|c|}{ 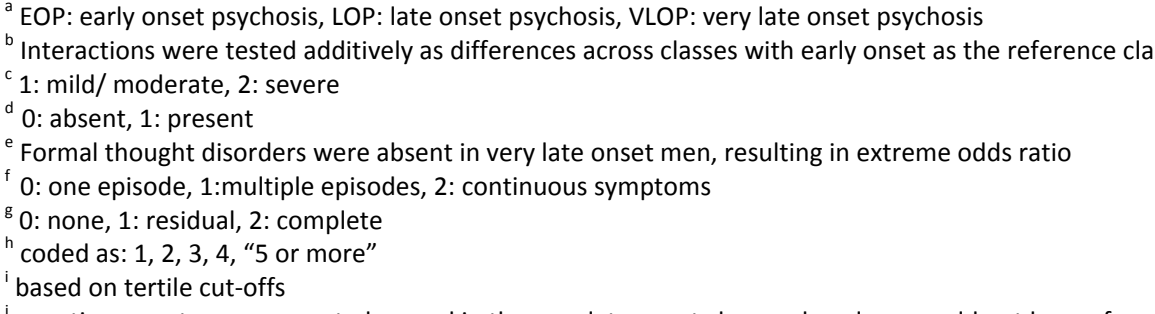 } \\
\hline
\end{tabular}

\section{Discussion}

Consistent with the published literature, we found women to have a later age of onset and better outcome than men $(14,148)$. Later age of onset was also associated with better outcome, although in the VLOP class the result was mixed. Thus, VLOP patients' psychopathology was milder with decreased likelihood of functional deterioration, less readmission rates and more time spent living independently, while they were less likely to have complete remission and more 
likely to have long episodes. Estimating the joint effects of gender and age of onset strongly supports an effect measure modification with men displaying poorer outcome in the early age of onset class. However their prognosis improved as age of onset increased. In contrast, women had a more favourable outcome profile in young or middle age onset, but tended to have a poorer outcome in the very late onset cases, particularly in terms of course type, longest episode and remission type. The lack of published studies examining gender differences in outcome across the whole range of age of onset may in part explain why the idea that women have better outcome, regardless of age of onset interactions, has prevailed $(14,146)$.

The gender difference in age of onset and clinical characteristics has been postulated to be due to an anti-psychotic effect of estrogens on dopamine-D2 receptors. This hypothesis suggests that the disorder only becomes apparent after menopause, for a proportion of women who have a psychosis liability $(17,18)$. Although this 'estrogen-hypothesis' may have some utility in explaining differences in mean age of onset and the second incidence peak in middle-aged women, it cannot explain gender differences in older age groups. Psychosis in the second half of life may represent a final common pathway of various disease processes of differing aetiology including hormonal changes, neurodegenerative conditions and gender-linked genetic effects (165). Therefore, women with a genetic vulnerability for psychotic disorder might be protected when they are younger, but develop psychotic disorder of a chronic type when their vulnerability becomes expressed later in life, under the influence of, for example, neurodegenerative mechanisms. On the other hand, genetically vulnerable men will be more likely to express their liability at an earlier age. Consequently, only men with lower levels of vulnerability develop psychotic disorders in old age, therefore displaying better outcome than their female counterparts.

Studies regarding the putative role of neurodegeneration in LOP/VLOP have so far been inconclusive, with some reporting transition to dementia rates of $13 \%$ to $47 \%$ (follow-up ranging from 5 to 15 years) $(20,21,23)$, while other studies, of comparable follow-up durations, do not find such high rates $(24,26)$. Likewise, neuropsychological testing and neuroimaging studies have generally failed to find clear evidence of accelerated cognitive decline (166-168). However, none of these studies, to date, has examined the effect separately for gender or gender-age interactions. Interestingly, one study did find that elderly women with schizophrenia more often displayed neuropathological changes of Braak stages III and IV, indicative of possible Alzheimer disease, especially if onset was after 40 years of age (169). Unfortunately, we do not have detailed neuropsychological testing on the current study sample, so were not able to investigate this important issue and potential cause for the observed inter-gender variation on outcome.

This paper should be interpreted in the light of its methodology. First, we assessed outcome retrospectively and mainly by chart review. Only one-third of the patients could be interviewed face-to-face, which may have resulted in incomplete and 
selective information. However, multiple information sources were used including high quality, complete case notes, and the WHO LCS and the LTDS are both standardized instruments designed for retrospective assessment of symptom course and disability. In addition, 93\% of all live participants were still in contact with the clinical community services. As there is little staff turnover within the region of $D \& G$, this facilitated more consistent long-term documentation. Secondly, the LTDS was completed by a single rater, which ensures consistency of rating, but can also potentially introduce bias if the rater had preconceptions when assessing outcome (e.g. male gender and earlier age of onset go together with worse outcome). It seems unlikely however that such a bias has driven our main finding, i.e. the reversed prognosis in older psychotic women. Thirdly, we present data on a heterogeneous sample of psychosis patients because it has been previously shown that a priori restriction to a certain diagnostic subgroup in the study of later onset psychosis is likely to introduce bias (170). Fourthly, we defined onset as first contact with psychiatric services. The advantage of this measure is that it constitutes a precise datable event and is generally regarded as suitable proxy for age of onset (165). Still, first signs of psychosis may arise many years before a person comes in contact with psychiatric services and some later onset patients might represent long term 'silent sufferers'. While this cannot be ruled out for some cases, it seems unlikely that it accounts for the majority. Fifthly, some of the more borderline statistically significant effects should be interpreted with some caution as we tested multiple associations. However, there was a consistent pattern of change in effect size as a function of age of onset and gender across conceptually related outcome measures.

This study has significant strengths, including the complete case ascertainment of all first ever psychotic disorder presenting to a geographically well-defined catchment area, which included not only inpatients but all outpatient and informal contacts to psychiatric services, for all psychotic disorders; the careful tracing of patients using several local and national registrars; assessment of outcome across a wide range of domains (symptomatic, functional, psychosocial); attempt to derive natural classes of age of onset in order to increase the sensitivity to non-linearity in associations between age of onset and course. Taken together, to the best of our knowledge, this makes it the most detailed study on the influence of age of onset and gender on (mid-term) outcome of psychotic disorders. 
PART TWO

\section{Late life depression}





\section{Late life depression and cognitive decline in the general population}

Köhler S, van Boxtel MP, van Os J, Thomas AJ, O'Brien JT, Jolles J, Verhey FRJ, Allardyce J. Depressive symptoms, cognitive decline and the 6-year risk for mild cognitive impairment in community dwelling older adults. Submitted. 


\section{Abstract}

Background: The identification of at-risk mental states for cognitive decline and dementia is paramount for developing effective prevention and treatment strategies. While depression is a candidate risk factor for cognitive decline, the nature of the association is poorly understood.

Aim: To examine the temporal association of depressive symptoms, cognitive functioning and incident mild cognitive impairment $(\mathrm{MCl})$ and estimate the effect measure modification of apolipoprotein $\varepsilon-4$ genotype on this relationship.

Methods: Depressive symptoms and neurocognitive functioning were serially measured in 598 non-demented older adults (aged $\geq 60$ years) and their associations longitudinally assessed using linear mixed models. The risk of baseline depressive symptoms for $\mathrm{MCl}$ was examined using logistic regression.

Results: High levels of depressive symptoms at baseline and a persistently high level of depression predict accelerated cognitive decline, at six years follow up, in the domains of memory, processing speed, attention and global cognitive functioning. Clinically relevant depression at baseline also predicted incident multidomain $\mathrm{MCl}$, particularly of the amnestic variant. Apolipoprotein $\varepsilon$-4 genotype carriers had an increased risk of $\mathrm{MCl}$, but carrying the risk allele did not moderate the effect of depression on cognitive decline.

Conclusions: Depressive symptoms and apolipoprotein $\varepsilon-4$ genotype act independently to increase the risk for cognitive decline and $\mathrm{MCl}$. 


\section{Introduction}

Clinically relevant depression is one of the most prevalent psychiatric conditions of later life, affecting up to $35 \%$ of the general population over the age of 60 (with rates as high as $4 \%$ reported for DSM-IV major depressive disorder) $(32,33)$. Community studies in normally-ageing populations suggest depression is associated with cognitive decline $(45-53)$ and dementia $(54,171)$, though this is not a consistent finding (172-177). However, whether depression is a vulnerability marker, antecedent or a contingent risk factor for dementia is not yet established (55), and research that has tried to link depression to dementia, e.g. by studying a shared genetic basis or common pathogenic pathway, has produced mixed results. So, while the $\varepsilon-4$ genotype of the apolipoprotein-E promoter gene APOE is linked to accelerated cognitive decline in normal aging populations and Alzheimer's disease (178-182), its contribution to depression-related cognitive deficits remains controversial $(51,183-185)$.

This study aims to further our understanding of the relationship between depressive symptoms and cognitive decline, by examining the predictive power of depressive symptoms on subsequent cognitive decline and onset of mild cognitive impairment $(\mathrm{MCl})$ at three and six years follow up, in a community sample of nondemented older adults (aged 60 years or older), and to measure the effect measure modification of APOE genotype on these associations. We hypothesized that depressive symptoms at baseline would be associated with i) lower neurocognitive test scores at follow-up, ii) accelerated cognitive decline iii) higher likelihood of incident $\mathrm{MCl}$, and iv) evidence of dose response associations (effect gradient), with the severe and persistent depressive symptoms having a stronger association with future cognitive decline.

\section{Methods}

\subsection{Study participants}

The Maastricht Ageing Study (MAAS) is a longitudinal study examining the determinants of cognitive ageing (186). Participants without major neurological conditions or psychiatric disorders were approached between 1993-1995 via the collaborative network of family practices in Limburg, the Netherlands (187). At baseline (T0), 661 participants were over 60 years old. We excluded people with a Mini-Mental-State-Examination score below $24(n=12)$, previous anti-depressants use $(n=19)$, or missing scores on the Symptom Checklist 90 depression subscale ( $n$ = 32), leaving a potential cohort of 598 individuals. Of these, 479 (80\% of baseline sample) were followed up at 3 years (F1) and 412 (69\% of baseline sample) at 6 years (F2). Reasons for loss-to follow-up (LTFU) at F2 were death $(n=87)$, loss of interest $(n=49)$, bad health and incapacity $(n=46)$ and other reasons $(n=4)$. 


\subsection{Measures of depression}

Depressive symptoms were assessed using the revised 90-item version of the Symptom Checklist (SCL-90) (188). In MAAS, only the 29 items assessing depression, anxiety and sleeping problems were administered from F0 to F2. The sixteen items of the depression subscale rate the severity of symptoms from ' $1=$ not at all' to ' 5 = extremely', yielding a sum score (range: 16-80) which were used to generate ordered categories of depression severity, defined by quartile cut offs. As women are known to score higher on the depression subscale (189), severity categories were generated separately for men and women. We labelled the four severity categories 'absent', 'low, 'middle' and 'high'. The highest quartile group had scores that were considered clinically meaningful, so stability of depression was defined as a score within the upper quartile group on two consecutive assessments (baseline and/or follow-up (either F1 or F2)). This produced four groups ( 0 = 'no depression', 1 = 'depression at baseline', 2 = 'depression at followup', 3 = 'persistent depression').

\subsection{APOE genotype}

APOE genotyping was determined on genomic DNA extracted from EDTAanticoagulated blood using the polymerase chain reaction technique (190).

\subsection{Measures of cognitive outcome}

A comprehensive neuropsychological assessment was carried out. Episodic verbal memory was measured with the three conditions (immediate recall, delayed recall, delayed recognition) of the Visual Verbal Learning Test (VVLT) (191). Selective attention was assessed with the Stroop Colour Word Test (SCWT) $(192,193)$, and the difference it takes to read card three (colour names printed in an incongruent colour) compared to cards one (colour names) and two (coloured bars) was used to calculate an interference susceptibility index. The Letter Digit Substitution Test (LDST) was administered as a test of information processing speed (194). This is an adaptation of the Digit Symbol Substitution Test (195), but it uses highly overlearned signs, namely letters instead of abstract symbols, to minimize working memory load. Global cognition was assessed with the Mini-Mental-StateExamination (MMSE) (196). General IQ was estimated with the subtests arithmetic, vocabulary, mental rotation and analogies from the Groningen Intelligence Scale (197).

$\mathrm{MCl}$ is generally defined as a significant cognitive impairment (with or without prominent memory deficits) and subjective cognitive complaints in the context of preserved ADL functioning and in the absence of dementia. As published work demonstrates a higher sensitivity for later dementia by omitting the subjective complaints criterion (198), we operationally defined $\mathrm{MCl}$ as having a test score 1.5 standard deviations below the sample mean on the VVLT, SCWT or LDMT and an $\mathrm{MMSE}$ score $\geq 24$. $\mathrm{MCl}$ was then subdivided into a multi-domain amnestic (mdMCl- 
$\mathrm{a}+)$ and multi-domain non-amnestic (mdMCl-a-) variant based on whether individuals had a memory impairment or not (199).

\subsection{Statistical analyses}

Associations between baseline demographics and depressive symptom scores were analyzed using T-tests and linear regression analyses. To facilitate comparisons, neuropsychological test scores were standardized by sample mean and standard deviation at baseline, generating z-scores. The three z-scores reflecting memory (VVLT immediate recall, delayed recall and delayed recognition) were combined into a compound 'memory' score arithmetically, to reduce the number of cognitive outcome measures (200). Cross-sectional baseline associations were measured using depressive symptom scores as the independent variable regressed on to each neurocognitive test in turn. Linear mixed-model (LMM) analysis was used to measure the association of baseline depressive symptoms and averaged neurocognition score from F1 and F2 as the dependent neurocognitive variable, and a depression-time interaction term was included in the above LMM to test for changes across the follow up. The last three analytical steps were repeated replacing depressive symptom scores by our categorical measures of depression severity and stability of depression. Risk for $\mathrm{MCl}$ (either F1 or F2) was estimated using logistic regression.

The effect measure modification of the apolipoprotein $\varepsilon-4$ genotype was analyzed in a sub-sample ( $n=338,57 \%$ of baseline sample) by including the $\varepsilon-4$ allele (present or absent) as an independent variable in the model, and testing for statistical interaction with depression and three-way interaction with depressionAPOE-time. All analyses were adjusted for age, sex and education (low, middle, high) using STATA 9.2 (163).

\section{Results}

Baseline demographic information is shown in Table 1. The mean SCL-90 depressive symptom score was 20.5, with women scoring on average 1.9 points higher than men $(F=17.65, D F=1 / 596, P<.001)$. Depressive symptom scores were further dependent on education $(F=4.36, D F=2 / 595, P=.013)$ but not on age $(F=0.08$, $D F=1 / 595, P=.783)$. One-hundred-and-thirty-two participants $(22 \%)$ scored high on depressive symptoms at baseline, $96(20 \%)$ at F1 and $88(23 \%)$ at F2. Collapsed down to four depression stability categories, 223 (54\%) participants had no depressive symptoms at any assessment, $33(8 \%)$ had symptoms at baseline only, $103(25 \%)$ at follow-up visits only and $50(12 \%)$ displayed persistent symptoms of depression. 
Table 1. Demographics of the sample at baseline $(N=598)$.

$\begin{array}{llc}\text { Age, mean (range) } & & 69.4(60.0-82.7) \\ \text { Women, } \mathrm{n}(\%) & & 286(48) \\ \text { Education, } \mathrm{n}(\%) & \text { Low } & 305(51) \\ & \text { Middle } & 208(35) \\ & \text { High } & 85(14) \\ \text { IQ, mean (range) } & & 116(73-147) \\ \text { SCL-90 depression, mean (range) } & & 20.5(16-58) \\ \text { Levels of depression, } \mathrm{n}(\%) & \text { Absent } & 166(28) \\ & \text { Low } & 164(27) \\ \text { Stability of depression, } \mathrm{n}(\%)^{\mathrm{a}} & \text { Middle } & 136(23) \\ & \text { High } & 132(22) \\ & \text { No depression } & 223(55)\end{array}$

${ }^{a}$ percentages do not add up to hundred due to rounding errors

Measures were not available at F2 for 186 participants ( $31 \%$ of baseline sample). However, there was no systematic difference between participants who remained in the study and those who dropped out with regard to sex $\left(\chi^{2}=0.27, D F=1 / 596, P\right.$ $=.601)$, education $\left(\chi^{2}=2.35, D F=2 / 595, P=.309\right)$ and estimated IQ $(T=-1.05, D F=$ $1 / 596, P=.296)$. Those lost to follow-up were older $(T=6.78, D F=1 / 596, P<.001)$, with higher baseline depressive symptom scores $(T=2.37, D F=1 / 596, P=.018)$, and had lower baseline z-scores on tests of memory $(T=-4.32, D F=1 / 596, P<$ $.001)$, processing speed $(T=-4.51, \mathrm{DF}=1 / 593, \mathrm{P}<.001)$, attention $(\mathrm{T}=-5.24, \mathrm{DF}=$ $1 / 585, P<.001)$ and global cognition $(T=-3.80, D F=1 / 596, P<.001)$, indicating higher baseline impairment.

\subsection{Continuous depressive symptoms}

Adjusting for differences in baseline cognition, no significant changes from baseline to $\mathrm{F} 1$ were seen as a function of baseline depressive symptoms, with the exception of global cognition $(\mathrm{P}=.038$ ) (Table 2). However, at F2, baseline depressive symptoms predicted change in memory $(P \leq .001)$, processing speed $(P=.002)$, attention $(P=.030)$ and global cognition $(P=.020)$, leading to impaired neurocognition at follow-up in these domains (memory: $\mathrm{P}=.004$; processing speed: $\mathrm{P}=.004$; attention: $\mathrm{P} \leq .001$; global cognition: $\mathrm{P} \leq .001$ ). 
Table 2. Difference in cognition mean z-scores (95\% confidence intervals) with increasing depressive symptoms and change over time.

\begin{tabular}{|c|c|c|c|c|c|c|}
\hline & \multicolumn{2}{|l|}{ At baseline $^{a}$} & \multicolumn{2}{|c|}{ At follow-up ${ }^{a}$} & \multicolumn{2}{|c|}{ Change from baseline $^{b}$} \\
\hline & Difference & $95 \% \mathrm{Cl}$ & Difference & $95 \% \mathrm{Cl}$ & Difference & $95 \% \mathrm{Cl}$ \\
\hline & & & & & to F1: -0.01 & $-0.02,0.00$ \\
\hline Memory & -0.01 & $-0.02,0.00$ & $-0.02 * *$ & $-0.04,-0.01$ & to $\mathrm{F} 2:-0.02 * * *$ & $-0.03,-0.01$ \\
\hline \multirow{2}{*}{$\begin{array}{l}\text { Processing } \\
\text { speed }\end{array}$} & & & & & to F1: -0.01 & $-0.02,0.01$ \\
\hline & -0.01 & $-0.03,0.00$ & $-0.02 * *$ & $-0.04,-0.01$ & to $\mathrm{F} 2:-0.02^{* *}$ & $-0.03,-0.01$ \\
\hline & & & & & to F1: 0.01 & $-0.01,0.02$ \\
\hline Attention & -0.01 & $-0.03,0.00$ & $-0.03 * * *$ & $-0.05,-0.01$ & to $\mathrm{F} 2:-0.02 *$ & $-0.03,-0.00$ \\
\hline \multirow{2}{*}{$\begin{array}{l}\text { Mini-Mental } \\
\text { state }\end{array}$} & & & & & to F1: $-0.02 *$ & $-0.04,-0.00$ \\
\hline & $-0.02 *$ & $-0.03,-0.00$ & $-0.04 * * *$ & $-0.06,-0.03$ & to $\mathrm{F} 2:-0.03^{*}$ & $-0.05,-0.00$ \\
\hline
\end{tabular}

Table 3. Difference in cognition mean z-scores (and $95 \%$ confidence intervals) and change over time across depression severity groups.

\begin{tabular}{|c|c|c|c|c|c|c|c|}
\hline & \multirow{2}{*}{$\begin{array}{l}\text { Severity } \\
\text { group }^{a}\end{array}$} & \multicolumn{2}{|l|}{ Baseline $^{b}$} & \multicolumn{2}{|l|}{ Follow-up ${ }^{b}$} & \multicolumn{2}{|c|}{ Change baseline to $\mathrm{F}^{\mathrm{C}}$} \\
\hline & & Diff. & $95 \% \mathrm{Cl}$ & Diff. & $95 \% \mathrm{Cl}$ & Diff. & $95 \% \mathrm{Cl}$ \\
\hline \multirow[t]{3}{*}{ Memory } & Low & 0.07 & $-0.10,0.24$ & -0.05 & $-0.23,0.14$ & -0.11 & $-0.27,0.04$ \\
\hline & Middle & 0.02 & $-0.16,0.20$ & -0.19 & $-0.38,0.01$ & $-0.20^{*}$ & $-0.36,-0.02$ \\
\hline & High & -0.02 & $-0.20,0.16$ & $-0.26^{*}$ & $-0.46,-0.06$ & $-0.37 * * *$ & $-0.55,-0.20$ \\
\hline \multirow{3}{*}{$\begin{array}{l}\text { Processing } \\
\text { speed }\end{array}$} & Low & 0.00 & $-0.19,0.19$ & -0.03 & $-0.24,0.19$ & -0.03 & $-0.18,0.11$ \\
\hline & Middle & 0.05 & $-0.15,0.25$ & -0.11 & $-0.34,0.12$ & -0.09 & $-0.24,0.07$ \\
\hline & High & -0.14 & $-0.34,0.06$ & $-0.33^{* *}$ & $-0.56,-0.10$ & $-0.22 * *$ & $-0.38,-0.07$ \\
\hline \multirow[t]{3}{*}{ Attention } & Low & -0.01 & $-0.22,0.20$ & 0.09 & $-0.16,0.34$ & 0.10 & $-0.10,0.30$ \\
\hline & Middle & -0.02 & $-0.23,0.20$ & -0.02 & $-0.29,0.25$ & -0.04 & $-0.26,0.18$ \\
\hline & High & -0.12 & $-0.34,0.10$ & -0.25 & $-0.53,0.02$ & -0.17 & $-0.39,0.06$ \\
\hline \multirow{3}{*}{$\begin{array}{l}\text { Mini- } \\
\text { Mental } \\
\text { state }\end{array}$} & Low & -0.10 & $-0.30,0.10$ & -0.05 & $-0.28,0.18$ & 0.15 & $-0.13,0.42$ \\
\hline & Middle & -0.11 & $-0.32,0.11$ & $-0.25^{*}$ & $-0.50,-0.00$ & -0.00 & $-0.37,0.22$ \\
\hline & High & $-0.22^{*}$ & $-0.43,-0.00$ & $-0.50 * * *$ & $-0.75,-0.24$ & $-0.34^{*}$ & $-0.61,-0.01$ \\
\hline
\end{tabular}

$* \mathrm{p}<.05 * * \mathrm{p} \leq .01 * * * \mathrm{p} \leq .001$

a based on SCL-90 quartile scores at baseline, with the bottom quartile ('absent depression') as the reference group

${ }^{\mathrm{b}}$ corrected for age, sex and education

${ }^{c}$ corrected for age, sex, education and baseline cognition scores 


\subsection{Depression severity groups}

At baseline, the high depression severity group had worse global cognition ( $P=$ .049) compared to the no depressive symptom reference group. (Table 3 ). There were no other significant baseline associations. An effect gradient was evident for severity of baseline depression and neurocognition at follow up, with the middle and high depressive symptom groups demonstrating significantly greater rates of decline at $F 2$ in regard to memory (middle versus absent: $P=.025$; high versus absent: $P \leq .001$, high versus low: $P=.003)$, with additional decline only in the high depression group in processing speed (high versus absent: $P=.005$, high versus low: $\mathrm{P}=.016$ ) and global cognition (high versus absent: $\mathrm{P}=.045$, high versus low: $\mathrm{P}$ $=.003$ ), leading to cognitive impairment in these domains at follow-up (memory, high versus absent: $\mathrm{P}=.012$, high versus low: $\mathrm{P}=.04$; processing speed, high versus absent: $\mathrm{P}=.005$, high versus low: $\mathrm{P}=.009$; global cognition, high versus absent: $\mathrm{P} \leq$ .001 , high versus low: $\mathrm{P} \leq .001)$.

Table 4. Difference in cognition mean z-scores (and 95\% confidence intervals) and change over time across stability of depression groups.

\begin{tabular}{|c|c|c|c|c|c|c|c|}
\hline & \multirow[t]{2}{*}{$\begin{array}{l}\text { Stability of } \\
\text { depression }^{a}\end{array}$} & \multicolumn{2}{|l|}{ Baseline $^{b}$} & \multicolumn{2}{|c|}{ Follow-up } & \multicolumn{2}{|c|}{ Change baseline to $\mathrm{F}^{\mathrm{C}}$} \\
\hline & & Diff. & $95 \% \mathrm{Cl}$ & Diff. & $95 \% \mathrm{Cl}$ & Diff. & $95 \% \mathrm{Cl}$ \\
\hline \multirow[t]{3}{*}{ Memory } & At baseline & 0.04 & $-0.24,0.31$ & -0.07 & $-0.33,0.18$ & -0.21 & $-0.45, \quad 0.03$ \\
\hline & At follow-up & $-0.18^{*}$ & $-0.36,-0.00$ & $-0.30 * * *$ & $-0.47,-0.13$ & -0.10 & $-0.26, \quad 0.06$ \\
\hline & Persistent & -0.11 & $-0.34,0.12$ & $-0.38 * * *$ & $-0.60,-0.16$ & $-0.36 * * *$ & $-0.57,-0.15$ \\
\hline \multirow{3}{*}{$\begin{array}{l}\text { Processing } \\
\text { speed }\end{array}$} & At baseline & -0.16 & $-0.48,0.16$ & -0.26 & $-0.58,0.06$ & -0.11 & $-0.33,0.12$ \\
\hline & At follow-up & -0.21 & $-0.41,0.00$ & $-0.32 * *$ & $-0.53,-0.11$ & $-0.17^{*}$ & $-0.32,-0.02$ \\
\hline & Persistent & $-0.28 *$ & $-0.55,-0.01$ & $-0.44 * *$ & $-0.71,-0.16$ & $-0.31^{* *}$ & $-0.51,-0.11$ \\
\hline \multirow[t]{3}{*}{ Attention } & At baseline & 0.05 & $-0.23,0.34$ & 0.07 & $-0.23,0.38$ & -0.04 & $-0.30,0.21$ \\
\hline & At follow-up & -0.11 & $-0.29,0.08$ & -0.18 & $-0.38,0.01$ & -0.03 & $-0.20,0.14$ \\
\hline & Persistent & $-0.42 * * *$ & $-0.65,-0.18$ & $-0.44 * * *$ & $-0.70,0.18$ & -0.10 & $-0.33,0.13$ \\
\hline \multirow{3}{*}{$\begin{array}{l}\text { Mini- } \\
\text { Mental } \\
\text { state }\end{array}$} & At baseline & -0.20 & $-0.54,0.14$ & -0.15 & $-0.47,0.16$ & -0.01 & $-0.42,0.39$ \\
\hline & At follow-up & -0.08 & $-0.30,0.13$ & -0.09 & $-0.30,0.12$ & 0.02 & $-0.24,0.29$ \\
\hline & Persistent & -0.08 & $-0.37,0.20$ & $-0.49 * * *$ & $-0.75,-0.22$ & $-0.46 * *$ & $-0.81,-0.11$ \\
\hline
\end{tabular}

$* \mathrm{p}<.05 * * \mathrm{p} \leq .01 * * * \mathrm{p} \leq .001$

${ }^{a}$ Presence of depression based on upper SCL-90 quartile, with those not scoring in the upper quartile at any measurement ( = 'no depression') as the reference group

${ }^{b}$ corrected for age, sex and education

c corrected for age, sex, education and baseline cognition scores 


\subsection{Stability of depression}

'Depression at follow-up' was associated with poorer memory scores at baseline ( $P$ $=.045)$, while 'persistent depression' showed impaired processing speed $(P=.040)$ and attention ( $P \leq .001$ ) (Table 4). 'Depression at follow-up' showed significant decline in processing speed $(P=.028)$ leading to impairment at follow-up $(P=.003)$ additional to on-going memory deficits $(P \leq .001)$. 'Persistent depression' showed a more widespread pattern of decline including memory $(P \leq .001)$, processing speed $(P=.002)$, and global cognition $(P=.010)$, leading to impaired neurocognition at follow up in these domains (memory: $P \leq .001$, attention: $P \leq .001$, processing speed: $\mathrm{P}=.002$, global cognition: $\mathrm{P} \leq .001)$.

Table 5. Risk for mild cognitive impairment (MCl) at follow (risk set: $\mathrm{N}=496$ ).

\begin{tabular}{|c|c|c|c|c|c|c|c|}
\hline \multicolumn{2}{|c|}{ Depression measure } & \multirow{2}{*}{\multicolumn{2}{|c|}{$\begin{array}{l}\text { Multi domain } \mathrm{MCl} \\
\mathrm{N}=\mathbf{5 0}\end{array}$}} & \multirow{2}{*}{\multicolumn{2}{|c|}{$\begin{array}{l}\text { amnestic } \mathrm{MCl} \\
\mathrm{N}=25\end{array}$}} & \multirow{2}{*}{\multicolumn{2}{|c|}{$\begin{array}{l}\text { non-amnestic } \mathrm{MCl} \\
\mathrm{N}=\mathbf{2 5}\end{array}$}} \\
\hline & & & & & & & \\
\hline & & $O R$ & $95 \% \mathrm{Cl}$ & $O R$ & $95 \% \mathrm{Cl}$ & $O R$ & $95 \% \mathrm{Cl}$ \\
\hline Continuou & toms & $1.08^{*}$ & $1.01,1.15$ & $1.11^{*}$ & $1.02,1.20$ & 1.03 & $0.93,1.13$ \\
\hline \multirow[t]{3}{*}{ Severity ${ }^{\mathrm{a}}$} & Low & 0.72 & $0.29,1.78$ & 0.87 & $0.25,3.02$ & 0.62 & $0.19,2.03$ \\
\hline & Middle & 0.87 & $0.34,2.23$ & 0.69 & $0.16,2.95$ & 1.03 & $0.32,3.27$ \\
\hline & High & 2.08 & $0.90,4.82$ & $2.98^{*}$ & $1.00,8.89$ & 1.07 & $0.33,3.45$ \\
\hline \multirow[t]{3}{*}{ Stability ${ }^{b}$} & At baseline & 2.41 & $0.81,7.20$ & 2.61 & $0.60,11.35$ & 1.73 & $0.42,7.04$ \\
\hline & At follow-up & 1.58 & $0.64,3.86$ & 1.29 & $0.32,5.29$ & 1.97 & $0.67,5.85$ \\
\hline & Persistent & $2.89^{*}$ & $1.04,7.98$ & 3.49 & $0.93,13.08$ & 1.94 & $0.48,7.79$ \\
\hline
\end{tabular}

$* \mathrm{p} \leq .05$, all analyses corrected for age, sex and education

${ }^{a}$ Depressive symptom group based on SCL-90 quartile scores at baseline, with the bottom quartile (absent depression) as the reference group

${ }^{b}$ Presence of depression based on upper SCL-90 quartile, with those not scoring in the upper quartile at any measurement (= no depression) as the reference group

\subsection{Incident mild cognitive impairment}

At baseline, 102 out of 598 individuals (17\%) met our criteria for $\mathrm{MCl}$ and were excluded from further analyses. Of the remaining 359 individuals who still participated at follow-up, 50 (14\%) developed $\mathrm{MCl}$ (Table 5). A one point increase on the SCL-90 depression subscale increased the risk of $\mathrm{MCl}$ by $8 \%(\mathrm{P}=.024)$. This effect was only significant for the $\mathrm{mdMCl}-\mathrm{a}+$ subtype $(P=.011)$. Analyses using depression severity categorical measures found only membership of the high severity group predicted the development of mdMCl-a+ $(P=.050)$ but not the $\mathrm{mdMCl}-\mathrm{a}$ - or the combined $\mathrm{MCl}$ outcome. As this group stratification resulted in small cell size (indicated by relatively wide and skewed confidence intervals) we collapsed the categories to create an indicator variable of scores in the upper quartile of the SCL-90. Depression so defined significantly increased the risk of $\mathrm{MCl}$ 
moderately $(\mathrm{OR}=2.58,95 \% \mathrm{Cl}=1.14 ; 5.80, \mathrm{p}=.022)$, and showed a strong association with the risk for $\mathrm{mdMCl}-\mathrm{a}+(\mathrm{OR}=5.03,95 \% \mathrm{Cl}=1.99 ; 12.72, \mathrm{p}=.001)$, but not for mdMCl-a- $(\mathrm{OR}=0.67,95 \% \mathrm{Cl}=0.15 ; 3.04, \mathrm{p}=.604)$. 'Persistent depression' carried an increased risk of $\mathrm{MCl}(\mathrm{P}=.041)$, but testing its association with the $\mathrm{mdMCl}-\mathrm{a}+$ subtype failed levels of significance.

\subsection{APOE genotype}

Those genotyped on average were younger ( $T=4.91, D F=1 / 595, P \leq .001)$ and performed better on baseline tests of memory $(B=0.20,95 \% \mathrm{Cl}=0.06-0.34, \mathrm{P}=$ $.004)$, attention $(\mathrm{B}=8.18,95 \% \mathrm{Cl}=0.36-16.01, \mathrm{P}=.040)$ and global cognition $(\mathrm{B}=$ $0.27,95 \% \mathrm{Cl}=0.01-0.54, \mathrm{P}=.044)$, but there were no difference in baseline depressive symptoms, follow-up cognition, or rates of cognitive decline. Of those tested, 204 participants (60\%) had the common $\varepsilon-3 / \varepsilon-3$ genotype, 52 (15\%) had the $\varepsilon-2 / \varepsilon-3$ or $\varepsilon-2 / \varepsilon-2$ genotype, 77 (23\%) had the $\varepsilon-3 / \varepsilon-4$ or $\varepsilon-4 / \varepsilon-4$ genotype and 5 (1\%) had the $\varepsilon-2 / \varepsilon-4$ genotype. The latter two groups were combined to form a group containing at least one $\varepsilon-4$ risk allele and their cognitive test scores were compared to those without the $\varepsilon-4$ risk allele. APOE genotype was not significantly associated with baseline cognition or change in cognition over time, but there was an association between carrying the $\varepsilon-4$ risk allele and poorer performance on follow-up tests of memory $(\mathrm{B}=-0.21,95 \% \mathrm{Cl}=-0.40 ;-0.02, \mathrm{P}=.032)$ and global cognition $(B=-0.30,95 \% C l=-0.52 ;-0.09, P=.006)$ adjusted for age, sex, education and depression at baseline. In addition, $\varepsilon-4$ carriers had an increased risk of $\mathrm{MCl}$ $(\mathrm{OR}=2.17,95 \% \mathrm{Cl}=1.09 ; 4.29, \mathrm{P}=.027)$, but this was not specific to a subtype (mdMCl-a+: $\mathrm{OR}=2.06,95 \% \mathrm{Cl}=0.83 ; 5.10, \mathrm{P}=.119 ; \mathrm{mdMCl}-\mathrm{a}-\mathrm{O}: \mathrm{OR}=1.46,95 \% \mathrm{Cl}=$ $0.65 ; 3.26, P=.358)$. Importantly, there were no statistically significant interactions between APOE genotype and depressive symptom scores or levels of depressive symptoms regressed on neurocognition at any time point, change in cognition over time, or $\mathrm{MCl}$ risk.

\section{Discussion}

\subsection{Main findings}

In this community based study, a robust relationship between depressive symptoms and subsequent cognitive decline was observed. Clinically meaningful and persistent depressive symptoms were associated with accelerated cognitive decline and predicted development of future $\mathrm{MCl}$, of the multi-domain amnestic variant. Participants who had one or more copies of the apolipoprotein $\varepsilon-4$ risk allele were also at increased risk for $\mathrm{MCl}$, however APOE genotype had a negligible moderating effect on the association between depression and cognitive outcome. This is concordant with other studies $(184,185)$, though not all $(51,183)$, and suggests that cognitive decline in depression operates independently of the $\varepsilon-4$ variant mediated acceleration of amyloid depositions, associated with senile Alzheimer's dementia (AD) (201). 
These results support the findings from previous prospective studies (45-53), and strongly suggests the contribution of depression to cognitive decline and development of $\mathrm{MCl}$, in the absence of baseline cognitive impairment. Furthermore, cognitive decline is greatest in individuals with persistent or chronic depressive symptoms $(47,49)$, suggesting that while depressive symptoms may wax and wane, their persistence identifies a subgroup of individuals with lasting organic changes.

\subsection{Risk factor or prodromal sign}

It has however been speculated that instead of being a risk factor, depression may be an early harbinger or prodromal symptom of dementia (55). This is a plausible explanation for some of the cases in this study where depression emerged at follow-up with concurrent cognitive decline. However, depression has not been shown to increase during the prodromal phase of dementia (202). Furthermore, a published meta-regression estimated the risk for $A D$ was positively associated with the length of interval between the diagnosis of depression and dementia, suggesting depression is indeed a risk factor for $A D$, rather than a prodromal marker symptom (54). This has been corroborated by subsequent work showing lifetime history of depression (not just current depressive symptoms) increases risk of subsequent AD (203), with evidence of a dose response relationship, where increasing number of episodes of depression is associated with higher risk of dementia (204).

\subsection{Strengths and limitations of the study}

This study has several strengths: it uses a large and epidemiologically well-defined sample with a long follow-up and reliable repeated measure design of symptoms measures and neurocognitive psychometric tests of multiple domains. However the findings should be interpreted in the light of a few methodological limitations. First, we did not apply a formal diagnosis of depression but used a standard self-report questionnaire, due to the community sample design. We therefore do not assume that depression in this sample necessarily reflects major depressive disorder as defined by a particular classification system. In the current study, it was not our intention to verify an etiological model of late life depressive symptoms, but to show their association with cognitive decline, irrespective of underlying cause for the depressive symptoms, which may have different causes. Furthermore, the APOE genotyping was not obligatory and is therefore only available in a sub-sample of the total cohort. The prevalence of the $\varepsilon-4$ genotype was low, especially in the homozygous form. This reduced contrast may account in part for the small effects measured for $\varepsilon-4$ moderation of cognition and risk for $\mathrm{MCl}$. Also, those genotyped had superior cognitive functioning at baseline, making them less representative of the total sample. However importantly, the genotyped sample did not differ at follow-up from those not genotyped on any variable of interest. Therefore, any trajectory drops from baseline to follow-up would be greater than for the total sample, making a bias towards effect more likely. 


\subsection{Conclusions}

The present study adds valuable information to the ongoing debate whether depressive symptoms predispose to cognitive decline by showing that depressive symptoms are predictive of future neurocognitive deterioration and increase the risk of incident $\mathrm{MCl}$. The risk increases as people move towards more clinically meaningful depressive symptom severity and persistent depression. 


\section{CHAPTER 5}

\section{Pattern and course of cognitive impairment in late life depression}

Köhler S, Thomas AJ, Barnett NA, O'Brien JT. The pattern and course of cognitive impairment in late life depression. Psychological Medicine. In press. 


\section{Abstract}

Background: Cognitive deficits persist despite clinical recovery in subjects with late life depression, but more needs to be known about their longer-term outcome and factors affecting their course. To investigate this, we followed the pattern of cognitive impairments over time and examined the effects of current mood, remission status, age of depression onset and antidepressant treatment on these deficits.

Methods: Sixty-seven subjects aged 60 or over with DSM-IV major depressive disorder and 36 healthy comparison subjects underwent tests of global cognition, memory, executive functioning and processing speed at baseline, 6 and 18 months, with some subjects tested again after 4 years. Z-scores were compared between groups, with analyses of clinical factors which may have influenced cognitive performance in depressed subjects.

Results: Half of the patients exhibited a generalized cognitive impairment that persisted after 18 months ( $O R=5.2, p=.011$ ). Patients performed worse across all cognitive domains at all time points, without substantial variability due to current mood, remission status or antidepressant treatment. Late age of onset was significantly associated with decline in memory and executive functioning. Impaired processing speed may be a partial mediator of some deficits, but was insufficient to explain differences between patients and controls. Four year follow-up data suggest impairments persist, but do not further decline.

Conclusion: Cognitive deficits in late life depression persist up to 4 years, affect multiple domains and are related to trait rather than state effects. Differences in severity and course between early and late onset depression suggest different pathogenic processes. 


\section{Introduction}

Cognitive deficits are a core feature of depression in adults of all ages, consistently found in the domains of memory, executive functioning and processing speed (34). Previously such deficits were thought to be transient, in its most severe forms called 'depressive pseudodementia' (35), but mounting evidence shows cognitive deficits persist despite remission of depressive symptoms (36-44). These persisting deficits may be related to underlying neurobiological changes, including brain atrophy and an increased prevalence of white matter hyperintensities $(66,205)$.

Although cognitive impairment is nowadays believed to be stable for the group of patients as a whole, recent studies have been short term (not exceeding 12 months) and longer-term outcome has not been determined. There might also be differences between patients with specific clinical characteristics. For example, younger patients show a similar cognitive profile, but impairment is generally found to be more severe in older individuals $(206,207)$ and might be related to a late onset of depressive disorder ( $\geq 60$ years) in particular (208). While modest improvement of cognition may occur in patients who were selected based on good response to antidepressant (AD) treatment (209-211), it is largely unknown whether current AD treatment impacts on patients' cognition compared to healthy subjects. Furthermore, controversy still remains as to whether cognitive impairment affects all cognitive domains or whether apparently multi-modal deficits in fact reflect a deficit in a single core neuropsychological function. Although the most suitable candidate, processing speed, has indeed been found to be a strong mediator of other cognitive deficits $(38,212)$, its effect might be greater for executive functioning than for episodic memory (213).

To address these questions we examined the pattern of cognitive deficits in healthy subjects and individuals with late-life major depression over time. We report differences between patients due to current symptom severity, remission status, age of depression onset, and antidepressant treatment. We hypothesized that i) current symptom severity would only marginally affect cognitive deficits, ii) remitted patients would therefore show some amelioration of deficits but remain impaired, iii) later age of onset would be associated with more severe deficits without differences in the domains affected and iv) that those treated with antidepressants would not differ from those not treated. In addition, we addressed the question whether processing speed mediates deficits in other cognitive domains. 


\section{Methods}

\subsection{Case ascertainment}

Sixty-seven patients aged 60 and over who fulfilled DSM IV criteria for major depression were recruited from clinical old age psychiatry services covering geographically based catchment areas and included referrals from day hospitals, inpatient units and outpatient clinics. A control group $(n=36)$ of similar aged older people (also all over 60 years of age) with no past history of depression or current depression were recruited from community sources such as The Royal British Legion and spouses of patients attending the same hospital units. The baseline neuropsychological profile of this group has been previously reported (64). We excluded both subjects and controls with a history of prior cognitive impairment, history or evidence of stroke or transient ischemic attack, severe or unstable physical illness (e.g. insulin dependent diabetes mellitus, untreated hypothyroidism, uncontrolled heart failure, cancer) or a Cambridge Cognitive Examination (CAMCOG) (214) score of $<75$ (patients) or $<80$ (controls). Additional exclusion criteria were: history or current substance/alcohol abuse; long term use (> 2 months) of steroids during lifetime; use of steroid or other medication within the last 3 months thought to interfere with HPA axis; ECT in last 3 months; use of medication thought to affect cognition (e.g. non-hypnotic benzodiazepines, antipsychotics or anticholinergic medication); presence of other neurological diagnosis. Use of newer antidepressants (e.g. SSRI's and venlafaxine) and lithium was permitted, and only seven patients were taking tricyclic antidepressants ( 1 dothiepin, 6 lofepramine). The study was approved by the local ethics committee and all patients and controls gave written informed consent.

\subsection{Assessment}

All depressed cases underwent a comprehensive psychiatric assessment including history, mental state, physical examination and a test of general cognitive functioning (CAMCOG). The CAMCOG is part of the Cambridge Mental Disorders of the Elderly Examination (CAMDEX) (214) and assesses general cognitive functioning and is frequently used in research and clinical practice.

Depression was diagnosed according to DSM-IV criteria (215) and symptom severity was rated using the MADRS (216). In the present study, remission was defined as a MADRS score $\leq 9(217,218)$. Demographic information (including past and current medical and psychiatric history, medication taken, family history, education and social class) and psychiatric history of past episodes of depression were collected from multiple sources to validate or enrich information from faceto-face interviews with subjects and informants (e.g. case notes, GP records and informant accounts to determine number of previous episodes, age of onset and total lifetime duration of depression). An extensive neuropsychological test battery was administered to controls and all patients who consented to it. 


\subsection{Neuropsychological assessment}

The test battery was primarily designed to measure memory, processing speed and executive function as they represent core neuropsychological deficits in late life depression (34). Tests used in the present study included both traditional pen and paper and computerised tasks:

a) The Rey Auditory Verbal Learning Test (AVLT)(219), a test of episodic memory. The three measures immediate recall, delayed recall and delayed recognition (number of correct items) were used.

b) The FAS verbal fluency test (200), a task sensitive to frontal lobe impairment.

c) The Trail Making Test (TMT) (200), a test of mental flexibility and divided attention.

d) The Stroop Colour Word Test (SCWT) (192), a test for response inhibition and selective attention.

e) A computerised continuous performance task (VIGIL)(220). Over 8 minutes, subjects have to press a button to a complex target stimulus (letter $\mathrm{K}$ when preceded by the letter $\mathrm{A}$ ), presented 100 times within a total of 480 stimuli (displayed serially in a pseudo-random fashion). Errors of omission and commission can be used as a measure of vigilance and inhibition but in the present study only response latencies (in $\mathrm{msec}$ ) were used as a measure of processing speed.

\subsection{Definition of generalized cognitive impairment (GCI)}

There is no universally accepted definition of a suitable cut-off to denote significant cognitive impairment and 1, 1.5 and 2 standard deviations (SD) have all been used. In their definition of ageing associated cognitive decline Levy et al. chose 1 SD (221). The narrower, and more universally accepted, concept of mild cognitive impairment (222) used 1.5SD. Consistent with this, we defined $\mathrm{GCl}$ as a score of more than 1.5 standard deviations below the healthy control groups' mean on the CAMCOG at each assessment.

\subsection{Follow-up}

Patients and controls were re-assessed 6 and 18 months and again 4 years after baseline. At each time point, a psychiatric assessment, administration of rating scales and neuropsychological tests were repeated. At 6 months, 93 (90\%) participants of the baseline sample were re-assessed and 78 (76\%) at 18 months. At 4 year, only 36 (35\%) individuals, including 15 patients, were available for followup. Our analysis therefore focuses on the 6 and 18 months follow-up data but because longer-term follow-up cognitive data on such patients is rarely available we have included the four-year data too. While all patients had undergone clinical examination and CAMCOG testing at baseline, only 34 out of 67 of them were tested with the extended neuropsychological battery. While more could be tested at 6 (51 out of 57) and 18 (41 out of 45) months, this means that samples at different time points were not perfectly comparable. We thus decided to look at the associations cross-sectionally only. 


\subsection{Statistical analysis}

For ease of comparison, neuropsychological test scores were standardized using the control group's mean and standard deviation at baseline. An overall memory zscore was created by adding up the three z-scores of the AVLT (immediate recall, delayed recall, delayed recognition) and this 'compound score' was again standardized to a z-score using the control group's mean and standard deviation at baseline. Similarly, an overall executive functioning z-score was created by adding up the z-scores of verbal fluency, Trail Making Test difference A-B and SCWT correct responses. By this, we had three cognitive domains with higher scores indicating better performance: memory, executive functioning and processing speed (VIGIL latencies). The risk of having $\mathrm{GCl}$ at follow-up was assessed with logistic regression analyses yielding odds ratio's (OR) and 95\% confidence intervals (CI). We then used multiple linear regression analyses to test associations within cognitive domains. The impact of key clinical variables was investigated by comparing remitters and non-remitters, early onset and late onset, and AD users and non-users to healthy controls. In patients we also tested whether current MADRS scores (symptom severity), continuous age of onset and lifetime duration of $A D$ intake predicted neuropsychological performance. All comparisons were adjusted for age, gender and years of education. The alpha-level for statistical significance was fixed at $p \leq 0.05$. All tests were performed with STATA 9.2 (163).

\section{Results}

\subsection{Descriptive analyses}

Patients and their comparison subjects were well matched for age $(p=.609)$ and gender $(p=.633)$, but patients had higher MADRS scores $(t=-12.2$, $d f=101, p<$ .001 ) and fewer years of formal education $(t=2.06, d f=101, p=.042)$ (Table 1$)$.

Table 1. Baseline demographic characteristics for depressed and control subjects.

\begin{tabular}{llll}
\hline & Patients & Controls & \\
& $N=67$ & $N=36$ & $P$ \\
\hline Age, years, mean(SD) & $74.1(6.7)$ & $73.4(6.9)$ & $\mathrm{ns}$ \\
Gender, \% female & $53(79)$ & $27(75)$ & $\mathrm{ns}$ \\
Education, years, mean(SD) & $9.6(2.1)$ & $10.5(2.1)$ & .042 \\
MADRS, mean(SD) & $23.6(10.4)$ & $2.2(2.2)$ & $<.001$
\end{tabular}




\section{CHAPTER 6}

\section{Late life depression, continuing cognitive impairment and vascular brain lesions}

Köhler S, Thomas AJ, Lloyd A, Barber R, Almeida OP, O'Brien JT. Relationship between white matter hyperintensities, cortisol levels, brain atrophy and continuing cognitive deficits in late life depression. Submitted. 


\section{Abstract}

Objectives: Cerebrovascular changes and glucocorticoid mediated hippocampal atrophy are considered relevant for depression-related cognitive deficits, forming putative treatment targets. This study examined the relative contribution of cortisol levels, brain atrophy and white matter hyperintensities to the persistence of cognitive deficits in older depressed adults.

Method: Thirty-five people aged $\geq 60$ years with DSM-IV major depression and 29 healthy comparison subjects underwent MRI scanning and were followed-up for 18 months. We analyzed the relationship between baseline salivary cortisol levels, whole brain, frontal lobe and hippocampal volumes, severity of white matter hyperintensities and follow-up cognitive function in both groups by testing the interaction between subject group and these biological measures on tests of memory, executive functions and processing speed in linear regression models.

Results: Group differences in memory and executive functions follow-up scores were associated with ratings of white matter hyperintensities, especially of the deep white matter and periventricular regions. Compared with healthy comparison subjects, depressed subjects scoring within the third tertile of white matter hyperintensities dropped two and three standard deviations in executive functions and memory scores, respectively. No biological measure related to group differences in processing speed, and there were no significant interactions between group and cortisol levels, or volumetric MRI measures.

Conclusions: White matter hyperintensities, rather than cortisol levels or brain atrophy, are associated with continuing cognitive impairments in depressed older adults. The findings suggest that cerebrovascular disease rather than glucocorticoid-mediated brain damage are responsible for the persistence of cognitive deficits associated with depression in older age. 


\section{Introduction}

Cognitive deficits affecting multiple cognitive domains are a core feature of depressive disorder at all ages (34). In late life depression, these deficits have been shown to persist despite recovery from mood symptoms $(43,44)$. Further, structural brain changes in late life depression have been found to include volume reductions in the medial temporal lobe/hippocampus $(61,62,64)$, frontal lobe $(63$, $205,226)$, and increased prevalence of white matter hyperintensities (WMH) (66). Several studies have shown that these cerebral changes relate to cognitive deficits in depression: hippocampal volume reductions have been associated with memory deficits $(62,64)$, and $\mathrm{WMH}$ have been associated with impaired memory $(70,230$, $231)$, executive dysfunction $(71,230,232)$ and reduced processing speed (230).

However, the relationship between other biological changes in depression, such as hypercortisolaemia and brain atrophy, and cognitive impairment is less clear. While excessive adrenal glucocorticoid secretion in rodent brains has been shown to lead to hippocampal cell death by excessive glutamate inflow (56), studies in humans have been inconclusive (64). In addition, few studies have examined which biological and cerebral changes have prognostic utility for the long-term persistence of cognitive impairments in late life depression. We have previously shown that baseline measures of hippocampal volume predicted persistence of memory impairment after six months, while levels of cortisol did not (64). However, the role of WMH was not examined in that study, neither were relations with other cognitive domains.

The aim of the present project was to extend these initial findings to a longer observation period and to examine whether other biological changes are associated with continuing cognitive impairments. We hypothesized that the worse cognitive functioning seen in older adults with depression relative to controls would be associated with more severe $\mathrm{WMH}$, and frontal and hippocampal volume reductions at baseline. Based on our previous findings reported (64), we expected hypercortisolaemia to play no role in the persistence of these deficits in the long term.

\section{Methods}

\subsection{Subjects}

Sixty-six patients aged 60 and over with DSM-IV major depression were recruited from clinical old age psychiatry services covering geographically based catchment areas, and included referrals from day hospitals, inpatient units and outpatient clinics. A control group ( $n=36$ ) of older people (all over 60 years of age) with no current or past history of depression were recruited from community sources such as The Royal British Legion and spouses of patients attending the same hospital 
units. After complete description of the study to the subjects, written informed consent was obtained. We excluded older adults with a history of prior cognitive impairment, history or evidence of stroke or transient ischemic attack, severe or unstable physical illness (e.g. insulin dependent diabetes mellitus, untreated hypothyroidism, uncontrolled heart failure, cancer) or a Cambridge Cognitive Examination (CAMCOG) (214) score of < 70. Additional exclusion criteria were: history or current substance/alcohol abuse; long term use (> 2 months) of steroids during lifetime; use of steroid or other medication within the last 3 months thought to interfere with HPA axis; ECT in last 3 months; use of medication thought to affect cognition (e.g. non-hypnotic benzodiazepines, antipsychotics, sedative tricyclic antidepressants or anticholinergic medication); presence of other neurological diagnosis. Use of newer antidepressants (e.g. SSRI's and venlafaxine) and lithium was permitted. The local ethics committee approved the study, and after complete description of the study all patients and controls gave written informed consent.

\subsection{Assessment}

Participants underwent a comprehensive assessment including psychiatric history, mental state and physical examination. Depression was diagnosed according to DSM-IV criteria and symptom severity rated with the Montgomery-Åsberg Depression Rating Scale (MADRS) (216). Demographic information (including past and current medical and psychiatric history, medication taken, family history, education and social class) and history of depressive episodes were collected from multiple sources to validate or enrich information from face-to-face interviews (e.g. case notes, GP records and informant accounts to determine number of previous episodes, age of onset and total lifetime duration of depression). An extensive neuropsychological test battery was administered to consenting participants (detailed below). Subjects were re-assessed after 6 and 18 months. Ninety-three (90\%) and 78 (76\%) participants were available for the extended examinations at 6 and 18 months, respectively.

\subsubsection{Neuropsychological assessment}

The test battery was primarily designed to measure memory, processing speed and executive functions, as they represent core neuropsychological deficits in geriatric depression (34). Tests used in the present study included both traditional pen and paper and computerized tasks:

a) The Rey Auditory Verbal Learning Test (AVLT)(219), a test of episodic memory. The three measures immediate recall, delayed recall and delayed recognition (number of correct positives) were used.

b) The FAS verbal fluency test (200), a task sensitive to frontal lobe impairment.

c) The Trail Making Test (TMT) (200), a test of mental flexibility and divided attention.

d) The Stroop Colour Word Test (SCWT) (192), a test for response inhibition and selective attention. 
e) A computerized continuous performance task (VIGIL)(220). Over 8 minutes, subjects have to press a button to a complex target stimulus (letter $\mathrm{K}$ when preceded by the letter $\mathrm{A}$ ), presented 100 times within a total of 480 stimuli (displayed serially in a pseudo-random fashion). Errors of omission and commission can be used as a measure of vigilance and inhibition but in the present study only response latencies (in $\mathrm{msec}$ ) were used as a measure of processing speed.

\subsubsection{Salivary cortisol analysis}

Cortisol levels were assessed by collecting saliva using Salivettes (Sarstedt, Nümbrecht, Germany). Subjects chew on a cotton wool plug to produce saliva. Samples were collected at baseline at four time points (8am, 12pm, 4pm, 8pm) over three consecutive days, followed by centrifugation and storage at $-20^{\prime} \mathrm{C}$ until assayed. Salivary cortisol was measured using an $1^{125}$ disequilibrium assay, the radioactive cortisol for which was supplied by Amersham Health, Amersham, UK, the primary antibody Ab1002 and the solid phase anti-rabbit serum by IDS, Tyne and Wear, UK. The intra- and inter-assay coefficients of variation for 7.0, 47 and 87 $\mathrm{nmol} / \mathrm{l}$ cortisol samples were $13.0 \%$ and $14.6 \%, 10.7$ and $9.8 \%, 9.4$ and $10.2 \%$ respectively. Average area under the curve (AUC) for the 3 days was calculated. Baseline cortisol data were available for 34 (94\%) controls and 42 (64\%) depressed subjects.

\subsubsection{MRI scanning protocol and analysis}

As described previously $(64,229)$, images were acquired using a 1.0 Tesla Siemens Magnetom Impact Expert System (Siemens Medical, Erlangen, Germany). Whole brain T1-weighted three-dimensional magnetization prepared rapid-acquisition gradient echo (3D-MPRAGE) turbo flash data sets were acquired in the sagittal plane (repetition time: $11.4 \mathrm{msec}$, echo time: $4.4 \mathrm{msec}$, inversion time: $400 \mathrm{msec}$, flip angle: $15^{\circ}$, matrix: $256 \times 256$, slice thickness: $1 \mathrm{~mm}$, cubic voxels of $1 \mathrm{~mm}$ ) resulting in truly isotropic voxels of $1 \times 1 \times 1 \mathrm{~mm}$ for optimal gray-white matter contrast. Axial dual spin echo sequences were also obtained to yield proton density and T2 images. Proton density and T2 images were yielded from RARE (rapid acquisition with relaxation enhancement) technique dual echo (TR=2800ms, TE14(PD) ms / 85(T2) ms, matrix $256 \times 256$, field of view $230 \mathrm{~mm}$, pixel size $0.92 \times$ $0.92 \mathrm{~mm}$, acquisition time 4 minutes 13 seconds) sequences with axial slice thickness $5 \mathrm{~mm}$ and $0.5 \mathrm{~mm}$ gap. For volumetric analyses, T1 images were then transferred to a Sun Ultra 10 work station running Solaris 2.7 (Sun Microsystems, Mountain View, Calif.).

Hippocampal volume was analyzed by a single operator ( $A L)$ who was blind to diagnosis using the AnalyzeAVW-3.0 software (AnalyzeDirect.com, Lenexa, Kan.; Mayo Foundation Biomedical Imaging Resource, Rochester, Minn.). To ensure consistent slicing, images were re-orientated along the long axis of the hippocampus (for regional demarcation see (64)). Whole brain volume was analyzed by a semi-automated iterative process of erosion and region-growing. 
Hippocampal volume was normalized by dividing it by whole brain volume and multiplied by 1000 for convenience of presentation. Whole-brain normalized frontal lobe volume ( $x$ factor 1000) was analyzed with the Medical Information Display and Analysis System (MIDAS-3.0) and analyzed by a single operator (OA) as described earlier (63). White matter hyperintensities were rated visually from the axial dual echo scans by two experienced raters (RB and JOB) using the well established Scheltens scale (233). This can provide a measure of overall severity of white matter hyperintensities by summing scores for the four regions covered by the scale (periventricular, deep white matter, basal ganglia and infratentorial) on the rating scale. Severity if WMH could be successfully rated in 27 (75\%) controls and $51(76 \%)$ patients. MRI images of brain volumes could be successfully analyzed in $35(97 \%)$ controls and $51(76 \%)$ patients.

\subsection{Statistical analysis}

Neuropsychological test scores were standardized in relation to the non-depressed controls. An overall memory z-score was created by adding up the AVLT z-scores of immediate recall, delayed recall and delayed recognition, and this 'compound memory score' was again standardized. Similarly, an overall executive functions zscore was created by adding up the z-scores of verbal fluency, TMT difference A-B and SCWT correct responses. As a result, we produced three summary measures of cognitive function, with higher scores indicating better performance: memory, executive functions and processing speed (VIGIL latencies). We analyzed the impact of our biological measures on the difference in cognitive outcome between control and depressed subjects by testing the interaction between group ( $0=$ controls, $1=$ depressed) and the biological measures on the neuropsychological z-scores. Analyses were adjusted a priori for age, gender and years of education. The alphalevel was fixed at $p<.05$ and all statistical tests reported are two-tailed. In addition, we report $p$-values derived from Simes' modification of the Bonferroni correction in order to control for multiple testing (234). Simes' procedure is less conservative than traditional Bonferroni correction and is therefore considered superior if outcomes are correlated with each other, as in this study. A test is considered significant if the observed $p$-value is lower than Simes' adjusted significance level. All analyses were performed in STATA 10.1 (235).

\section{Results}

At 18 months, 45 out of 66 (68\%) older depressed adults were available for assessment, of which none met DSM-IV criteria for dementia. Of those lost-to follow-up, 19 withdrew consent and 3 died. There were no differences between participants available and not available for follow up in relation to age $(t=0.10, d f$ $=65, p=.919)$, gender $\left(x^{2}=0.07, d f=65, p=.797\right)$, years of education $(t=-0.17, d f$ $=65, p=.785)$, age of onset $(t=-0.04, d f=65, p=.972)$, MADRS score (baseline: $t=$ $-1.47, \mathrm{df}=65, \mathrm{p}=.147 ; 6$ months: $\mathrm{t}=0.34, \mathrm{df}=55, \mathrm{p}=.739)$, remission status 
(baseline: $\chi^{2}=0.53, \mathrm{df}=65, \mathrm{p}=.466 ; 6$ months: $\chi^{2}=1.04$, $\mathrm{df}=55, \mathrm{p}=.308$ ). Similarly, there were no differences between participants with depression who were or not available for follow up on z-scores for memory (baseline: $t=1.12$, df $=$ $32, \mathrm{p}=.270 ; 6$ months: $\mathrm{t}=1.11, \mathrm{df}=49, \mathrm{p}=.274$ ), executive functions (baseline: $\mathrm{t}=$ $1.19, \mathrm{df}=35, \mathrm{p}=.241 ; 6$ months: $\mathrm{t}=1.87, \mathrm{df}=49, \mathrm{p}=.067$ ) or processing speed (baseline: $t=0.83, d f=28, p=.414 ; 6$ months: $t=0.72$, $d f=44, p=.478$ ). Finally, there were no differences between these two groups on cortisol concentration $(t=$ 0.82, $\mathrm{df}=40, \mathrm{p}=.415)$, whole brain volume $(\mathrm{t}=-1.78, \mathrm{df}=49, \mathrm{p}=.082)$, hippocampal volume $(t=0.10, d f=49, p=.921)$, frontal lobe volume $(t=-0.07, d f=$ $49, \mathrm{p}=.942)$, or overall $\mathrm{WMH}(\mathrm{t}=-0.67, \mathrm{df}=49, \mathrm{p}=.508)$.

Table 1. Differences in demographic and clinical characteristics between healthy controls and depressed subjects who had data available from baseline MRI scanning or cortisol and follow-up neuropsychological testing.

\begin{tabular}{|c|c|c|c|c|c|c|c|}
\hline & \multicolumn{2}{|c|}{$\begin{array}{l}\text { Depressed subjects } \\
\qquad \mathrm{N}=35\end{array}$} & \multicolumn{2}{|c|}{$\begin{array}{l}\text { Healthy subjects } \\
\qquad \mathrm{N}=29\end{array}$} & \multicolumn{3}{|c|}{ Analysis } \\
\hline & Mean / N & $\mathrm{SD} / \%$ & Mean / N & $\mathrm{SD} / \%$ & $t / x^{2}$ & $d f$ & $p$ \\
\hline Age, years & 74.1 & 6.5 & 72.8 & 6.9 & -0.81 & 62 & .422 \\
\hline Female & 28 & 80 & 22 & 76 & 0.16 & 62 & .690 \\
\hline Education, years & 9.4 & 2.0 & 10.6 & 2.2 & 2.14 & 62 & .037 \\
\hline MADRS at baseline & 20.6 & 9.8 & 2.0 & 2.1 & -10.01 & 62 & $\leq .001$ \\
\hline MADRS at 18 months & 8.0 & 10.2 & 1.6 & 2.0 & -3.32 & 62 & .002 \\
\hline Illness duration, weeks & 58.3 & 56.0 & & & & & \\
\hline Number of episodes & 3.6 & 3.2 & & & & & \\
\hline Antidepressant use & 28 & 80 & & & & & \\
\hline Memory at 18 months & -1.7 & 2.1 & 0.1 & 0.9 & 4.19 & 62 & $\leq .001$ \\
\hline Executive functions at 18 months & -1.3 & 1.8 & 0.0 & 1.0 & 3.26 & 60 & .002 \\
\hline Processing speed at 18 months & -0.7 & 1.2 & 0.1 & 1.0 & -2.71 & 58 & .009 \\
\hline Cortisol at baseline & 158 & 80 & 100 & 24 & -3.63 & 43 & $\leq .001$ \\
\hline Whole brain volume (in $\mathrm{mm}^{3}$ ) & 965 & 81 & 969 & 88 & 0.20 & 61 & .844 \\
\hline $\mathrm{L}+\mathrm{R}$ raw frontal volume (in $\mathrm{mm}^{3}$ ) & 96 & 16 & 98 & 14 & 0.52 & 62 & 609 \\
\hline$L+R$ normalized frontal volume ${ }^{1}$ & 92 & 12 & 92 & 7 & 0.07 & 62 & .944 \\
\hline $\mathrm{L}+\mathrm{R}$ raw hippocampal volume (in $\mathrm{mm}^{3}$ ) & 5.6 & 0.9 & 5.8 & 0.8 & 0.55 & 61 & .583 \\
\hline L+R normalized hippocampal volume ${ }^{2}$ & 5.8 & 0.7 & 5.9 & 0.5 & 0.63 & 61 & .533 \\
\hline Overall white matter hyperintensities & 12.2 & 5.4 & 13.2 & 9.9 & 0.47 & 53 & .642 \\
\hline
\end{tabular}

${ }^{1}$ measured as ( $L+R$ raw frontal volume / whole brain volume) $X 1000$

${ }^{2}$ measured as ( $L+R$ raw hippocampal volume / whole brain volume) X 1000

Baseline MRI data and follow-up neuropsychological test scores were available for 35 depressed subjects and 29 healthy controls. Patients on average had fewer 
years of formal education and higher depression scores at baseline and follow-up compared with healthy controls (Table 1). They performed worse on all neuropsychological tests at follow-up and had higher area-under-the-curve cortisol levels at baseline, but there were no significant differences in total, frontal or hippocampal brain volume, and overall $\mathrm{WMH}$.

Table 2. Interactions between baseline biological measures and group ( 0 = healthy comparison, $1=$ depressed subjects) on neurocognitive outcomes at 18 months.

\begin{tabular}{|c|c|c|c|c|c|c|c|c|c|}
\hline & \multicolumn{3}{|c|}{ Memory z-scores } & \multicolumn{3}{|c|}{ Executive functions z-scores } & \multicolumn{3}{|c|}{ Processing speed z-scores } \\
\hline & $b$ & $95 \% \mathrm{Cl}$ & $P$ & $b$ & $95 \% \mathrm{Cl}$ & $p$ & $b$ & $95 \% \mathrm{Cl}$ & $p$ \\
\hline Cortisol & 0.01 & $-5.17 / 1.12$ & .505 & -0.01 & $-0.04 / 0.01$ & .288 & 0.01 & $-0.01 / 0.02$ & .393 \\
\hline $\begin{array}{l}\text { Whole brain } \\
\text { volume }\end{array}$ & 0.00 & $-0.01 / 0.01$ & .593 & 0.00 & $-0.01 / 0.01$ & .709 & 0.00 & $-0.00 / 0.01$ & .575 \\
\hline $\begin{array}{l}\text { Frontal lobe } \\
\text { volume }\end{array}$ & -0.03 & $-0.14 / 0.09$ & .636 & -0.05 & $-0.15 / 0.04$ & .279 & -0.02 & $-0.10 / 0.05$ & .554 \\
\hline $\begin{array}{l}\text { Hippocampal } \\
\text { volume }\end{array}$ & 0.47 & $-1.00 / 1.95$ & .521 & 0.94 & $-0.36 / 2.24$ & .153 & 0.16 & $-0.82 / 1.14$ & .741 \\
\hline Overall WMH & -0.21 & $-0.32 /-0.10$ & $\leq .001^{\mathrm{a}}$ & -0.18 & $-0.29 /-0.06$ & $.004^{b}$ & -0.03 & $-0.12 / 0.05$ & .460 \\
\hline
\end{tabular}

\subsection{Impact of biological measures on group differences in neurocognitive function} Tests for interactions between group and biological measures on neurocognitive outcome adjusted for age, gender and years of education are summarized in Table 2. Differences in memory z-scores at 18 months between depressed and healthy comparison subjects were not moderated by cortisol levels or volumetric measures, but showed a significant interaction with overall WMH. With every one point increase in WMH severity, patients' score on memory declined by 0.21 standard deviations. Likewise, there were no significant interactions between group and cortisol levels or volumetric measures on executive functions z-scores, but yet again there was a significant interaction with overall WMH (decline of 0.18 standard deviations with every one point increase in WMH severity). Both effects remained significant when multiple testing was controlled for. In contrast, group differences in processing speed were not moderated by any biological measure. 
Figure 1. Differences in neurocognition across groups and across tertiles of white matter hyperintensities (WMH).
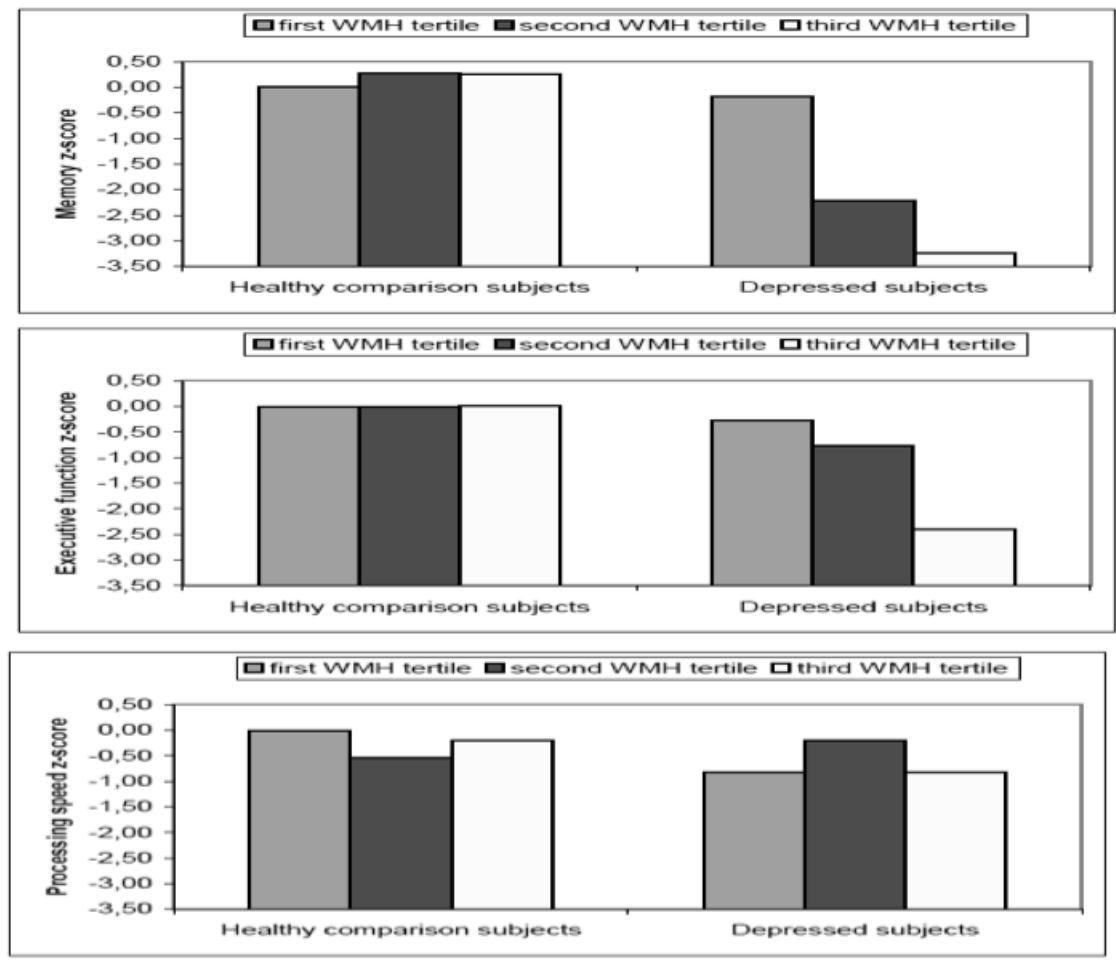

\subsection{Further explorations into the role of white matter hyperintensities}

In order to clarify the role of WMH further, we investigated potential doseresponse relations between $\mathrm{WMH}$ severity and neurocognitive outcome by dividing the overall severity rating into tertiles. There were significant interactions between group and $\mathrm{WMH}$ tertiles on memory and executive functions scores that showed evidence of an effect gradient (Figure 1). Using the healthy comparison subjects within the first tertile (no/minor $\mathrm{WMH}, \mathrm{n}=10$ ) as the reference group, depressed subjects within the same tertile $(n=11)$ did not differ in memory scores ( $z$-score difference with reference group $=-0.18,95 \% \mathrm{Cl}=-1.41 / 1.06, \mathrm{p}=.775)$. However, being depressed within the second $\mathrm{WMH}$ tertile $(n=11)$ was associated with a decline of two standard deviations in memory (z-score difference with reference group $=2.21,95 \% \mathrm{Cl}=-3.68 /-0.74, \mathrm{p}=.004$; test for interaction of group and $\mathrm{WMH}$ tertile (first versus second): $b=-2.04,95 \% \mathrm{Cl}=-3.92 /-0.14, \mathrm{p}=0.36$ ). Being depressed in the third WMH tertile $(n=11)$ went together with a decline of three standard deviations ( $\mathrm{z}$-score difference $=-3.23,95 \% \mathrm{Cl}=-4.56 /-1.91, \mathrm{p} \leq .001$; test for interaction of group and $\mathrm{WMH}$ tertile (first versus third): $\mathrm{b}=-3.06,95 \% \mathrm{Cl}=-$ $4.84 /-1.27, p \leq .001)$. For executive functions, depressed subjects within the first $\mathrm{WMH}$ tertile did not differ from the reference group ( $\mathrm{z}$-score difference $=-0.28$, 
$05 \% \mathrm{Cl}=-1.45 / 0.91, \mathrm{p}=.643)$, and those within the second $\mathrm{WMH}$ tertile did neither ( $\mathrm{z}$-score difference $=-0.77,95 \% \mathrm{Cl}=-2.18 / 0.64, \mathrm{p}=.276$; test for interaction: $\mathrm{b}=$ $0.50,95 \% \mathrm{Cl}=-2.31 / 1.31, \mathrm{p}=.583)$. Only $\mathrm{WMH}$ within the third tertile were associated with worse executive functions scores in depressed subjects (z-score difference $=-2.40,95 \% \mathrm{Cl}=-3.72 /-1.08, \mathrm{p} \leq .001$; test for interaction: $\mathrm{b}=-2.12$, $95 \% \mathrm{Cl}=-3.86 /-0.39, \mathrm{p}=.018)$.

In order to clarify the role of the anatomical location of $\mathrm{WMH}$, the continuous overall severity rating was divided into its constituent parts: deep $\mathrm{WMH}$, periventricular $\mathrm{WMH}$, basal ganglia hyperintensities and infratentorial hyperintensities. Adjusted analyses showed that group difference in memory zscores were moderated by deep (test for interaction: $b=-0.30,95 \% \mathrm{Cl}=-0.47 /-$ $0.13, \mathrm{p} \leq .001$ ) and periventricular $\mathrm{WMH}$ (test for interaction: $\mathrm{b}=-0.68,95 \% \mathrm{Cl}=-$ $1.21 /-0.15, p=.014$ ), but not basal ganglia (test for interaction: $b=-0.07,95 \% \mathrm{Cl}=-$ $0.50 / 0.35, p=.729$ ) or infratentorial hyperintensities (test for interaction: $b=-0.32$, $95 \% \mathrm{Cl}=-1.07 / 0.43, \mathrm{p}=.398)$. Group differences in executive functions were moderated by deep $\mathrm{WMH}$ (test for interaction: $\mathrm{b}=-0.21,95 \% \mathrm{Cl}=-0.40 /-0.02, \mathrm{p}=$ .027 ), but not periventricular $\mathrm{WMH}$ (test for interaction: $\mathrm{b}=-0.46,95 \% \mathrm{Cl}=-$ $0.99 / 0.06, p=.082$ ), basal ganglia (test for interaction: $b=-0.07,95 \% \mathrm{Cl}=-$ $0.46 / 0.32, p=.708$ ) or infratentorial hyperintensities (test for interaction: $b=-0.39$, $95 \% \mathrm{Cl}=-1.07 / 0.30, \mathrm{p}=.260)$.

\section{Discussion}

In the present study, we found robust associations between ratings of white matter hyperintensities and neurocognitive impairment amongst older depressed adults who were followed up for 18 months. More severe white matter lesions, especially in the deep white matter and periventricular regions, were associated with greater deficits in memory and executive functions at follow-up compared with a healthy comparison group. In contrast, whole or regional brain volume, including the hippocampus, and cortisol levels were unrelated to persisting cognitive deficits. Further, WMH predicted cognitive deficits in depressed patients but were unrelated to cognitive performance in healthy control subjects. This confirms earlier reports (71) and is in line with studies showing that white matter lesions are commonly present in the brains of healthy older adults, where they do not necessarily relate to poor cognitive outcome (236). Several mechanisms might explain this. First, depressed individuals might have lowered brain reserve to compensate for the damage exerted by $\mathrm{WMH}$ due to the effects of accumulated genetic and environmental risk exposure. As a consequence, the additional burden placed by $\mathrm{WMH}$ gives rise to cognitive deficits in this group. Alternatively, the neuropathology of WMH might be different in depression compared with normal ageing. Indeed, previous work has shown that WMH in depression are more often ischemic in nature (227). Third, the strategic anatomical lesion location, and 
consequently the neuro-circuits disrupted, might differ between the groups. Late life depression is particularly associated with deep white matter lesions affecting projection to and from the frontal lobes, thereby disrupting circuits for cognitive and emotional control, leading to depressive symptoms and executive dysfunction (71).

Our findings are consistent with previous cross-sectional reports showing total brain hyperintensities correlate with impaired episodic memory $(70,230,231)$ and executive functions in older people with depression $(71,230,232)$. They also indicate that $\mathrm{WMH}$ may contribute to the persistence of cognitive dysfunction observed amongst some older people with depression. These findings are consistent with the vascular hypothesis of depression (65), and indicate that WMH and cerebrovascular disease play an important role in the phenotypic expression of depression in later life $(66,227)$. The etiological relevance of vascular factors in the onset or recurrence of depression has been implicated by research showing that WMH can predate the onset of depression $(72,73)$, and are likely to further progress over time in subjects with prevalent depression (73). In addition, more severe white matter changes have been associated with worse prognosis of depression, including poor response to antidepressant treatment $(74,237)$, chronic and relapsing course (75), an increased risk for dementia and higher mortality (76). These findings have led to the consideration of 'vascular depression' as a distinct diagnostic subtype in the upcoming fifth edition of the Diagnostic and Statistical Manual of Mental Disorders associated with old age, WMH, late onset and deficits in executive functions (238). Recently, Sneed and colleagues using latent class analysis reported that the presence of deep white matter lesions has almost perfect discriminating ability for distinguishing classes of vascular and non-vascular depression (239). Our study adds that such WMH have predictive validity, as they are associated over 18 months with poorer memory and executive functions. However, the predictive validity of WMH for treatment response, clinical and other cognitive outcomes has to be clarified further before any criteria of vascular depression can be recommended for use in regular clinical practice.

The present study provides important evidence that whilst $\mathrm{WMH}$ are associated with key cognitive outcomes, other biological abnormalities, including hypercortisolaemia, are not. Despite evidence for a toxic effect of chronic glucocorticoid hypersecretion on hippocampal neurons in animal models (56) and humans (240), we found no effect of baseline cortisol levels or hippocampal volume on differences between depressed and healthy comparison subjects in follow-up neurocognition. As we reported previously, cortisol levels are further not associated with hippocampal volume or baseline memory function (64). In another report using this same sample, we found that late onset but not early onset subjects had reduced hippocampal volume (229), which has been replicated by other volumetric studies $(62,241)$, and contradicts the idea that cumulative (lifetime) cortisol exposure is sufficient to explain hippocampal damage in depression. We acknowledge that our results are not consistent with some reports 
in younger depressed subjects (242), and thus suggest that in older depressed subjects pathogenic mechanisms other than hypercortisolemia might explain hippocampal volume loss and associated memory deficits, including vascular pathology.

Notable strengths of this study are a comprehensive assessment of biological parameters that have been suggested to impact on cognitive functioning in depression, a relatively long follow-up duration, the assessment of core cognitive domains, and the inclusion of a matched-comparison group of healthy subjects that was followed-up in parallel. Yet, some methodological aspects deserve attention. MRI image analyses of different regions of interest were performed using different software packages, though correlations of whole brain volumes obtained using both packages was very high $(r=.91)$. Ratings of white matter hyperintensities were based on visual rather than volumetric data, although this approach has been shown to be reliable and to have good face validity (233).

In conclusion, white matter hyperintensities moderate the severity of continuing cognitive deficits in older depressed subjects in a dose-response fashion. In contrast, high levels of cortisol and hippocampal volume loss do not appear to play a major role in the persistence of depression-related cognitive deficits. 
CHAPTER 7

General discussion 
The aim of the present thesis was to foster our understanding of psychosis and depression in later life given the paucity of research in this area.

\section{Psychosis in later life}

The first part of this thesis targeted at he widespread preconceptions that onset of psychosis in the second half of life is a rare event and knows a favourable prognosis. These ideas date back to the seminal work from Manfred Bleuler (243). Among his patients, all of whom were admitted to the clinic of Burghölzli in Switzerland, he observed that $20 \%$ had an onset after age 40 years while only $4 \%$ had an onset after the age of 60 years. Bleuler also ascribed a relatively benign prognosis to these later onset groups, saying that they are less likely to end up in severe defective states that are so commonly seen in younger patients. Likewise, other researchers have reported people with an onset after age 45 to be less likely to be rehospitalized for psychosis, but they did not differentiate between patients with onset before and after 60 or 65 years $(15,16)$. In contrast, our results from a general population sample suggest that the incidence for clinically relevant symptoms in middle life does not differ substantially from the figures seen in younger age groups. Further, among 463 patients with incident psychosis in Southwest Scotland we found a relatively high proportion of $42 \%$ of cases to have a later onset ( $25 \%$ late, $17 \%$ very late), contradicting earlier, mainly hospital-based findings that have implied that these groups compromise a rather small group of patients. Next, our findings do support the general notion of a linear association between increasing age of onset and better outcome - but only if the onset occurred before the age of 65 years. Thereafter, we found that patients, especially women, had a mixed outcome pattern, which included milder symptoms and less rehospitalizations on the one hand, yet longer-lasting episodes and less chance of remission on the other hand. It has to be pointed out that this pattern is not necessarily contradictory. The milder symptom levels might make hospitalization seem less urgent from a clinical stance, but at the same time might render the disorder treated suboptimal, which in turn increases the risk of chronicity. Further, older people with psychosis have been said to have a greater reluctance to actively engage in help-seeking behaviour due to their stereotypes regarding mental health (133). This further delays optimal treatment and, taken together, might have contributed to an underestimation of the number of people affected and a too favourable account of their natural history in previous studies.

\subsection{The role of female gender}

Possible biological mechanisms for the female overrepresentation in later onset psychoses and gender-age effects on outcome of psychosis include protective hormonal effects ${ }^{1}$. In women, schizophrenia onset has been associated with a drop

\footnotetext{
${ }^{1}$ An association between menopause and late onset psychosis has long been proposed in the German literature, see e.g. Kleist's 'involutional psychosis', which he described as onset of paranoid delusions between age 40 and 50 in predisposed women with premorbid paranoid personality traits (244) or Albrecht's related concept of 'presenile paraphrenia' (245).
} 
in estrogen levels, e.g. before or during menstruation or after childbirth (246). Further evidence for a positive effect of estrogens comes from clinical trials in which estradiol, a major estrogen in humans, was added to patients' antipsychotic medication and resulted in an alleviation of positive symptoms (247). Whether estrogens can delay the onset of psychosis is however unknown. Although an earlier age at menarche has been found to be associated with a later onset of psychosis in young women (248), this was not confirmed by a recent study (249). The estrogen hypothesis might nevertheless explain the relatively benign prognosis in middle-aged women. In the absence of aetiologically relevant "hits" for early psychosis expression, antidopaminergic estrogen effects might mask any preexisting genetic vulnerability. As these women do not have to struggle with the consequences of the disorder and its treatment during the critical period of adolescence, their premorbid psychosocial development might progress relatively successful (e.g. finishing formal education, getting a job, building of social networks or getting married), which in turn would allow them to cope better with disorder onset, resulting in a relatively mild psychosis when levels of estrogens drop around the age of $40 / 45$.

\subsection{The role of neurodegeneration}

Positive psychotic symptoms are also present in $\mathrm{MCl}$, but their prevalence is far below those for other neuropsychiatric symptoms, e.g. depression or apathy (250, 251). While psychosis might therefore contribute to $\mathrm{MCl}$ development in only relatively few cases, it has been suggested that if one belongs to these cases, one is highly likely to develop $\mathrm{MCl}$ (252). However, more direct evidence that a neurodegenerative process underlies later onset psychosis has been inconsistent. So, neuropsychological testing has shown a pattern of widespread cognitive impairment similar to early onset psychosis and no evidence of further cognitive decline $(25,168,253)$. Likewise, neuroimaging studies report brain changes comparable to those seen in younger patients (including increased ventricle-tobrain ratios and temporal lobe reductions) or no abnormalities compared to a healthy comparison group (254). Yet, differences with early onset psychosis have also been reported to include atrophic changes (255), reduced cerebral blood flow in temporal cortices (256), and increased white matter changes $(137,168,257$, 258). In addition, Casanova et al. report women with late onset psychosis and no diagnosis of dementia do have higher Alzheimer pathology load as indicated by high Braak stages III and IV in post-mortem brain tissue (169). Whether the latter finding represents a subgroup with progressive brain changes or whether findings are due to misclassification of some patients with other aetiologies is unknown and findings thus wait replication. Interestingly, a recent series of case-register studies by Kørner et al. suggest that patients with both, late and very late onset psychosis, have an increased risk for dementia compared with the general population, with some variation in dementia rates across the spectrum of psychotic disorder diagnoses (29-31). Again, this finding asks for replication. 


\subsection{Psychosis as a final common pathway}

Earlier studies often clustered late and very late onset psychosis together as if it was one group. Yet, contrasting onset groups defined by admixture analysis (described in chapter 2 ) revealed interesting non-linear associations between onset age and course that would not have been detected otherwise. Psychosis with onset in later life might in fact be the final common pathway of different disease processes. So, in some cases it might be the clinical manifestation of schizophrenia in old age, but in others it might mimic the clinical presentation of schizophrenia at first glance but has a different underlying pathogenesis. Indeed, the distribution of aetiological factors varies across the age of onset range and across the genders, leading to substantial heterogeneity in clinical presentation and outcome. Early onset psychosis presumably is the result of a genetic predisposition for psychosis and the accumulation of risk factors for disease expression in early life (e.g. cannabis use, living in cities, childhood trauma) (8). The onset might however be delayed into middle age in the absence of such risk factors or in the presence of protective factors (e.g. estrogen protection, preserved social network). In old age, neuronal loss due to impeding dementia or the ageing-process itself might suffice to promote schizophrenia-like symptoms in individuals without a genetic vulnerability for schizophrenia. These pathways are not mutually exclusive but might interact in causing symptom expression. For example, a genetically vulnerable person might live into old age without disease expression due to protective factors, but develops schizophrenia when cognitive ageing disrupts crucial neuronal pathways further.

As it has been pointed out, age of onset is the single most important characteristic of schizophrenia that could yield clues to its origin (165). One way of reducing the heterogeneity seen in later onset psychosis therefore is the careful study age of onset, but also of gender and age-gender relationships. Since psychosis in later life seems to be a potential candidate risk state for cognitive decline and dementia, longitudinal studies are needed that assess neurocognitive functions at multiple time points and record dementia progression. They should focus on/ use a) the interaction between gender and age of psychosis onset by a thorough assessment of the timing of menarche and menopause or measures of estrogens concentrations (e.g. bone densitometry for lifetime estrogens exposure), b) magnetic imaging techniques to detect Alzheimer pathology and white matter changes, and c) genotyping and testing of epigenetic moderation ${ }^{2}$. In addition, studying factors that delay the onset of psychosis (e.g. hormonal or epigenetic factors) holds promises for new prevention and (early) treatment strategies. In this regard, the study of late onset psychosis is not a mere psychogeriatric endeavour, but new findings will serve all patients with this devastating disorder.

\footnotetext{
${ }^{2}$ This is a hard endeavour indeed. Everyone who has worked in the field of late onset psychosis knows that paranoid delusions and social isolation interact in building up a sometimes profound guardedness towards mental health specialists and researchers. In an ideal world, such studies would be transdisciplinary multi-centre studies with a thorough tracking of reasons for study entry refusal.
} 


\section{Depression in later life}

While research into psychosis in later life still appears to be in its infancy, more is known about factors contributing to the emergence or re-occurrence of late life depression. The second part of this thesis aimed at challenging the (partly now decaying) ideas that cognitive impairment in depression is generally reversible, and that if irreversible occur during prodromal Alzheimer dementia. The studies presented in this part of the thesis demonstrate that cognitive deficits are trait markers of late life depression, unrelated to state factors such as current symptom severity, remission status or antidepressant use. The findings add to the mounting evidence showing that cognitive deficits in late life depression are persistent in nature and affect multiple cognitive domains $(36-38,43,44)$. In MAAS, we further showed that late life depression is associated with age-accelerated cognitive decline and predicted mild cognitive impairment, a potential dementia prodrome. These findings support earlier community studies $(45,48,51)$ and studies that have shown that depression increases the risk for Alzheimer dementia $(54,171)$.

\subsection{Vascular lesion location}

Our results also emphasize the relevance of vascular lesions over glucocorticoidmediated brain changes by demonstrating that white matter changes but not hippocampal atrophy or elevated cortisol levels explain persistent cognitive deficits in late life depression. White matter changes have furthermore been shown to precede the onset of depression (72) and to progress in subjects with prevalent depression over time (73). In addition, increasing severity of white matter changes is associated with worse prognosis, including poor response to antidepressant treatment (74), chronic and relapsing course (75), an increased risk for dementia and higher mortality (76). Such findings have led to the consideration of 'vascular depression' as a distinct diagnostic subtype in the upcoming fifth edition of the Diagnostic and Statistical Manual of Mental Disorders (DSM-V) (238). Circumscribed cerebrovascular changes are however frequently found in healthy older adults where they do not necessarily lead to significant cognitive impairment (236). Interestingly, we showed that while healthy and depressed individuals did not differ in the total amount of white matter changes per se, cerebrovascular changes related to cognitive deficits in the depressed group only, especially if such changes were found in the deep white matter (as opposed to lesions in the basal ganglia or infratentorial regions). Accordingly, not the mere presence of vascular changes seems to account for the observed cognitive deficits but the strategic lesion location. Indeed, it has been suggested that a disconnection of white matter tracks linking frontal and limbic areas might be crucial in this regard, as they are relevant for emotional control and cognitive functions (71). Still, few studies have looked at the integrity of microstructural pathways in depression using diffusion tensor imaging and other state-of-the art techniques.

\subsection{Biomarkers for vascular disease in depression, new treatment strategies}

As depression and vascular disease are both candidate risk factors for cognitive impairment and subsequent dementia, their co-occurrence in 'vascular depression' 
probably indicates a high-risk state for such adverse outcomes that could however be treated effectively using currently available treatment options. The identification of biomarkers of vascular disease in depression is paramount for this ends. Promising candidates include common genetic factors, high homocysteine levels and endothelial dysfunction (259). Studies using these biomarkers are clearly needed as they will have essential prognostic and therapeutic implications (260). Questions that need to be addressed are: Do vascular risk factors modify the longitudinal relationship between depression, cognitive decline and dementia? What is the exact vascular lesion location that drives cognitive impairment in late life depression? Can we identify biomarkers for vascular disease in depression that have the potential to guide the development of novel treatment options?

\section{An integrative model for the association between neuropsychiatric disorders and dementia}

As has been outlined, psychosis and depression are thus both associated with cognitive impairment, vascular brain lesions and age-accelerated cognitive decline, and so are other neuropsychiatric disorders, suggesting a common operating mechanism (261). For instance, cognitive deficits in bipolar disorder have been demonstrated in symptomatic young and euthymic older patients $(262,263)$. Elderly bipolar patients show decreased cortico-limbic connectivity similar to late life depression (264), and their risk for dementia increases by $6 \%$ with every bipolar episode during lifetime (compared to $13 \%$ for depression) (204). Still, only a subgroup of those affected by these disorders will ultimately develop dementia, making it highly likely that other factors have to be present simultaneously. Likewise, the high frequency of Alzheimer's disease pathology in individuals without objective cognitive impairment indicates that neurotoxic processes such as accelerated amyloid plaque deposition are likely to be non-specific signs of the ageing brain that increase an individual's vulnerability to develop dementia but might not be sufficient to cause it $(265)^{3}$. The same applies to vascular brain lesions, which might progress to vascular dementia in some individuals, while they have no impact on cognitive functioning in others (236). Again, the presence of vascular changes seems to render someone vulnerable for further cognitive decline. In line with this, the effects of Alzheimer and vascular pathology are known to be additive in causing dementia (266). Building models that study the interaction of these aetiologically relevant "multiple hits" might therefore be more promising than the quest for a single penetrating factor for dementia outcome. The concept of cognitive reserve could be useful in explaining these interacting effects. Based on the observation that there is no one-to-one relation between brain damage and its behavioural consequence, and that large inter-individual differences in the outcome of such damage exists, the concept of "cognitive capacity" or "brain

\footnotetext{
${ }^{3}$ In the study by Visser et al., makers for Alzheimer's disease (including increased concentrations of the 42 amino acid form of $\beta$-amyloid and total tau in the cerebrospinal fluid) were present in $79 \%$ of patients with amnestic $\mathrm{MCl}, 68 \%$ of patients with non-amnestic $\mathrm{MCl}, 52 \%$ of people with only subjective cognitive complaints and in $32 \%$ of cognitively intact controls.
} 
reserve capacity" states that people differ in their cerebral make-up which allows them to varying degrees to compensate for the loss of neurons or functional connections $(267,268)^{4}$. Hence, superior cognitive function is a renowned protective factor against dementia and the consequences of head injury, but might also lower the risk for developing neuropsychiatric disorders (269). Recently, Butters et al. used the concept of cognitive reserve to illustrated potential pathways linking depression to dementia (270). The authors suggest that the most common pathway evolves via the lifetime accumulation of Alzheimer pathology and/or cerebrovascular brain changes, thereby lowering cognitive capacities. The onset or re-emergence of depression in later life might then suffice to cause someone's cognitive reserve to exceed a critical threshold, where he or she is unable to compensate for the additional cognitive burden any further and develops dementia. While focusing on depression, this model can be extended to include other neuropsychiatric disorders as shown in Figure 1.

Figure 1. "Two hit model" of cognitive decline associated with neuropsychiatric disorders. Cognitive reserve is compromised by the neuropathological changes associated with psychosis, depression or bipolar disorder, leading to significant cognitive impairment. The risk for dementia increases further as neuropathology changes (e.g. amyloid plaque deposition, cerebrovascular changes or Lewy bodies) accumulate within an individual's life.

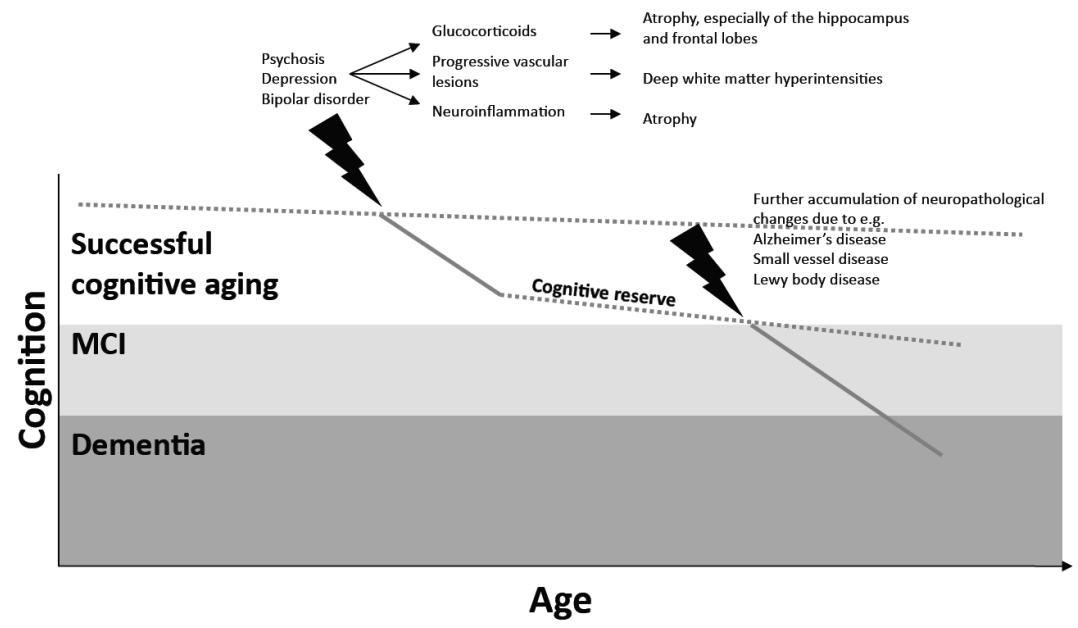

Although being overtly simplistic, the model is testable and might generate new hypothesis regarding the association between late life mental disorders and cognitive decline. In some individuals however, Alzheimer's disease or cerebrovascular pathology progression might be severe enough to cause dementia

\footnotetext{
${ }^{4}$ Although closely related, the concepts of cognitive capacity and brain reserve capacity are however not totally identical. Brain reserve capacity stresses individual differences in brain structure such as neuronal redundancy and synaptic density, whereas cognitive capacity refers to differences in efficiency of task performance and the ability to recruit alternative cortical networks.
} 
onset itself. Here, onset of psychotic or depressive symptoms might signal that neuronal networks crucial for higher order cognitive processes have now been damaged, i.e. they are prodromal symptoms.

\subsection{Leaving the ivory tower: implications for clinical practice}

No matter whether psychosis and depression are risk factors sufficient to cause cognitive decline or whether they signal an underlying pathogenic process related to prodromal dementia, their presence delineates a mental at-risk state for negative cognitive outcomes. This knowledge can guide novel prevention programmes, in which older adults presenting with paranoid ideation or depressed mood are followed on a regular basis, allowing for a tighter visitation schedule than would normally be the case. Such programmes might already start in mid-life since the risk for dementia is already increased if onset of psychosis or depression occurs before the age of 65 years. Examinations should include a comprehensive psychiatric and neuropsychological assessment, yet patients might also be screened for the presence of vascular morbidity such as hyper- of hypotension, angina pectoris, myocardial infarction or cerebral white matter lesions, since its treatment might proof beneficial in averting cognitive decline. Dietary advice might be given to prevent vascular co-morbidity to emerge in the first place. While treatment options for Alzheimer's disease have not been developed so far, cognitive enhancers (e.g. acetylcholinesterase inhibitors) might slow down the underlying degeneration process. Psychotic elders are remarkably reluctant to enter mental health care settings, and consequently the general practitioner or a community nurse is often the only health professional tolerated by him or her. ${ }^{5}$ These professions therefore need special training in order to increase their awareness of the (often intelligible) symptoms displayed by the patient. Treatment plans can then be initiated on a trustful doctor-patient relationship, and the patient might finally agree to see a mental health professional. The often chronic course of very late onset psychosis suggests that current treatment options work suboptimal in this patient group. To date, elderly psychotic patients are treated with antipsychotic medication developed for early onset schizophrenia. On the basis of the current literature, no safe advice can be given as to the optimal treatment. This was also the result of a systematic review by the Cochrane Collaboration, which was unable to identify a single study that met their strict inclusion criteria (271). Consequently, the authors concluded that this vulnerable group is not well served by the research community. In general, a "start low, go slow" regime appears most appropriate when managing psychosis in later life, but there will be wide individual variations in effective and tolerated dosages (272). Atypical antipsychotics appear to be superior to typical antipsychotics by minimizing negative side effects such as

\footnotetext{
${ }^{5}$ Another profession that has frequent contact with this patient group is that of the police officer. As a consequence of a patient's paranoid ideation or auditory hallucinations, they are called to duty in order to settle a neighbourhood quarrel or check for supposed suspects strolling around the patient's home. While only very few patients take direct actions towards their "persecutor", they comply to their local police office frequently, some even daily.
} 
extrapyramidal symptoms and tardive dyskinesia $(273,274)$. In addition, the anticholinergic effects of typical antipsychotics can have unfavourable effects on a patient's cognitive functioning. In contrast, atypical antipsychotics might even alleviate cognitive symptoms in young and old patients with early onset schizophrenia, but it is unknown whether they have the same potential in late onset psychosis (273).

A decade has passed since an international expert group forecasted an upcoming crisis in geriatric mental health and sketched a research agenda for the next 20 years, so time is running. Many late life mental disorders remain ill understood and are treated ineffectively. Tomorrow's patients' needs ask for our combined effort to increase the understanding of these disorders and to find new ways for prevention and treatment. 


\section{References}

1. De Hollander AEM, Hoeymans N, Melse JM, Van Oers JAM, Polder JJ, editors. Zorg voor gezondheid. Volksgezondheid Toekomst Verkenning 2006. RIVM-rapportnr. 270061003. Houten: Bohn Stafleu Van Loghum; 2006.

2. Polder JJ, Takkern J, Meerding WJ, Kommer GJ, Stokx LJ. Kosten van ziekten in Nederland: de zorgeuro ontrafeld. Bilthoven: RIVM2002.

3. Satariano WA. Epidemiology of Aging: An Ecological Approach. Suburry, Massachusetts: Jones and Bartlett Publishers, Inc; 2006.

4. Jeste DV, Alexopoulos GS, Bartels SJ, Cummings JL, Gallo JJ, Gottlieb GL, et al. Consensus statement on the upcoming crisis in geriatric mental health: Research agenda for the next 2 decades. Arch Gen Psychiatry. 1999 56(9):848-53.

5. van Os J, Hanssen M, Bijl RV, Ravelli A. Strauss (1969) revisited: a psychosis continuum in the general population? Schizophr Res. 2000 45:11-20.

6. McGrath J, Saha S, Welham J, El Saadi O, MacCauley C, Chant D. A systematic review of the incidence of schizophrenia: the distribution of rates and the influence of sex, urbanicity, migrant status and methodology. BMC Med. 2004 2:13.

7. Howard R, Rabins PV, Seeman MV, Jeste DV, the International Late-Onset Schizophrenia Group. Late-onset schizophrenia and very-late-onset schizophrenia-like psychosis: an international consensus. Am J Psychiatry. 2000 157:172-8.

8. Green MF. Schizophrenia Revealed: From Neurons to Social Interactions. New York: W.W. Norton \& Company, Inc.; 2003.

9. Östling S, Skoog I. Psychotic symptoms and paranoid ideation in a nondemented population-based sample of the very old. Arch Gen Psychiatry. 2002 59(1):53-9.

10. Östling S, Pálsson SP, Skoog I. The incidence of first-onset psychotic symptoms and paranoid ideation in a representative population sample followed from age 70-90 years. Relation to mortality and later development of dementia. Int J Geriatr Psychiatry. 2007 22(6):520-8.

11. Klages W. Die Spätschizophrenie [Late-onset schizophrenia]. Stuttgart, Germany: Ferdinand Enke Verlag; 1961.

12. Riecher-Rössler A. Late onset schizophrenia: The German concept and literature. In: Howard R, Rabins PV, Castle DJ, editors. Late onset schizophrenia. Petersfield, UK: Wrightson Biomedical Publishing Ltd; 1999. p. 3-16.

13. Jeste DV, Symonds LL, Harris MJ, Paulsen JS, Palmer BW, Heaton RK. Nondementia nonpraecox dementia praecox? Late-onset schizophrenia. Am J Geriatr Psychiatry. 1997 5(4):302-17.

14. Leung A, Chue P. Sex differences in schizophrenia, a review of the literature. Acta Psychiatr Scand Suppl. 2000 401:3-38.

15. Haro JM, Eaton WW, Bilker WB, Mortensen PB. Predictability of rehospitalization for schizophrenia. Eur Arch Psychiatry Clin Neurosci. 1994 244(5):241-6.

16. Rabinowitz J, Levine SZ, Hafner H. A population based elaboration of the role of age of onset on the course of schizophrenia. Schizophr Res. 2006 88(1-3):96-101.

17. Seeman MV, Lang M. The role of estrogens in schizophrenia gender differences. Schizophr Bull. 1990 16(2):185-94.

18. Häfner H, An der Heiden W, Behrens S, Gattaz WF, Hambrecht M, Löffler W, et al. Causes and consequences of the gender difference in age at onset of schizophrenia. Schizophr Bull. 1998 24(1):99-113.

19. Blessed G, Wilson I. The contemporary natural history of mental disorder in old age. $\mathrm{Br} \mathrm{J}$ Psychiatry. 1982 141(1):59-67.

20. Jorgensen P, Munk-Jorgensen P. Paranoid psychosis in the elderly. A follow-up study. Acta Psychiatr Scand. 1985 72(4):358-63.

21. Holden NL. Late paraphrenia or the paraphrenias? A descriptive study with a 10-year follow-up. $\mathrm{Br}$ J Psychiatry. 1987 150:635-9.

22. Craig TJ, Bregman Z. Late onset schizophrenia-like illness. J Am Geriatr Soc. 1988 36(2):104-7.

23. Brodaty H, Sachdev P, Koschera A, Monk D, Cullen B. Long-term outcome of late-onset schizophrenia: 5-year follow-up study. Br J Psychiatry. 2003 183(3):213-9. 
24. Hymas N, Naguib M, Levy R. Late paraphrenia - a follow-up study. Int J Geriatr Psychiatry. 1989 4(1):23-9.

25. Palmer BW, Bondi MW, Twamley EW, Thal L, Golshan S, Jeste DV. Are late-onset schizophrenia spectrum disorders neurodegenerative conditions? Annual rates of change on two dementia measures. J Neuropsychiatry Clin Neurosci. 2003 15(1):45-52.

26. Rabins PV, Lavrisha M. Long-term follow-up and phenomenologic differences distinguish among late-onset schizophrenia, late-life depression, and progressive dementia. Am J Geriatr Psychiatry. 2003 11(6):589-94.

27. Mazeh D, Zemishlani C, Aizenberg D, Barak Y. Patients with very-late-onset schizophrenia-like psychosis: a follow-up study. Am J Geriatr Psychiatry. 2005 13(5):417-9.

28. Laks J, Fontenelle LF, Chalita A, Mendlowicz MV. Absence of dementia in late-onset schizophrenia: a one year follow-up of a Brazilian case series. Arq Neuropsiquiatr. 2006 64(4):946-9.

29. Kørner A, Lopez AG, Lauritzen L, Andersen PK, Kessing LV. Delusional disorder in old age and the risk of developing dementia-a nationwide register-based study. Aging \& Mental Health. 2008 12(5):625 - 9.

30. Kørner A, Lopez AG, Lauritzen L, Andersen PK, Kessing LV. Acute and transient psychosis in old age and the subsequent risk of dementia: A nationwide register-based study. Geriatrics \& Gerontology International. 2009 9(1):62-8.

31. Kørner A, Lopez AG, Lauritzen L, Andersen PK, Kessing LV. Late and very-late first-contact schizophrenia and the risk of dementia-a nationwide register based study. International Journal of Geriatric Psychiatry. 2009 24(1):61-7.

32. Steffens DC, Skoog I, Norton MC, Hart AD, Tschanz JT, Plassman BL, et al. Prevalence of depression and its treatment in an elderly population: The Cache County Study. Arch Gen Psychiatry. 2000 57(6):601-7.

33. Beekman A, Copeland J, Prince M. Review of community prevalence of depression in later life. Br J Psychiatry. 1999 174(4):307-11.

34. Thomas AJ, O'Brien JT. Depression and cognition in older adults. Current Opinion in Psychiatry. 2008 21(1):8-13.

35. Bulbena A, Berrios G. Pseudodementia: facts and figures. Br J Psychiatry. 1986 148(1):87-94.

36. Abas MA, Sahakian BJ, Levy R. Neuropsychological deficits and CT scan changes in elderly depressives. Psychol Med. 1990 20(3):507-20.

37. Beats BC, Sahakian BJ, Levy R. Cognitive performance in tests sensitive to frontal lobe dysfunction in the elderly depressed. Psychol Med. 1996 26(3):591-603.

38. Nebes RD, Butters MA, Mulsant BH, Pollock BG, Zmuda MD, Houck PR, et al. Decreased working memory and processing speed mediate cognitive impairment in geriatric depression. Psychol Med. 2000 30(03):679-91.

39. Devanand DP, Pelton GH, Marston K, Camacho Y, Roose SP, Stern Y, et al. Sertraline treatment of elderly patients with depression and cognitive impairment. Int J Geriatr Psychiatry. 2003 18(2):123-30.

40. Portella MJ, Marcos T, Rami L, Navarro V, Gastó C, Salamero M. Residual cognitive impairment in late-life depression after a 12-month period follow-up. Int J Geriatr Psychiatry. 2003 18(7):571-6.

41. Adler G, Chwalek K, Jajcevic A. Six-month course of mild cognitive impairment and affective symptoms in late-life depression. European Psychiatry. 2004 19(8):502-5.

42. Neu P, Bajbouj M, Schilling A, Godemann F, Berman RM, Schlattmann P. Cognitive function over the treatment course of depression in middle-aged patients: correlation with brain MRI signal hyperintensities. Journal of Psychiatric Research. 2005 39(2):129-35.

43. Bhalla RK, Butters MA, Mulsant BH, Begley AE, Zmuda MD, Schoderbek B, et al. Persistence of neuropsychologic deficits in the remitted state of late-life depression. Am J Geriatr Psychiatry. 2006 14(5):419-27.

44. Lee JS, Potter GG, Wagner HR, Welsh-Bohmer KA, Steffens DC. Persistent mild cognitive impairment in geriatric depression. Int Psychogeriatr. 2007 19(1):125-35.

45. Yaffe K, Blackwell T, Gore R, Sands L, Reus V, Browner WS. Depressive symptoms and cognitive decline in nondemented elderly women: A prospective study. Arch Gen Psychiatry. 1999 56(5):425-30. 
46. Comijs HC, Jonker C, Beekman ATF, Deeg DJH. The association between depressive symptoms and cognitive decline in community-dwelling elderly persons. Int J Geriatr Psychiatry. 2001 16(4):3617.

47. Paterniti S, Verdier-Taillefer $\mathrm{M}-\mathrm{H}$, Dufouil $\mathrm{C}$, Alperovitch A. Depressive symptoms and cognitive decline in elderly people: Longitudinal study. Br J Psychiatry. 2002 181(5):406-10.

48. Lopez OL, Jagust WJ, Dulberg C, Becker JT, DeKosky ST, Fitzpatrick A, et al. Risk factors for mild cognitive impairment in the Cardiovascular Health Study Cognition Study: Part 2. Arch Neurol. 2003 60(10):1394-9.

49. Comijs HC, van Tilburg T, Geerlings SW, Jonker C, Deeg DJ, van Tilburg W, et al. Do severity and duration of depressive symptoms predict cognitive decline in older persons? Results of the Longitudinal Aging Study Amsterdam. Aging Clin Exp Res. 2004 16(3):226-32.

50. Sachs-Ericsson N, Joiner T, Plant EA, Blazer DG. The influence of depression on cognitive decline in community-dwelling elderly persons. Am J Geriatr Psychiatry. 2005 13(5):402-8.

51. Geda YE, Knopman DS, Mrazek DA, Jicha GA, Smith GE, Negash S, et al. Depression, apolipoprotein E genotype, and the incidence of mild cognitive impairment: A prospective cohort study. Arch Neurol. 2006 63(3):435-40.

52. Raji MA, Reyes-Ortiz CA, Kuo Y-F, Markides KS, Ottenbacher KJ. Depressive symptoms and cognitive change in older Mexican Americans. J Geriatr Psychiatry Neurol. 2007 20(3):145-52.

53. Chodosh J, Kado DM, Seeman TE, Karlamangla AS. Depressive symptoms as a predictor of cognitive decline: MacArthur Studies of Successful Aging. Am J Geriatr Psychiatry. 2007 15(5):40615.

54. Ownby RL, Crocco E, Acevedo A, John V, Loewenstein D. Depression and risk for Alzheimer Disease: Systematic review, meta-analysis, and metaregression analysis. Arch Gen Psychiatry. 2006 63(5):530-8.

55. Jorm AF. Is depression a risk factor for dementia or cognitive decline? A review. Gerontology. 2000 46(4):219-27.

56. Sapolsky RM, Krey LC, McEwen BS. The neuroendocrinology of stress and aging: the glucocorticoid cascade hypothesis. Endocrine Reviews. 1986 7(3):284-301.

57. Alexopoulos GS, Meyers BS, Young RC, Campbell S, Silbersweig D, Charlson M. 'Vascular depression' hypothesis. Arch Gen Psychiatry. 1997 54(10):915-22.

58. Sapolsky RM. Glucocorticoids and hippocampal atrophy in neuropsychiatric disorders. Arch Gen Psychiatry. 2000 57(10):925-35.

59. McEwen BS. Glucocorticoids, depression, and mood disorders: structural remodeling in the brain. Metabolism. 2005 54(5, Supplement 1):20-3.

60. Bao A-M, Meynen G, Swaab DF. The stress system in depression and neurodegeneration: Focus on the human hypothalamus. Brain Research Reviews. 2008 57(2):531-53.

61. Steffens DC, Byrum CE, McQuoid DR, Greenberg DL, Payne ME, Blitchington TF, et al. Hippocampal volume in geriatric depression. Biol Psychiatry. 2000 48(4):301-9.

62. Hickie I, Naismith S, Ward PB, Turner K, Scott E, Mitchell P, et al. Reduced hippocampal volumes and memory loss in patients with early- and late-onset depression. Br J Psychiatry. 2005 186(3):197-202.

63. Almeida OP, Burton EJ, Ferrier N, McKeith IG, O'Brien JT. Depression with late onset is associated with right frontal lobe atrophy. Psychol Med. 2003 33(4):675-81.

64. O'Brien JT, Lloyd A, McKeith I, Gholkar A, Ferrier N. A longitudinal study of hippocampal volume, cortisol levels, and cognition in older depressed subjects. Am J Psychiatry. 2004 161(11):2081-90.

65. Alexopoulos GS. The vascular depression hypothesis: 10 years later. Biol Psychiatry. 2006 60(12):1304-5.

66. Herrmann LL, Le Masurier M, Ebmeier KP. White matter hyperintensities in late life depression: a systematic review. J Neurol Neurosurg Psychiatry. 2008 79(6):619-24.

67. Folstein M, Liu T, Peter I, Buel J, Arsenault L, Scott T, et al. The homocysteine hypothesis of depression. Am J Psychiatry. 2007 164(6):861-7.

68. Turken AU, Whitfield-Gabrieli S, Bammer R, Baldo JV, Dronkers NF, Gabrieli JDE. Cognitive processing speed and the structure of white matter pathways: Convergent evidence from normal variation and lesion studies. Neurolmage. 2008 42(2):1032-44.

69. Amato MP, Zipoli V, Portaccio E. Cognitive changes in multiple sclerosis. Expert Review of Neurotherapeutics. 2008 8(10):1585-96. 
70. Jenkins M, Malloy P, Salloway S, Cohen R, Rogg J, Tung G, et al. Memory processes in depressed geriatric patients with and without subcortical hyperintensities on MRI. Journal of Neuroimaging. 1998 8(1):20-6.

71. Sheline YI, Price JL, Vaishnavi SN, Mintun MA, Barch DM, Epstein AA, et al. Regional white matter hyperintensity burden in automated segmentation distinguishes late-life depressed subjects from comparison subjects matched for vascular risk factors. Am J Psychiatry. 2008 165(4):524-32.

72. Teodorczuk A, O'Brien JT, Firbank MJ, Pantoni L, Poggesi A, Erkinjuntti T, et al. White matter changes and late-life depressive symptoms: Longitudinal study. Br J Psychiatry. 2007 191(3):2127.

73. Godin O, Dufouil C, Maillard P, Delcroix N, Mazoyer B, Crivello F, et al. White matter lesions as a predictor of depression in the elderly: The 3C-Dijon Study. Biol Psychiatry. 2008 63(7):663-9.

74. Hickie I, Scott E, Mitchell P, Wilhelm K, Austin M-P, Bennett B. Subcortical hyperintensities on magnetic resonance imaging: Clinical correlates and prognostic significance in patients with severe depression. Biol Psychiatry. 1995 37(3):151-60.

75. O'Brien J, Ames D, Chiu E, Schweitzer I, Desmond P, Tress B. Severe deep white matter lesions and outcome in elderly patients with major depressive disorder: follow up study. BMJ. 1998 317(7164):982-4.

76. Baldwin RC, Walker S, Simpson SW, Jackson A, Burns A. The prognostic significance of abnormalities seen on magnetic resonance imaging in late life depression: clinical outcome, mortality and progression to dementia at three years. Int J Geriatr Psychiatry. 2000 15(12):1097104.

77. Häfner H. Gender differences in schizophrenia. Psychoneuroendocrinology. 2003 28(Supplement 2):17.

78. Howard R, Castle DJ, O'Brien J, Almeida O, Levy R. Permeable walls, floors, ceilings and doors. Partition delusions in late paraphrenia. Int J Geriatr Psychiatry. 1992 7(10):719-24.

79. Howard R, Castle D, Wessely S, Murray R. A comparative study of 470 cases of early-onset and late-onset schizophrenia. Br J Psychiatry. 1993 163(3):352-7.

80. Castle DJ, Wessely S, Howard R, Murray RM. Schizophrenia with the onset at the extremes of adult life. Int J Geriatr Psychiatry. 1997 12(7):712-7.

81. Pearlson G, Rabins P. The late-onset psychoses. Possible risk factors. Psychiatr Clin North Am. 1988 11(1):15-32.

82. Sato T, Bottlender R, Schroter A, Moller H-J. Psychopathology of early-onset versus late-onset schizophrenia revisited: an observation of 473 neuroleptic-naive patients before and after firstadmission treatments. Schizophr Res. 2004 67(2-3):175.

83. Kay DW, Cooper AF, Garside RF, Roth M. The differentiation of paranoid from affective psychoses by patients' premorbid characteristics. Br J Psychiatry. 1976 129:207-15.

84. Post F. Persistent persecutory states of the elderly. Oxford, England: Pergamon Press; 1966.

85. Jeste DV, Harris MJ, Pearlson GD, Rabins PV, Lesser I, Miller BL, et al. Late-onset schizophrenia. Studying clinical validity. Psychiatr Clin North Am. 1988 11:1-13.

86. Copeland JR, Dewey ME, Scott A, Gilmore C, Larkin BA, Cleave N, et al. Schizophrenia and delusional disorder in older age: community prevalence, incidence, comorbidity, and outcome. Schizophrenia Bulletin. 1998 24(1):153-61.

87. Castle DJ, Murray RM. The epidemiology of late-onset schizophrenia. Schizophr Bull. 1993 19(4):691-700.

88. Kay DW. Schizophrenia and schizophrenia-like states in the elderly. British Journal of Hospital Medicine. 1972 8:369-76.

89. van Os J, Howard R, Takei N, Murray R. Increasing age is a risk factor for psychosis in the elderly. Soc Psychiatry Psychiatr Epidemiol. 1995 30:161-4.

90. Häfner H, An der Heiden W. Epidemiology of schizophrenia. Can J Psychiatry. 1997 42(2):139-51.

91. Salokangas RKR. First-contact rate for schizophrenia in community psychiatric care: Consideration of the oestrogen hypothesis. Eur Arch Psychiatry Clin Neurosci. 1993 242(6):337-46.

92. Perala J, Suvisaari J, Saarni SI, Kuoppasalmi K, Isometsa E, Pirkola S, et al. Lifetime prevalence of psychotic and bipolar I disorders in a general population. Arch Gen Psychiatry. 2007 64(1):19-28.

93. Wynn Owen PA, Castle DJ. Late-onset schizophrenia: epidemiology, diagnosis, managment and outcomes. Drugs and Aging. 1999 15(2):81-9. 
94. Christenson R, Blazer D. Epidemiology of persecutory ideation in an elderly population in the community. Am J Psychiatry. 1984 141(9):1088-91.

95. Henderson AS, Korten AE, Levings C, Jorm AF, Christensen H, Jacomb PA, et al. Psychotic symptoms in the elderly: a prospective study in a population sample. Int J Geriatr Psychiatry. 1998 13(7):484-92.

96. Andreasson S, Allebeck P, Engstrom A, Rydberg U. Cannabis and schizophrenia. Lancet. 1988 1(8592):1000-1.

97. Henquet C, Murray R, Linszen D, van Os J. The environment and schizophrenia: The role of cannabis use. Schizophr Bull. 2005 31(3):608-12.

98. van Os J, Bak M, Hanssen M, Bijl RV, de Graaf R, Verdoux H. Cannabis use and psychosis: A longitudinal population-based study. Am J Epidemiol. 2002 156(4):319-27.

99. Janssen I, Krabbendam L, Bak M, Hanssen M, Vollebergh W, Graaf R, et al. Childhood abuse as a risk factor for psychotic experiences. Acta Psychiatr Scand. 2004 109(1):38-45.

100. Lataster T, van Os J, Drukker M, Henquet C, Feron F, Gunther N, et al. Childhood victimisation and developmental expression of non-clinical delusional ideation and hallucinatory experiences. Soc Psychiatry Psychiatr Epidemiol. 2006 41(6):423-8.

101. Spauwen J, Krabbendam L, Lieb R, Wittchen H-U, van Os J. Does urbanicity shift the population expression of psychosis? J Psychiatr Res. 2004 38(6):613-8.

102. Spauwen J, Krabbendam L, Lieb R, Wittchen HU, van Os J. Evidence that the outcome of developmental expression of psychosis is worse for adolescents growing up in an urban environment. Psychol Med. 2006 36(3):407-15.

103. van Os J, Hanssen M, Bijl RV, Vollebergh W. Prevalence of psychotic disorder and community level of psychotic symptoms: An urban-rural comparison. Arch Gen Psychiatry. 2001 58(7):663-8.

104. Crespo-Facorro B, Piven MLS, Schultz SK. Psychosis in late life: How does it fit into current diagnostic criteria? Am J Psychiatry. 1999 156(4):624-9.

105. Krabbendam L, Janssen I, Bak M, Bijl RV, De Graaf R, van Os J. Neuroticism and low self-esteem as risk factors for psychosis. Soc Psychiatry Psychiatr Epidemiol. 2002 37(1):1-6.

106. Krabbendam L, van Os J. Affective processes in the onset and persistence of psychosis. Eur Arch Psychiatry Clin Neurosci. 2005 255(3):185-9.

107. Yung AR, Phillips LJ, Yuen HP, Francey SM, McFarlane CA, Hallgren M, et al. Psychosis prediction: 12-month follow up of a high-risk group. Schizophr Res. 2003 60(1):21-32.

108. Rodriguez-Ferrera S, Vassilas CA, Haque S. Older people with schizophrenia: a community study in a rural catchment area. Int J Geriatr Psychiatry. 2004 19(12):1181-7.

109. Schürhoff F, Golmard J-L, Szoke A, Bellivier F, Berthier A, Meary A, et al. Admixture analysis of age at onset in schizophrenia. Schizophr Res. 2004 71(1):35-41.

110. Alici-Evcimen Y, Ertan T, Eker E. Case series with late-onset psychosis hospitalized in a geriatric psychiatry unit in Turkey: experience in 9 years. Int Psychogeriatr. 2003 15(1):69-72.

111. Salokangas RKR, Honkonen T, Saarinen S. Women have later onset than men in schizophrenia--but only in its paranoid form. Results of the DSP project. European Psychiatry. 2003 18(6):274-81.

112. Craig MC, Cutter WJ, Wickham H, van Amelsvoort TAMJ, Rymer J, Whitehead M, et al. Effect of long-term estrogen therapy on dopaminergic responsivity in post-menopausal women--a preliminary study. Psychoneuroendocrinology. 2004 29(10):1309-16.

113. Maric N, Popovic V, Jasovic-Gasic M, Pilipovic N, van Os J. Cumulative exposure to estrogen and psychosis: a peak bone mass, case-control study in first episode psychosis. Schizophr Res. 2005 73:351-5.

114. Howard R, Cox T, Almeida O, Mullen R, Graves P, Reveley A, et al. White matter signal hyperintensities in the brains of patients with late paraphrenia and the normal, community-living elderly. Biol Psychiatry. 1995 38(2):86-91.

115. Prager S, Jeste DV. Sensory impairment in late-life schizophrenia. Schizophr Bull. 1993 19(4):75572.

116. Thewissen V, Myin-Germeys I, Bentall R, de Graaf R, Vollebergh W, van Os J. Hearing impairment and psychosis revisited. Schizophr Res. 2005 76(1):99-103.

117. Stefanis N, Thewissen V, Bakoula C, van Os J, Myin-Germeys I. Hearing impairment and psychosis: A replication in a cohort of young adults. Schizophr Res. 2006 85:266-72. 
118. Bijl RV, Ravelli A, van Zessen G. Prevalence of psychiatric disorder in the general population: results of the Netherlands Mental Health Survey and Incidence Study (NEMESIS). Soc Psychiatry Psychiatr Epidemiol. 1998 33(12):587.

119. Bijl RV, van Zessen G, Ravelli A, de Rijk C, Langendoen Y. The Netherlands Mental Health Survey and Incidence Study (NEMESIS): objectives and design. Soc Psychiatry Psychiatr Epidemiol. 1998 33(12):581.

120. De Graaf R, Bijl RV, Ravelli A, Smit F, Vollebergh WAM. Predictors of first incidence of DSM-III-R psychiatric disorders in the general population: findings from the Netherlands Mental Health Survey and Incidence Study. Acta Psychiatr Scand. 2002 106(4):303.

121. Goldberg DP, Williams P. A users guide to the General Health Questionnaire. Windsor: Nelson; 1988.

122. Smeets RMV, Dingemans PMAJ. Composite International Diagnostic Interview (CIDI), Version 1.1 (in Dutch). Amsterdam/Geneva: World Health Organization; 1993.

123. Cottler LB, Robins LN, Grant BF, Blaine J, Towle LH, Wittchen HU, et al. The CIDI-core substance abuse and dependence questions: cross-cultural and nosological issues. The WHO/ADAMHA Field Trial. Br J Psychiatry. 1991 159:653-8.

124. Wittchen HU. Reliability and clinical validity studies of the WHO-Composite International Diagnostic Interview (CIDI): a critical review. J Psychiatr Res. 1994 28(1):57-84.

125. Spitzer RL, Williams JB, Gibbon M, First MB. The Structured Clinical Interview for DSM-III-R (SCID). I: History, rationale, and description. Arch Gen Psychiatry. 1992 49(8):624-9.

126. Regeer EJ, Krabbendam L, De Graaf R, Ten Have M, Nolen WA, van Os J. A prospective study of the transition rates of subthreshold (hypo)mania and depression in the general population. Psychol Med. 2006 36(5):619-27.

127. Ormel J. Moeite met leven of een moeilijk leven [Difficulties with living or a difficult life]. Groningen, The Netherlands: University of Groningen; 1980.

128. StataCorp. STATA Statistical Software: Release 9.1. Texas: College Station; 2005.

129. Darroch J. Biologic synergism and parallelism. Am J Epidemiol. 1997 145(7):661-8.

130. Bak M, Krabbendam L, Janssen I, Graaf R, Vollebergh W, van Os J. Early trauma may increase the risk for psychotic experiences by impacting on emotional response and perception of control. Acta Psychiatr Scand. 2005 112(5):360-6.

131. Hanssen M, Krabbendam L, de Graaf R, Vollebergh W, van Os J. Role of distress in delusion formation. Br J Psychiatry. 2005 187(48):s55-8.

132. Breitner JCS. Paranoid psychoses in old age: Much more common than previously thought? Arch Gen Psychiatry. 2002 59(1):60-1.

133. Reeves S, Sauer J, Stewart R, Granger A, Howard RJ. Increased first-contact rates for very-lateonset schizophrenia-like psychosis in African- and Caribbean-born elders. Br J Psychiatry. 2001 179(2):172-4.

134. Riecher-Rössler A, Löffler W, Munk-Jorgensen P. What do we really know about late-onset schizophrenia? Eur Arch Psychiatry Clin Neurosci. 1997 247(4):195-208.

135. Hanssen M, Bak M, Bijl R, Vollebergh W, van Os J. The incidence and outcome of subclinical psychotic experiences in the general population. Br J Clin Psychol. 2005 44(2):181-91.

136. Maina G, Albert U, Bada A, Bogetto F. Occurrence and clinical correlates of psychiatric comorbidity in delusional disorder. European Psychiatry. 2001 16(4):222-8.

137. Tonkonogy JM, Geller JL. Late-onset paranoid psychosis as a distinct clinicopathologic entity: magnetic resonance imaging data in elderly patients with paranoid psychosis of late onset and schizophrenia of early onset. Neuropsychiatry Neuropsychol Behav Neurol. 1999 12(4):230-5.

138. Hassett A. A descriptive study of first presentation psychosis in old age. Aust N Z J Psychiatry. 1999 33(6):814-24.

139. Myin-Germeys I, van Os J, Schwartz JE, Stone AA, Delespaul PA. Emotional reactivity to daily life stress in psychosis. Arch Gen Psychiatry. 2001 58(12):1137-44.

140. Lysaker PH, Wilt MA, Plascak-Hallberg CD, Brenner CA, Clements CA. Personality dimensions in schizophrenia: associations with symptoms and coping. J Nerv Ment Dis. 2003 191(2):80-6.

141. Almeida OP. Early- vs. late-onset schizophrenia: Is it time to define the difference? Am J Geriatr Psychiatry. 1998 6(4):345-6. 
142. Myin-Germeys I, Spauwen J, Jacobs N, Lieb R, Wittchen HU, van Os J. The aetiological continuum of psychosis. In: Gattaz WF, Häfner H, editors. Search for the causes of schizophrenia V. Darmstadt: Steinkopff Verlag Darmstadt; 2004. p. 342-66.

143. Andreasen N. The validation of psychiatric diagnosis: new models and approaches. Am J Psychiatry. 1995 152(2):161-2.

144. Kendell RE. Clinical validity. Psychol Med. 1989 19(1):45-55.

145. Robins E, Guze SB. Establishment of diagnostic validity in psychiatric illness: its application to schizophrenia. Am J Psychiatry. 1970 126(7):983-7.

146. Goldstein J. Gender differences in the course of schizophrenia. Am J Psychiatry. 1988 145(6):6849.

147. Castle DJ, Abel K, Takei N, Murray RM. Gender differences in schizophrenia: hormonal effect or subtypes? Schizophr Bull. 1995 21(1):1-12.

148. Angermeyer MC, Kuhn L. Gender differences in age at onset of schizophrenia. An overview. Eur Arch Psychiatry Neurol Sci. 1988 237(6):351-64.

149. Malla A, Norman R, Schmitz N, Manchanda R, Bechard-Evans L, Takhar J, et al. Predictors of rate and time to remission in first-episode psychosis: a two-year outcome study. Psychol Med. 2006 36(5):649-58.

150. van Os J, Wright $P$, Murray R. Risk factors for emergence and persistence of psychosis. In: Weller MPI, van Kampen DP, editors. Progress in Clinical Psychiatry: Number 1. Philadelphia: W.B. Saunders Company; 1997.

151. Allardyce J, Morrison G, McCreadie RG, van Os J, Kelly J, Murray RM. Schizophrenia is not disappearing in south-west Scotland. Br J Psychiatry. 2000 177(1):38-41.

152. McGuffin P, Farmer A, Harvey I. A polydiagnostic appliciation of operational criteria in studies of psychotic illness: Development and reliability od the OPCRIT system. Arch Gen Psychiatry. 1991 48(8):764-70.

153. Allardyce J, McCreadie RG, Morrison G, van Os J. Do symptom dimensions or categorical diagnoses best discriminate between known risk factors for psychosis? Soc Psychiatry Psychiatr Epidemiol. 2007 42(6):429-37.

154. World Health Organization. Life Chart Schedule. Geneva: World Health Organization; 1992.

155. Levinson DF, Mowry BJ, Escamilla MA, Faraone SV. The Lifetime Dimensions of Psychosis Scale (LDPS): Description and interrater reliability. Schizophr Bull. 2002 28(4):683-95.

156. Muthen LK, Muthen BO. Mplus user's guide. Los Angeles: Muthen \& Muthen; 2006.

157. McLachlan G, Peel D. Finite Mixture Models. New York: John Wiley \& Sons; 2000.

158. Lo Y, Mendell NR, Rubin DB. Testing the number of components in a normal mixture. Biometrika. $200188(3): 767-78$.

159. Akaike H. Factor analysis and the AIC. Psychometrica. 1987 52:317-32.

160. Schwartz G. Estimating the dimensions of a model. Annals of Statistics. 1978 6:461-4.

161. Ramaswamy V, DeSarbo W, Reibstein D, Robinson W. An empirical pooling approach for estimating marketing mix elasticities with PIMS data. Marketing Science. 1993 12:103-24.

162. Rubin DB. Inference and missing data. Biometrika. 1976 63(3):581-92.

163. StataCorp. STATA Statistical Software: Release 9.2. Texas: College Station; 2006.

164. Royston P. Multiple imputation of missing values: update of ice. Stata Journal. 2005 5:527-36.

165. DeLisi LE. The significance of age of onset for schizophrenia. Schizophr Bull. 1992 18(2):209-15.

166. Barta PE, Powers RE, Aylward EH, Chase GA, Harris GJ, Rabins PV, et al. Quantitative MRI volume changes in late onset schizophrenia and Alzheimer's disease compared to normal controls. Psychiatry Res. 1997 68(2-3):65.

167. Lesser IM, Miller BL, Swartz JR, Boone KB, Mehringer CM, Mena I. Brain imaging in late-life schizophrenia and related psychoses. Schizophr Bull. 1993 19(4):773-82.

168. Sachdev P, Brodaty H, Rose N, Cathcart S. Schizophrenia with onset after age 50 years. 2: Neurological, neuropsychological and MRI investigation. Br J Psychiatry. 1999 175:416-21.

169. Casanova M, Stevens J, Brown R, Royston C, Bruton C. Disentangling the pathology of schizophrenia and paraphrenia. Acta Neuropathologica. 2002 103(4):313-20.

170. Riecher-Rössler A, Häfner H, Häfner-Ranabauer W, Löffler W, Reinhard I. Late-onset schizophrenia versus paranoid psychoses: A valid diagnostic distinction? Am J Geriatr Psychiatry. 2003 11(6):595-604. 
171. Barnes DE, Alexopoulos GS, Lopez OL, Williamson JD, Yaffe K. Depressive symptoms, vascular disease, and mild cognitive impairment: Findings from the Cardiovascular Health Study. Arch Gen Psychiatry. 2006 63(3):273-9.

172. Dufouil C, Fuhrer R, Dartigues J-F, Alperovitch A. Longitudinal analysis of the association between depressive symptomatology and cognitive deterioration. Am J Epidemiol. 1996 144(7):634-41.

173. Henderson AS, Korten AE, Jacomb PA, Mackinnon AJ, Jorm AF, Christensen $H$, et al. The course of depression in the elderly: a longitudinal community-based study in Australia. Psychol Med. 1997 27(1):119-29.

174. Bassuk SS, Berkman LF, Wypij D. Depressive symptomatology and incident cognitive decline in an elderly community sample. Arch Gen Psychiatry. 1998 55(12):1073-81.

175. Marquis S, Moore MM, Howieson DB, Sexton G, Payami H, Kaye JA, et al. Independent predictors of cognitive decline in healthy elderly persons. Arch Neurol. 2002 59(4):601-6.

176. Vinkers DJ, Gussekloo J, Stek ML, Westendorp RGJ, van der Mast RC. Temporal relation between depression and cognitive impairment in old age: prospective population based study. BMJ. 2004 329(7471):881.

177. Ganguli M, Du Y, Dodge HH, Ratcliff GG, Chang C-CH. Depressive symptoms and cognitive decline in late life: A prospective epidemiological study. Arch Gen Psychiatry. 2006 63(2):153-60.

178. Jonker C, Schmand B, Lindeboom J, Havekes LM, Launer L. Association between apolipoprotein E epsilon 4 and the rate of cognitive decline in community-dwelling elderly individuals with and without dementia. Arch Neurol. 1998 55(8):1065-9.

179. Wilson RS, Bienias JL, Berry-Kravis E, Evans DA, Bennett DA. The apolipoprotein E epsilon2 allele and decline in episodic memory. J Neurol Neurosurg Psychiatry. 2002 73(6):672-7.

180. Bretsky P, Guralnik JM, Launer L, Albert M, Seeman TE. The role of APOE- epsilon4 in longitudinal cognitive decline: MacArthur Studies of Successful Aging. Archives of Neurology. 2003 60(7):107781.

181. Blair CK, Folsom AR, Knopman DS, Bray MS, Mosley TH, Boerwinkle E, et al. APOE genotype and cognitive decline in a middle-aged cohort. Archives of Neurology. 2005 64(2):268-76.

182. Packard CJ, Westendorp RGJ, Stott DJ, Caslake MJ, Murray HM, Shepherd J, et al. Association between apolipoprotein $E$ epsilon4 and cognitive decline in elderly adults. Journal of the American Geriatrics Society. 2007 55(11):1777-85.

183. Krishnan KRR, Tupler LA, Ritchie J, James C., McDonald WM, Knight DL, Nemeroff CB, et al. Apolipoprotein E-epsilon4 frequency in geriatric depression. Biol Psychiatry. 1996 40(1):69-71.

184. Jackson EJ, Rajah S, Morris C, Ballard C, Thomas AJ, O'Brien JT. Is apolipoprotein e4 associated with cognitive decline in depression? Int J Geriatr Psychiatry. 2001 16(4):436-7.

185. Butters MA, Sweet RA, Mulsant BH, Kamboh MI, Pollock BG, Begley AE, et al. APOE is associated with age-of-onset, but not cognitive functioning, in late-life depression. Int J Geriatr Psychiatry. 2003 18(12):1075-81.

186. Jolles J, Houx PJ, van Boxtel MP, Ponds R. The Maastricht Aging Study: determinants of cognitive aging. Maastricht: Neuropsych Publishers; 1995.

187. Metsemakers JFM, Höppener P, Knottnerus JA, Kocken RJJ, Limonard CBG. Computerized health information in the Netherlands: a registration network of family practices. Br J Gen Pract. 1992 42:102-6.

188. Arrindell WA, Ettema JHM. SCL-90. Handleiding bij een multidimensionele psychopathologieindicator [SCL-90. Manual of a multidimensional psychopathology of indicator]. Lisse, the Netherlands: Swets Test Publishers; 2003.

189. Dekker J, Koelen JA, Peen J, Schoevers RA, Gijsbers-van Wijk C. Gender differences in clinical features of depressed outpatients: preliminary evidence for subtyping of depression? Women Health. 2007 46(4):19-38.

190. Bekers O, op den Buijsch RAM, de Vries JE, Wijnen PAHM, van Dieijen-Visser MP. Capillary electrophoretic detection in apolipoprotein E genotyping. Electrophoresis. 2002 23(12):1878-81.

191. van der Elst W, van Boxtel MP, van Breukelen GJ, Jolles J. Rey's verbal learning test: normative data for 1855 healthy participants aged 24-81 years and the influence of age, sex, education, and mode of presentation. JINS. 2005 11(3):290-302.

192. Stroop J. Studies of interference in serial verbal reactions. Journal of Experimental Psychology. 1935 18:643-62. 
193. van der Elst W, van Boxtel MPJ, van Breukelen GJP, Jolles J. The Stroop Color-Word Test: influence of age, sex, and education; and normative data for a large sample across the adult age range. Assessment. 2006 13(1):62-79.

194. van der Elst W, van Boxtel MP, van Breukelen GJ, Jolles J. The Letter Digit Substitution Test: normative data for 1,858 healthy participants aged 24-81 from the Maastricht Aging Study (MAAS): influence of age, education, and sex. J Clin Exp Neuropsychol. 2006 28(6):998-1009.

195. Wechsler D. Manual for the Wechsler Adult Intelligence Scale-Revised. New York: Psychological Cooperation; 1981.

196. Folstein MF, Folstein SE, McHugh PR. Mini Mental State. A pratical method for grading the cognitive state of patients for the clinician. J Psychiatr Res. 1975 12:189-98.

197. Luteijn F, van der Ploeg FAE. Handleiding Groninger Intelligentietest (GIT) [Manual Groningen Intelligence Test]. Lisse, the Netherlands: Swets and Zeitlinger; 1983.

198. Baars MA, van Boxtel MP, Dijkstra JB, Visser PJ, van den Akker M, Verhey FR, et al. Predictive value of mild cognitive impairment for dementia. The influence of case definition and age. Dement Geriatr Cogn Disord. 2009 27(2):173-81.

199. Petersen RC, Morris JC. Mild cognitive impairment as a clinical entity and treatment target. Arch Neurol. 2005 62(7):1160-3.

200. Lezak MD, Howieson DB, Loring DW. Neuropsychological Assessment. 4 ed. Oxford, UK: Oxford University Press; 2004.

201. Poirier J. Apolipoprotein E and Alzheimer's disease. A role in amyloid catabolism. Annals of the New York Academy of Sciences. 2000 924:81-90.

202. Wilson RS, Arnold SE, Beck TL, Bienias JL, Bennett DA. Change in depressive symptoms during the prodromal phase of Alzheimer Disease. Arch Gen Psychiatry. 2008 65(4):439-45.

203. Geerlings MI, den Heijer T, Koudstaal PJ, Hofman A, Breteler MMB. History of depression, depressive symptoms, and medial temporal lobe atrophy and the risk of Alzheimer disease. Archives of Neurology. 2008 70(15):1258-64.

204. Kessing LV, Andersen PK. Does the risk of developing dementia increase with the number of episodes in patients with depressive disorder and in patients with bipolar disorder? J Neurol Neurosurg Psychiatry. 2004 75(12):1662-6.

205. Schweitzer I, Tuckwell V, Ames D, O'Brien J. Structural neuroimaging studies in late-life depression: A review. World Journal of Biological Psychiatry. 2001 2(2):83 - 8.

206. Gualtieri CT, Johnson LG. Age-related cognitive decline in patients with mood disorders. Progress in Neuro-Psychopharmacology and Biological Psychiatry. 2008 32(4):962-7.

207. Thomas AJ, Gallagher P, Robinson L, Porter RJ, Young AH, Ferrier IN, et al. A comparison of neurocognitive impairment in younger and older adults with major depression. Psychol Med. 2008:1-9.

208. Herrmann LL, Goodwin GM, Ebmeier KP. The cognitive neuropsychology of depression in the elderly. Psychol Med. 2007 37(12):1693-702.

209. Butters MA, Becker JT, Nebes RD, Zmuda MD, Mulsant BH, Pollock BG, et al. Changes in cognitive functioning following treatment of late-life depression. Am J Psychiatry. 2000 157(12):1949-54.

210. Gallassi R, Di Sarro R, Morreale A, Amore M. Memory impairment in patients with late-onset major depression: The effect of antidepressant therapy. J Affect Dis. 2006 91(2-3):243-50.

211. Mandelli L, Serretti A, Colombo C, Florita M, Santoro A, Rossini D, et al. Improvement of cognitive functioning in mood disorder patients with depressive symptomatic recovery during treatment: An exploratory analysis. Psychiatry and Clinical Neurosciences. 2006 60(5):598-604.

212. Butters MA, Whyte EM, Nebes RD, Begley $A E$, Dew MA, Mulsant BH, et al. The nature and determinants of neuropsychological functioning in late-life depression. Arch Gen Psychiatry. 2004 61(6):587-95.

213. Delaloye C, Baudois S, de Bilbao F, Dubois Remund C, Hofer F, Lamon M, et al. Cognitive impairment in late-onset depression. Limited to a decrement in information processing resources? Eur Neurol. 2008 60(3):149-54.

214. Roth M, Huppert FA, Mountjoy CQ, Tym E. The Cambridge Examination for Mental Disorders of the Elderly-Revised. Cambridge: Cambridge University Press; 1999.

215. American Psychiatric Association. Diagnostic and Statistical Manual of Mental Disoders. 4 ed. Washington DC: American Psychiatric Association; 1994. 
216. Montgomery S, Asberg M. A new depression scale designed to be sensitive to change. $\mathrm{Br} \mathrm{J}$ Psychiatry. 1979 134(4):382-9.

217. Hawley CJ, Gale TM, Sivakumaran T. Defining remission by cut off score on the MADRS: selecting the optimal value. J Affect Dis. 2002 72(2):177-84.

218. Zimmerman M, Chelminski I, Posternak M. A review of studies of the Montgomery-Asberg Depression Rating Scale in controls: implications for the definition of remission in treatment studies of depression. Int Clin Psychopharmacol. 2004 19(1):1-7.

219. Rey A. Clinical Examination in Psychology. Paris: University of Paris; 1964.

220. Cegalis J, Bowlin J. VIGIL: Software for the Assessment of Attention. Forthought: Nashua, NH; 1991.

221. Levy R, Working Party of the International Psychogeriatric Association in collaboration with the World Health Organization. Aging-Associated Cognitive Decline. Int Psychogeriatr. 1994 6(01):638.

222. Petersen RC, Smith GE, Waring SC, Ivnik RJ, Tangalos EG, Kokmen E. Mild cognitive impairment: Clinical characterization and outcome. Arch Neurol. 1999 56(3):303-8.

223. Weiland-Fiedler P, Erickson K, Waldeck T, Luckenbaugh DA, Pike D, Bonne O, et al. Evidence for continuing neuropsychological impairments in depression. J Affect Dis. 2004 82(2):253-8.

224. Airaksinen $E$, Wahlin $\AA$, Larsson $M$, Forsell $Y$. Cognitive and social functioning in recovery from depression: Results from a population-based three-year follow-up. J Affect Dis. 2006 96(1-2):10710.

225. Reppermund S, Zihl J, Lucae S, Horstmann S, Kloiber S, Holsboer F, et al. Persistent cognitive impairment in depression: The role of psychopathology and altered hypothalamic-pituitaryadrenocortical (HPA) system regulation. Biol Psychiatry. 2007 62(5):400-6.

226. Lavretsky HMD, Kurbanyan KBS, Ballmaier MMD, Mintz JPD, Toga APD, Kumar AMD, editors. Sex differences in brain structure in geriatric depression. Am J Geriatr Psychiatry; 2004.

227. Thomas AJ, O'Brien JT, Davis S, Ballard C, Barber R, Kalaria RN, et al. Ischemic basis for deep white matter hyperintensities in major depression: A neuropathological study. Arch Gen Psychiatry. 2002 59(9):785-92.

228. O'Brien JT. The "glucocorticoid cascade" hypothesis in man. Br J Psychiatry. 1997 170:199-201.

229. Lloyd AJ, Ferrier IN, Barber R, Gholkar A, Young AH, O'Brien JT. Hippocampal volume change in depression: late- and early-onset illness compared. Br J Psychiatry. 2004 184(6):488-95.

230. Simpson SW, Jackson A, Baldwin RC, Burns A. Subcortical hyperintensities in late-life depression: Acute response to treatment and neuropsychological impairment. Int Psychogeriatr. 1997 9(03):257-75.

231. Kramer-Ginsberg E, Greenwald BS, Krishnan KRR, Christiansen B, Hu J, Ashtari M, et al. Neuropsychological functioning and MRI signal hyperintensities in geriatric depression. Am J Psychiatry. 1999 156(3):438-44.

232. Potter GG, Blackwell AD, McQuoid DR, Payne ME, Steffens DC, Sahakian BJ, et al. Prefrontal white matter lesions and prefrontal task impersistence in depressed and nondepressed elders. Neuropsychopharmacology. 2007 32(10):2135-42.

233. Scheltens $\mathrm{P}$, Barkhof $F$, Leys $D$, Pruvo JP, Nauta JJ, Vermersch $\mathrm{P}$, et al. A semiquantative rating scale for the assessment of signal hyperintensities on magnetic resonance imaging. J Neurol Sci. 1993 114(1):7-12.

234. Simes RJ. An improved Bonferroni procedure for multiple tests of significance. Biometrika. 1986 73:751-4.

235. StataCorp. STATA Statistical Software: Release 10.1. Texas: College Station; 2009.

236. Fernando MS, Ince PG. Vascular pathologies and cognition in a population-based cohort of elderly people. Journal of the Neurological Sciences. 2004 226(1-2):13-7.

237. Alexopoulos GS, Murphy CF, Gunning-Dixon FM, Latoussakis V, Kanellopoulos D, Klimstra S, et al. Microstructural white matter abnormalities and remission of geriatric depression. Am J Psychiatry. 2008 165(2):238-44.

238. Sneed JR, Roose SP, Sackeim HA. Vascular depression: A distinct diagnostic subtype? Biol Psychiatry. 2006 60(12):1295-8.

239. Sneed JR, Rindskopf D, Steffens DC, Krishnan KRR, Roose SP. The vascular depression subtype: Evidence of internal validity. Biol Psychiatry. 2008 64(6):491-7. 
240. Lupien SJ, de Leon M, de Santi S, Convit A, Tarshish C, Nair NPV, et al. Cortisol levels during human aging predict hippocampal atrophy and memory deficits. Nature Neuroscience. 1998 1(1):69-73.

241. Ballmaier M, Narr KL, Toga AW, Elderkin-Thompson V, Thompson PM, Hamilton L, et al. Hippocampal morphology and distinguishing late-onset from early-onset elderly depression. Am J Psychiatry. 2008 165(2):229-37.

242. Sheline $\mathrm{YI}$, Sanghavi M, Mintun MA, Gado MH. Depression duration but not age predicts hippocampal volume loss in medically healthy women with recurrent major depression. Journal of Neuroscience. 1999 19(12):5034-43.

243. Bleuler M. Die spätschizophrenen Krankheitsbilder. Neurologie. 1943 15:259-90.

244. Kleist K. Die Involutionsparanoia. Allgemeine Zeitschrift fuer Psychiatrie. 1913 70:1-134.

245. Albrecht O. Die funktionellen Psychosen des Rueckbildungsalters. Zeitschrift fuer die gesamte Neurologie und Psychiatrie. 1914 22(1):306-44.

246. Bergemann N, Parzer P, Nagl I, Salbach B, Runnebaum B, Mundt C, et al. Acute psychiatric admission and menstrual cycle phase in women with schizophrenia. Archives of Women's Mental Health. 2002 5(3):119-26.

247. Kulkarni J. Oestrogen--a new treatment approach for schizophrenia? Med J Aust. 2009 190(4 Suppl):S37-8.

248. Cohen RZ, Seeman MV, Gotowiec A, Kopala L. Earlier puberty as a predictor of later onset of schizophrenia in women. American Journal of Psychiatry. 1999 156(7):1059-65.

249. Hochman KM, Lewine RR. Age of menarche and schizophrenia onset in women. Schizophrenia Research. 2004 69(2-3):183-8.

250. Ellison JM, Harper DG, Berlow Y, Zeranski L. Beyond the "C" in $\mathrm{MCl}$ : noncognitive symptoms in amnestic and non-amnestic mild cognitive impairment. CNS Spectrums. 2008 13(1):66-72.

251. Geda YE, Roberts RO, Knopman DS, Petersen RC, Christianson TJH, Pankratz VS, et al. Prevalence of neuropsychiatric symptoms in mild cognitive impairment and normal cognitive aging: Population-based study. Arch Gen Psychiatry. 2008 65(10):1193-8.

252. Geda YE, Roberts RO, Knopman DS, Petersen RC, Christianson TJH, Pankratz VS, et al. Prevalence of neuropsychiatric symptoms in mild cognitive impairment and normal cognitive aging: Population-based study. Arch Gen Psychiatry. 2008 65(10):1193-8.

253. Almeida OP. The neuropsychology of schizophrenia in late life. In: Howard R, Rabins PV, Castle DJ, editors. Late Onset Schizophrenia. Petersfield, UK: Wrightson Biomedical Publishing Ltd; 1999. p. 181-9.

254. Walterfang M, Mocellin R, Velakoulis D, Pantelis C. Neuroimaging in late-onset schizophrenia. In: Hasset A, Ames D, Chiu E, editors. Psychosis In The Eldery. London: Taylor \& Francis; 2005.

255. Förstl H, Dalgalarrondo P, Riecher-Rössler A, Lotz M, Geiger-Kabisch C, Hentschel F. Organic factors and the clinical features of late paranoid psychosis: a comparison with Alzheimer's disease and normal ageing. Acta Psychiatr Scand. 1994 89(5):335-40.

256. Sachdev P, Brodaty $H$, Rose N, Haindle W. Regional cerebral blood flow in late-onset schizophrenia: a SPECT study using 99mTc-HMPAO. Schizophr Res. 1997 27(2-3):105-17.

257. Rivkin P, Kraut M, Barta P, Anthony J, Arria AM, Pearlson G. White matter hyperintensity volume in late-onset and early-onset schizophrenia. Int J Geriatr Psychiatry. 2000 15(12):1085-9.

258. Casanova MF, Lindzen EC. Changes in gray-/white-matter ratios in the parahippocampal gyri of late-onset schizophrenia patients. Am J Geriatr Psychiatry. 2003 11(6):605-9.

259. Teper E, O'Brien JT. Vascular factors and depression. Int J Geriatr Psychiatry. 2008 23(10):9931000.

260. Blumberger DM, Daskalakis ZJ, Mulsant BH. Biomarkers in geriatric psychiatry: searching for the holy grail? Current Opinion in Psychiatry. 2008 21(6):533-9.

261. O'Brien J. Dementia associated with psychiatric disorders. Int Psychogeriatr. 2005 17(Supplement S1):S207-S21.

262. Quraishi S, Frangou S. Neuropsychology of bipolar disorder: a review. J Affect Dis. 2002 72(3):20926.

263. Gildengers AG, Butters MA, Seligman K, McShea M, Miller MD, Mulsant BH, et al. Cognitive functioning in late-life bipolar disorder. Am J Psychiatry. 2004 161(4):736-8.

264. Anand A, Li Y, Wang Y, Lowe MJ, Dzemidzic M. Resting state corticolimbic connectivity abnormalities in unmedicated bipolar disorder and unipolar depression. Psychiatry Research: Neuroimaging. 2009 171(3):189-98. 
265. Visser PJ, Verhey F, Knol DL, Scheltens P, Wahlund L-O, Freund-Levi Y, et al. Prevalence and prognostic value of CSF markers of Alzheimer's disease pathology in patients with subjective cognitive impairment and mild cognitive impairment in the DESCRIPA study: a prospective, casecontrol study. Lancet Neurology. In press.

266. O'Brien JT, Erkinjuntti T, Reisberg B, Roman G, Sawada T, Pantoni L, et al. Vascular cognitive impairment. The Lancet Neurology. 2003 2(2):89-98.

267. Satz P. Brain reserve capacity on symptom onset after brain injury: a formulation and review of evidence for threshold theory. Neuropsychology. 1993 7:273-95.

268. Stern Y. What is cognitive reserve? Theory and research application of the reserve concept. JINS. 2002 8:448-60.

269. Barnett JH, Salmond CH, Jones PB, Sahakian BJ. Cognitive reserve in neuropsychiatry. Psychol Med. 2006 36(08):1053-64.

270. Butters MA, Young JB, Lopez O, Aizenstein HJ, Mulsant BH, Reynolds CF, 3rd, et al. Pathways linking late-life depression to persistent cognitive impairment and dementia. Dialogues Clin Neurosci. 2008 10(3):345-57.

271. Arunpongpaisal S, Ahmed I, Aqeel N, Paholpak S. Antipsychotic drug treatment for elderly people with late-onset schizophrenia. The Cochrane Database of Systematic Reviews: Reviews 2003 Issue 2. 2003.

272. Zarit SH, Zarit JM. Mental Disorders in Older Adults: Fundamentals of Assessment and Treatment. 2nd ed. New York: Guilford Press; 2007.

273. Salzman C, Tune L. Neuroleptic treatment of late-life schizophrenia. Harvard Review of Psychiatry. 2001 9(2):77 - 83.

274. Jeste DV, Dolder CR, Nayak GV, Salzman C. Atypical antipsychotics in elderly patients with dementia or schizophrenia: review of recent literature. Harvard Review of Psychiatry. 2005 13(6):340 - 51. 


\section{Summary}

Research into psychosis and depression has made big advances in the past, including insights into risk factors, underlying neurobiology and course. Yet, such research has mainly focussed on young adults and relatively neglected middle-aged and older patients, especially if their disorder first emerges in the second half of life. In addition, many preconceptions still exist regarding the number of people affected as well as their prognosis. Chapter 1 of this thesis summarizes the main findings in the field of psychosis and depression in later life. Both conditions cause substantial suffering for the person affected and their beloved ones, while their treatment lays considerable costs on society. The ageing of the population will inevitably lead to an increase in the number of patients suffering from neuropsychiatric disorders. Accordingly, what has been considered a rare disorder in the past might become a major public health concern in the nearby future. It has already been acknowledged that our mental health systems are ill prepared for this situation and that current knowledge regarding these disorders is mainly based on research in younger cohorts. Hence, this thesis aims to increase that knowledge base by studying psychosis and depression in the second half of life. For this ends, existing data from three large epidemiological studies and one comprehensive clinical case-control study were analyzed.

The thesis consists of two parts. The first part comprises two studies into late onset psychosis, its risk in the general population and its clinical course over five years in first-episode patients. The second part includes three longitudinal studies into the neuropsychology and neurobiology of late life depression.

In chapter 2, the risk for onset of psychotic symptoms is studied in 7,076 individuals aged 18 to 64 years from a general population sample. Data from the Netherlands Mental Health Survey and Incidence Study (NEMESIS) were used to analyze risk differences among three age groups. After exclusion of participants with clinically relevant psychotic symptoms on the Composite International Diagnostic Interview (CIDI) at baseline, the percentage of those developing firstever symptoms at follow-up did not differ significantly between the age groups and ranged from $0.3 \%$ in the oldest age group (50 - 64 years) to $0.4 \%$ in the youngest (18-34) and middle age group (35 - 49 years). The risk for developing psychotic symptoms in the youngest age group increased significantly when people also reported having had depressive symptoms earlier in life, but the effect of depression declined in the later age groups. Likewise, neuroticism increased the psychosis risk across all age groups, yet this effect was most pronounced in the youngest age group and then declined as age increased. Although family history for schizophrenia and hearing impairment also seemed to moderate the psychosis risk across age groups, too, this remained at a trend level and too little participants were exposed to these risk factors to exclude the possibility of a spurious finding. What is more, no effect modification was observed for urbanization, lifetime 
cannabis use, lifetime manic symptoms, family history of psychiatric treatment, or single living status. Despite considerable similarities in the risk profile for psychotic symptoms, these findings suggest aetiological variation for psychosis onset across age groups, including less emotional and stress reactivity with psychosis onset in later life.

Chapter 3 reports on differences in prognosis of first-episode psychosis between men and women, and between patients with an early (14-41 years), late (42-64 years) or very late onset (65-94 years). Information on the symptomatic, functional and psychosocial course (using items from the Operational Checklist of Psychotic Disorders, Lifetime Dimensions of Psychosis Scale and the World Health Organization Life Chart Schedule) within five years after first presentation to any psychiatric service were obtained from a population of 463 incident psychoses within a well-defined catchment area in rural South Scotland. Women, who were overrepresented in the late and very late onset group, displayed a more favourable outcome pattern compared to men, including milder delusions, fewer negative symptoms, less deterioration from baseline functioning, fewer hospital readmissions and shorter psychotic episodes. Similarly, a later age of onset was associated with better outcome, too. However, when the interaction between gender and onset age was studied, men displayed poor outcome in the early onset class but had a more favorable prognosis with onset in later life, whereas women tended to have a more unfavorable prognosis just in the very late onset class, including less likelihood of remission and longer episodes. These findings challenge the ideas that psychosis is more benign in women and with increasing age of onset. In addition, it underscores the need to study the effects of gender and age of onset simultaneously and in non-linear models.

Opening the second part of this thesis, chapter 4 presents a study examining the prognostic value of depression for cognitive decline in a general population sample of older adults. In the Maastricht Aging Study (MAAS), depressive symptoms (SCL90) and cognitive functioning (memory, attention, processing speed, global cognition (MMSE)) were repeatedly assessed in 598 non-demented participants aged 60 years or older. Baseline depressive symptoms were associated with accelerated decline in all cognitive domains over the six-year follow-up and predicted incident $\mathrm{MCl}$, especially of the amnestic multi-domain variant. High levels of depression, i.e. scores within the upper quartile on the SCL-90 depression scale, predicted faster decline in memory, processing speed and global cognition in a dose-response relation. Participants who had persistently high levels of depression at follow-up were particularly likely to deteriorate. Participants in the upper depression quartile at baseline also had a five times higher risk for amnestic multidomain $\mathrm{MCl}$ compared to participants with lower depression levels. These associations were furthermore the same for carriers and non-carriers of the APOE $\varepsilon-4$ allele. The findings strongly support the idea that depression is a risk factor for accelerated cognitive decline and $\mathrm{MCl}$. The risk can work independent of genetic moderation by APOE associated with Alzheimer's disease. 
The case-control study in chapter $\mathbf{5}$ examines to what degree cognitive deficits persist despite antidepressant treatment and reduction in depressive symptoms, and whether there are differences in pattern and course of cognitive impairment in early and late onset patients. Out of 67 elderly patients (age 60 years and older) with DSM-IV major depression, half exhibited a generalized cognitive impairment (CAMCOG total score 1.5 standard deviations below the control group's mean) that persisted after 18 months. Compared to 37 healthy controls, patients performed worse across all cognitive domains (memory, executive functioning, processing speed) at all time points and without substantial variability due to current mood, remission status or antidepressant treatment. Late age of onset was significantly associated with decline in memory and executive functioning. Slowed processing speed was a partial mediator of some deficits, but was insufficient to fully explain differences in cognitive functions between patients and controls. Four year followup data suggest impairments persist, but do not further decline. The study shows that cognitive deficits in late life depression often persist, affect multiple domains and are related to trait rather than state effects. Differences in severity and course between early and late onset depression furthermore suggest different pathogenic processes.

Based in the findings in the previous chapter, chapter 6 presents a study into the possible neurobiological mechanisms underlying the continuing cognitive impairments in late life depression. Using the same sample described above, 35 patients and 29 healthy controls underwent MRI scanning and saliva collection in order to analyze the relationship between baseline cortisol levels, whole brain, frontal lobe and hippocampal volumes, severity of white matter hyperintensities and cognitive function at 18 months follow-up. Differences between patients and controls in memory and executive functions follow-up scores were associated with ratings of white matter hyperintensities, especially of the deep white matter and periventricular regions. Compared to healthy controls in the lowest tertile of white matter hyperintensities, patients within the upper tertile scored two and three standard deviations lower on tests of executive functions and memory, respectively. No biological measure related significantly to group differences in processing speed, and there were no significant interactions between group and cortisol levels, or group and volumetric MRI measures on cognitive outcome. The study highlights the relevance of white matter hyperintensities for continuing cognitive impairments and suggests that cerebrovascular changes rather than glucocorticoid-mediated brain damage are responsible for the persistence of cognitive deficits in depressed older adults.

Finally, chapter 7 provides a general discussion of the findings described in this thesis. Clinical and research implications resulting from the presented studies are outlined. Rather than being completely unrelated phenotypes, psychosis and depression - and maybe other neuropsychiatric disorders, e.g. late life bipolar disorder - show intriguing similarities as to the potential role of vascular pathology 
and neurodegenerative processes for their onset, persistence and prognosis. Both may exert their effects by lowering someone's cognitive reserve and hence increasing an individual's vulnerability for further cognitive decline and dementia. 


\section{Samenvatting (Dutch summary)}

Onderzoek naar psychose en depressie heeft in het verleden grote vooruitgang geboekt wat betreft inzicht in risicofactoren, onderliggende neurobiologie en beloop. Echter, dergelijk onderzoek heeft zich voornamelijk op jongeren gericht terwijl patiënten op middelbare en oudere leeftijd relatief genegeerd werden, met name wanneer de stoornis zich pas in de tweede levenshelft voor het eerst manifesteert. Bovendien bestaat er nog steeds veel misverstand over het aantal betrokken mensen en hun prognose. Hoofdstuk 1 van dit proefschrift vat de hoofdbevindingen op het gebied van psychose en depressie op later leeftijd samen. Beide aandoeningen veroorzaken enorm veel leed bij patiënten en hun naasten, terwijl de behandeling behoorlijke maatschappelijke kosten met zich mee brengt. De vergrijzing van de maatschappij leidt er onvermijdelijk toe dat het aantal patiënten met neuropsychiatrische stoornissen zal stijgen. Wat van oudsher als een zeldzame stoornis werd beschouwd zal in de nabije toekomst een belangrijk gezondheidsprobleem kunnen worden. Het werd al aanvaard dat ons geestelijk gezondheidssysteem niet helemaal goed voorbereid is op deze situatie en dat onze huidige kennis over deze stoornissen voornamelijk gebaseerd is op onderzoek bij jongeren. Het doel van dit proefschrift is dan ook om deze kennisbasis te verrijken door psychose en depressie in de tweede levenshelft te bestuderen. Voor dit doel werden reeds bestaande data van drie grote epidemiologische studies en één uitputtende case-control studie geanalyseerd.

Dit proefschrift bevat twee delen. Het eerste deel bevat twee studie naar laat ontstane psychose, het risico ervoor in de algemene populatie en het klinische beloop over vijf jaar in patiënten met een eerste psychotische episode. Het tweede deel bevat drie longitudinale studies naar de neuropsychologie en neurobiologie van depressie bij ouderen.

In hoofdstuk 2 wordt het risico voor het ontstaan van psychotische symptomen in 7076 individuen van de algemene bevolking met een leeftijd van 18 t/m 64 jaar bestudeerd. Data van de Netherlands Mental Health Survey and Incidence Study (NEMESIS) werden gebruikt om verschillen in psychose risico tussen drie leeftijdsgroepen te analyseren. Nadat mensen met klinisch relevante symptomen op baseline werden uitgesloten bleek dat het percentage van deelnemers met nieuw ontstane symptomen niet significant verschilde en tussen $0.3 \%$ in de oudste groep (50-64 jaar) en de $0.4 \%$ in de jongste (18-34 jaar) en middelste leeftijdsgroep (35-49 jaar) schommelde. Het risico voor het ontwikkelen van psychotische symptomen steeg op jonge leeftijd significant wanneer mensen rapporteerden dat ze eerder in hun leven wel eens depressieve symptomen hebben gehad, maar het effect van depressie nam met stijgende leeftijd af. Op een soortgelijke manier verhoogde neuroticisme het psychose risico over alle leeftijdsgroepen heen, echter, het effect was meest duidelijk aanwezig in de jongste leeftijdsgroep en nam af naarmate de leeftijd toenam. Hoewel een familiaire belasting voor schizofrenie 
en gehoorsproblemen het psychoserisico over leeftijdsgroepen heen leek te modereren, bleef dit slechts een statistische trend en was het aantal personen dat überhaupt aan deze risicofactoren was blootgesteld te klein om uit te kunnen sluiten dat dit toevalsbevindingen waren. Verder werd er geen effectmodificatie geobserveerd voor urbanisatie, cannabisgebruik, manische symptomen, bestaan van familieleden met (brede) psychische problemen die psychiatrische behandeling noodzakelijk maken of alleenstaand zijnde. Ondanks grote overlap in het risicoprofiel voor psychotische symptomen suggereren deze bevindingen enige etiologische variatie voor het ontstaan van psychose over leeftijdsgroepen heen, waaronder minder emotionele en stressgerelateerde reactiviteit indien de psychose zich op latere leeftijd voordoet.

Hoofdstuk 3 rapporteert verschillen in de prognose van een eerste psychotische episode tussen mannen en vrouwen en tussen patiënten met een vroeg (18-41 jaar), laat (42-64 jaar) of zeer laat ontstaan (65-94 jaar). Informatie omtrent het symptomatisch, functioneel en psychosociaal beloop (gebruik makend van items van de Operational Checklist of Psychotic Disorders, Lifetime Dimensions of Psychosis Scale en de World Health Organization Life Chart Schedule) over vijf jaar na het eerste contact met de geestelijke gezondheidszorg werd gehaald uit een populatie van 463 incidente psychosen in een goed omschreven catchment area in landelijk Zuidwest-Schotland. Vrouwen waren oververtegenwoordigd in de laat en zeer laat ontstane groep en hadden over het algemeen een gunstigere prognose dan mannen, met onder andere mildere wanen, minder negatieve symptomen, minder functionele achteruitgang, minder ziekenhuisopnames en kortere psychotische episoden. Op een soortgelijke manier was een later ontstaan ook geassocieerd met een beter uitkomst. Echter, wanneer de interactie tussen geslacht en leeftijd van ontstaan werd bestudeerd, bleek dat mannen vooral in de vroeg ontstane groep een ongunstige prognose kenden maar een betere uitkomst op later leeftijd hadden, terwijl vrouwen in de zeer laat ontstane groep juist een ongunstige prognose hadden, met onder andere een kleinere kans op remissie en langere episoden. Deze bevindingen dagen de opvattingen uit dat psychose goedaardiger verloopt bij vrouwen en met toenemende leeftijd van ontstaan. Bovendien benadrukken ze het belang om de effecten van geslacht en leeftijd van ontstaan simultaan en in niet-lineaire modellen te onderzoeken

Het tweede deel van dit proefschrift begint door in hoofdstuk 4 een studie naar de prognostische waarde van depressie voor cognitieve achteruitgang bij ouderen uit de algemene bevolking te presenteren. In de Maastricht Ageing Study (MAAS) werden depressieve symptomen (SCL-90) en cognitief functioneren (geheugen, aandacht, snelheid van informatieverwerking, globaal cognitief functioneren (MMSE)) op drie meetmomenten onderzocht in 598 niet-demente deelnemers met een leeftijd van 60 jaar en ouder. Baseline depressieve symptomen waren geassocieerd met snellere achteruitgang op alle cognitieve domeinen tijdens de zes jaar follow-up en voorspelde incidente milde cognitieve stoornissen (MCl), met name van de amnestische multi-domein variant. Een hoge mate van depressie, 
d.w.z. scores in het bovenste kwartieL van de SCL-90 depressie schaal, voorspelde versnelde achteruitgang in geheugen, snelheid van informatieverwerking en globaal cognitief functioneren in een dosisrespons relatie. Dit was vooral het geval voor deelnemers die een hoog niveau van depressie bleven vertonen op de followup metingen. Deelnemers in het bovenste depressie kwartiel hadden ook een vijf keer groter risico voor amnestisch multi-domein $\mathrm{MCl}$ vergeleken met deelnemers met een lager niveau van depressie. Deze associaties waren verder gelijk voor dragers en niet-dragers van het APOE $\varepsilon-4$ allel. De bevindingen ondersteunen het idee dat depressie een risicofactor is voor versnelde cognitieve achteruitgang en $\mathrm{MCl}$ in sterke mate. Het risico kan onafhankelijk werken van genetische moderatie door APOE, dat geassocieerd is met de ziekte van Alzheimer.

De case-control studie in hoofdstuk $\mathbf{5}$ onderzoekt in welke mate cognitieve stoornissen persisteren ondanks behandelingen met antidepressiva en symptoomreductie, en of er verschillen zijn in het profiel en het beloop van cognitieve stoornissen tussen vroeg en laat ontstane patiënten. Uit 67 oudere patiënten (leeftijd 60 jaar en ouder) met een DSM-IV depressieve stoornis vertoonde de helft een algemene cognitieve stoornis (CAMCOG totaalscore van 1.5 standaarddeviatie onder het gemiddelde van de controle groep) die aanhield na 18 maanden. In vergelijking met 37 gezonde controles presteerden de patiënten zwakker op alle cognitieve domeinen (geheugen, executieve functies, snelheid van informatieverwerking), op alle meetmomenten en zonder substantiële variabiliteit ten gevolg van actuele symptoomsterkte, remissie status of antidepressiva gebruik. Een leeftijd van ontstaan $\geq 60$ jaar was geassocieerd met een significante achteruitgang in geheugen en executieve functies. Een vertraging in de snelheid van informatieverwerking was een partiële moderator van cognitieve stoornissen in andere domeinen, maar kon de verschillen in cognitief functioneren tussen patiënten en controles niet uitputtend verklaren. Data van de vier jaar follow-up meting suggereren dat stoornissen blijven aanhouden, echter zonder verder achteruit te gaan. De studie laat zien dat de cognitieve stoornissen van depressieve ouderen vaak van blijvende aard zijn, meerdere cognitieve domeinen betreffen en eerder aan trait in plaats van aan state effecten verbonden zijn. Verschillen in de ernst en beloop tussen vroeg en laat ontstane depressie doen bovendien vermoeden dat er verschillende pathogene processen aan ten grondslag liggen.

Voortbordurend op de resultaten uit het voorgaande chapiter presenteert hoofdstuk 6 een studie naar potentiële neurobiologische processen die aan de aanhoudende cognitieve stoornissen van depressieve ouderen ten grondslag zouden kunnen liggen. Gebruik makend van de boven beschreven steekproef ondergingen 35 patiënten en 29 gezonde controles MRI scanning en speekselcollectie om de relatie tussen baseline cortisol concentraties, totale hersen-, frontaalkwab- en hippocampusvolume, ernst van witte stof hyperintensiteiten en cognitief functioneren tijdens de 18 maanden follow-up te onderzoeken. Verschillen tussen patiënten en controles in de follow-up scores in geheugen en executieve functies hingen samen met metingen van witte stof 
hyperintensiteiten, met name in de diepe witte stof en periventriculaire gebieden. In vergelijking met gezonde controles uit het onderste tertiel van witte stof hyperintensiteiten presteerden patiënten in het bovenste tertiel respectievelijk twee en drie standaarddeviaties lager op tests voor executieve functies en geheugen. Geen van de biologische maten hing significant samen met groepsverschillen in snelheid van informatieverwerking, en er waren geen significante interacties tussen groep en cortisol concentraties, of tussen groep en volumetrische MRI maten en cognitief functioneren. De studie benadrukt de relevantie van witte stof hyperintensiteiten voor aanhoudende cognitieve stoornissen en suggereert dat cerebrovasculaire afwijkingen in plaats van glucocorticoid-gemedieerde hersenschade verantwoordelijk zijn voor het persisteren van cognitieve stoornissen van depressieve ouderen.

Tot slot bevat hoofdstuk 7 een algemene discussie van de bevindingen beschreven in dit proefschrift. Klinische en wetenschappelijk implicaties die uit de gepresenteerde studies voortvloeien worden omschreven. Eerder dan dat ze twee compleet onafhankelijke fenotypen zijn vertonen psychose en depressie - en mogelijk ook andere neuropsychiatrische stoornissen zoals bipolaire stoornis interessante overeenkomsten met betrekking tot de mogelijke rol van vasculaire pathologie en neurodegeneratieve processen voor hun ontstaan, persistentie en beloop. Mogelijk werken beiden via het verlagen van de cognitieve reserves waardoor ze de kwetsbaarheid voor verdere cognitieve achteruitgang en dementie verhogen. 


\section{Dankwoord}

Het schrijven van dit proefschrift was geen lineair gebeuren en het was zeker niet monotoon. Misschien schrijf ik eens nog een ander boek met als titel "How to get a PhD in six months". Dit promotieproject begon in september 2005 als een ambitieus epidemiologisch onderzoek naar laat en zeer laat ontstane psychose, de Psychosis In The Eldery (PSITE) studie. Echter, dingen lopen niet zoals je het graag zou hebben. Ondanks enorme gemeenschappelijke inspanning van het team (Margriet reed naar Friesland om één iemand te interviewen!) bleek het moeilijk voldoende proefpersonen te vinden. Dat ik nu toch een proefschrift kan presenteren is te danken aan een aantal mensen.

Het promotieteam. Frans, bedankt voor je enorm vertrouwen in mij. Je hebt het zeker niet altijd makkelik gehad en ons wekelijks overleg moet vaak het dieptepunt van je werkweek zijn geweest. Toch bleef je altijd je humeur en je optimisme houden ondanks "het moeilijkst lopende promotieonderzoek ooit". Ik verheug me al op onze verdere samenwerking. Jim, je was zeker geen tweede promotor die slechts af en toe kwam vragen hoe het allemaal loopt. Bedankt voor je enthousiasme. Ik heb er veel van geleerd. Judith, I owe much to those people that forced you to be my copromotor. It seems to me that all I have learned about data analysis I learned from you. Thanks for letting me do every mistake man can make when doing statistics.

Lydia Krabbendam en Martin van Boxtel. Ook jullie bijgedragen aan het tot stand komen van dit proefschrift. Beste Lydia, bedankt voor je begeleiding tijdens het eerste jaar en het medeopzetten van PSITE. Martin, je had altijd een open oor voor mijn vragen en ideeën omtrent MAAS. Ik wil je ook danken voor je vertrouwen met betrekking tot toekomstige projecten.

Mijn lotgenoot. Lieve Margriet, ondanks de weinig indrukwekkende instroom van gemiddeld 0.5 proefpersonen per week, had ik toch nooit het gevoel werkeloos te zijn. Dat is te danken aan je organisatorische en logistieke vaardigheden. Heel vaak mocht ik profiteren van je diverse Excel tabellen en 'opdrachten reminders'. Volgens mij was PSITE zonder jou nooit van de grond gekomen en is het daarom ook vooral aan jou te danken dat er nu in Nederland deze unieke informatiebron over laat ontstane psychose bestaat.

My English host supervisors. I am deeply indebted to you, John and Alan. It was a great pleasure and honour to having worked with you. Thank you so much for all your support. Hopefully there will be opportunities for collaboration in the future.

Mijn 'vroege mentor', Gé van Woerden. Beste Gé, het is inmiddels zes jaar geleden dat ik op de afdeling Medische Psychologie van het Elkerliek kwam stage lopen. Inmiddels geniet jij van het leven als gepensioneerde terwijl ik nog steeds aan het 
begin sta. Zo voelt het. Ik hoop dat ik nooit ophoud met 'beginnen', net zoals jij nooit heb opgehouden nieuwsgierigheid en gefascineerd te zijn.

Meine Freunde, insbesondere Frank, Piet und Christian. Danke für euer ungeheucheltes Desinteresse an meiner Arbeit. Schließlich sind Freunde dafür da, einen immer wieder auf den Boden der Tatsachen zurückzuholen! Huh? Aha!

Meine Eltern. Liebe Mama, lieber Papa, ohne Euch gäbe es mich nicht. Und ohne euer niemals enden wollendes Vertrauen und ständige Unterstützung, gäbe es diese Doktorarbeit nicht. Nun ist der 6-jährige Junge, der - nach seinem Traumberuf gefragt - Professor werden wollte, seinem Ziel ein Stückchen näher gekommen. Danke dafür.

Meine kleine, aber wachsende Familie. Christina, ich verdanke Dir so viel. Gott weiß wieviel. Du bist der Mensch, bei dem ich zur Ruhe komme und der mir Kraft gibt. Danke für deine Geduld, vor allem in den letzten Monaten und Wochen, deinen Mut, mit nach England zu gehen, und deine Liebe, die mich immer wieder vor neue Rätsel stellt. You are the best thing that ever happened to me. Josia, danke für die schaflosen Nächte, volle Windeln und bespuckte Klamotten. Und dass mir das Herz zerreißen will, wenn du mich drückst. "Hab-i-lie"! 


\section{Curriculum vitae}

Sebastian Köhler was born 6 November 1978 in Schleswig, Germany. In 1998 he graduated from secondary school (Abitur) at Albertus-Magnus-Gymnasium in Dülken, Germany. After military service, he started his study of psychology in September 2000 at Radboud University Nijmegen where he received a Master of Arts in neuro- en rehabilitation psychology in August 2004 on the thesis entitled "Sequential learning in patients with a dementia with Lewy-bodies". Thereafter, Sebastian worked as fixed-term psychologist at the medical psychology unit of the Elkerliek Ziekenhuis in Helmond and as a research assistant at the Institute for Rehabilitation Research in Hoensbroek. Since September 2005, he has been a PhD candidate at the School for Mental Health and Neuroscience (division Clinical \& Cognitive Neurosciences and division Mental Health) within the Department of Psychiatry and Neuropsychology at Maastricht University. From November 2008 to April 2009, Sebastian worked as a Guest Member of Staff at the Institute for Ageing and Health at Newcastle University, UK. In May 2009, he received a KOOTSTRA fellowship for talented post-doc researchers from Maastricht University to continue his studies into depression and psychosis in later life in collaboration with the Institute of Public Health at Cambridge University and the Institute for Ageing and Health in Newcastle upon Tyne. In the same year, he received the Junior Investigator Award form the International College of Geriatric Psychoneuropharmacology. Sebastian lives with his wife Christina and his son Josia in Aachen, Germany. 